\title{
Barriers of Volunteerism for Coaches of Collegiate Division I Swimming Programs
}

\author{
Richard Allen West \\ West Virginia University, rwest2@mail.wvu.edu
}

Follow this and additional works at: https://researchrepository.wvu.edu/etd

Part of the Sports Sciences Commons

\section{Recommended Citation}

West, Richard Allen, "Barriers of Volunteerism for Coaches of Collegiate Division I Swimming Programs" (2021). Graduate Theses, Dissertations, and Problem Reports. 8084.

https://researchrepository.wvu.edu/etd/8084

This Dissertation is protected by copyright and/or related rights. It has been brought to you by the The Research Repository @ WVU with permission from the rights-holder(s). You are free to use this Dissertation in any way that is permitted by the copyright and related rights legislation that applies to your use. For other uses you must obtain permission from the rights-holder(s) directly, unless additional rights are indicated by a Creative Commons license in the record and/ or on the work itself. This Dissertation has been accepted for inclusion in WVU Graduate Theses, Dissertations, and Problem Reports collection by an authorized administrator of The Research Repository @ WVU.

For more information, please contact researchrepository@mail.wvu.edu. 
Graduate Theses, Dissertations, and Problem Reports

2021

Barriers of Volunteerism for Coaches of Collegiate Division I Swimming Programs

Richard Allen West

Follow this and additional works at: https://researchrepository.wvu.edu/etd

Part of the Sports Sciences Commons 
Barriers of Volunteerism for Coaches of Collegiate Division I Swimming Programs

Richard A. West, M.S.

Dissertation Submitted to the College of Physical Activity and Sport Sciences

at West Virginia University

in partial fulfillment of the requirements for the degree of

Doctor of Education in

Coaching and Teaching Studies

Kristen Dieffenbach, Ph.D., Chair

Sean Bulger, Ed.D.

Melissa Thompson, Ph.D.

Valerie Wayda, Ed.D.

Department of Coaching and Teaching Studies

Morgantown, West Virginia

2021

Keywords: coaching, volunteerism, executive volunteer, barriers

Copyright 2021 Richard A. West 


\begin{abstract}
Barriers of Volunteerism for Coaches of Collegiate Division I Swimming Programs
\end{abstract}

Richard A. West, M.S.

Barriers to volunteerism are not researched often or concretely in specific volunteer populations. The aim of this project was to find agreement among a group of potential executive level volunteers in coaching to identify the most impactful and prevalent barriers preventing them from volunteer service. A Delphi study was utilized to identify and find consensus for these barriers as identified by the 30 collegiate swimming coaches who participated. A verification interview was administered to add further clarity to the results and allow participants to speculate as to methods to overcome the barriers listed. Key findings included the themes of dedicated time, length of time for participation, and timing of the event during the season as being the most impactful and prevalent results. The findings serve as a key in creating mitigation strategies for organizations to overcome these barriers in the future. 


\section{Dedication}

This manuscript is dedicated to my wife Sarah. Your unwavering patience, support, and optimism have been the authority for my persistence during this degree. 


\section{Acknowledgements}

I would like to first thank the members of my committee who have been instrumental in the completion of this dissertation. Dr. Kristen Dieffenbach, for serving as my committee chair and for all of the hours of editing, revising, and guidance she has provided me over the years. Dr. Valerie Wayda and Dr. Melissa Thompson, for serving on my committee and their contributions to this study. I would also like to thank Dr. Patricia Obenauf, posthumously, for her support and guidance at the start of my proposal. Lastly, I would like to thank Dr. Sean Bulger for his assistance in both the classroom and as a committee member, in serving as a model for both teaching and research.

I would like to thank the coaches who took the time to participate in this project. The protocol of the Delphi does not permit me to list their names, but without their participation and assistance this study would not have been possible.

I would like to thank my former colleagues at West Liberty University. Dr. Rhonda Noble, a professor during my undergraduate work at WLU, wrote my letter of recommendation for the doctoral program at WVU, and hired me at WLU as an instructor. I am forever grateful and indebted to her. Dr. Stephen Richards, for his assistance with this study during the Delphi. A special acknowledgement to Dr. Ryan Koenig who assisted with this study during the Delphi and in proofreading drafts of this manuscript. I am thankful and privileged to call him a friend.

I would like to thank and acknowledge those who have coached with me over the past several years at WVU Swimming and Diving. Victor Riggs has been there to support, motivate, and at times make me laugh when needed, throughout this degree. I also extend my appreciation to all of the other staff members over the years who have helped support me throughout this endeavor.

I would be remiss if I did not thank my family who have given their time to this degree. I am blessed with four wonderful children, Alexander, Quinton, Sydney, and Carleigh who gave up their time with their father so he could pursue his dream. I would like to thank my mother and father in-law, Joseph and Sandra Bell, for their words of wisdom and encouragement. I am truly fortunate to have them in my life. I would like to thank my father, Richard K. West, who has been an inspiration to me for as long as I can remember. He has instilled in me the value of an education and the necessity of perseverance to achieve it. My father did not train as a formal educator; however, he has proven to be the best teacher I have ever known.

Finally, I would like to thank God for all of my blessings, but most especially, my wife Sarah West. She has been the glue that has held life together during this degree. Sarah has served every role that I could not during this time, and in full disclosure did it much better than I ever could have hoped to have done. Every trial has obstacles and low moments. I simply know that Sarah lifts me up during those times and for that reason, I love her. 
Introduction

Problem Statement and Research Question

Method

Participants

Administrative Procedures and Data Analysis

Results

Delphi

Verification Interview

Discussion

Strengths and Limitations

Applications for the field

Future Directions

Conclusion

References

Tables

Figures

Appendices

Appendix A: Chapter 1 Introduction

Appendix B: Chapter 2 Extended Literature Review

Appendix C: Chapter 3 Methods

Appendix D: Chapter 4 Extended Results

Appendix E: Extended Reference List 
Appendix G: Nonprofit Organization Summary 2

Appendix H: Participant Invitation Email

Appendix I: Introduction Email

Appendix J: Participant Consent Letter

Appendix K: Participant Consent Form

Appendix L: Demographic Information 


\section{List of Tables}

Table

Page

1. Participant Demographic Data 38

2. Condensed Round I Responses and Corresponding Category 39

3. Round II Ratings for Impact and Prevalence 40

4. Round III Ratings for Impact and Prevalence 41 


\section{Introduction}

Volunteers comprise the lifeblood of nonprofit organizations and support the mission and purposes of those organizations (Anheier, 2005; Lewis, 2001; Mook, Handy, Ginieniewicz, \& Quarter, 2007). The way a volunteer may provide service comes in many forms and has unique opportunities for that organization. A volunteer may select to become involved in just one event with a specific opportunity, or the volunteer may choose to serve the organization for a prolonged period of time whereby sustaining their volunteer efforts (Bouchet \& Lehe, 2010; Hustinx, Cnaan, \& Handy, 2010; Penner, 2002; Stebbins, 2009). Each volunteer chooses how to donate their resources to a nonprofit organization based on the role they will fulfill (Mitchell \& Clark, 2020). Olympic sporting clubs and organizations, nonprofit or profit, like many other groups in the United States, are reliant upon support from a variety of resources: (a) those produced by the organization, (b) subsidies from the government, or (c) in-kind funding or services from others (Wicker, 2017). Issues in the recruitment and retention of volunteers and coaches have been found at the sport club level (Seippel et al., 2020). The nonprofit sport organization's activity and health rely on these support measures to sustain and grow, especially those coming from the volunteer sector (Burgham \& Downward, 2005; Downward \& Ralston, 2006).

The variations and types of volunteers utilized by nonprofit organizations are as extensive as the tasks themselves (Hustinx et al., 2010; Wicker \& Downward, 2019). The length and depth of time by which a volunteer provides service to the nonprofit organization is coupled with the type of specific resources and roles that a volunteer donates to the organization, thereby creating a volunteer type or volunteer role (Hustinx et al., 2010; Sundeen, Raskoff, \& Garcia, 2007). The variables of age, gender, cultural heritage, religious affiliation, educational level, socioeconomic 
status, and physical location have all been used to describe and categorize different indicators of volunteers (Cnaan, Handy, \& Wadsworth, 1996; Stebbins, 2009; Wilson, 2012; Wilson \& Musick, 1997). The categorical nuances alone do not explain the total depth of the volunteer type. The roles and specific tasks or duties that volunteers provide the organization are meshed with the variables of the individual to describe a more specific volunteer category (Hustinx et al., 2010; Wilson \& Musick, 1997). A volunteer's recruitment can be impacted by the relationships that volunteer builds with other volunteers and the leaders associated with the organization (Senses-Ozyurt \& Villicana-Reyna, 2016).

Nonprofit sport organizations may establish role identities for volunteers to give them a sense of the role that they are to fulfill for the organization (Wegner, Jones, \& Jordan, 2019). The resources that categorize an individual as an executive volunteer are social status, influence, and ability to recruit others to the organization or tasks (Brown \& Ferris, 2007; Paik \& NavarreJackson, 2011; Wilson \& Musick, 1998). The executive volunteer creates an important link from the general population of volunteers to the organization and then to successful fulfillment of that organization's mission (Posner, 2015). The ability of the executive volunteer to use their social standing to attract and recruit additional volunteers affords them a unique attribute (Brown \& Ferris, 2007; Paik \& Navarre-Jackson, 2011).

In the area of sport, the coach of a team or organization may often be viewed as this executive individual who can provide the necessary volunteer service. Coaches at different levels have unique spheres of influence and visibility to those stakeholders who place an individual in a more highlighted role and thereby increase their social standing, social status, and visibility (Kihl, Leberman, \& Schull, 2010). The coach of a high-profile team or organization meets the criteria of the executive volunteer due to the nature of their position (Wicker \& Frick, 
2016). In order for an executive volunteer or any volunteer to act on their compulsion to serve an organization depends upon a complex set of motivators and barriers that when added together result in a decision to volunteer or not (Clary et al., 1998; Sundeen et al. 2007; Winniford, Carpenter, \& Grider, 1997). Community sport organizations look to coaches to provide transformative leadership to assist in their mission (Morgan \& Bush, 2016). An executive volunteer is then susceptible to the same barriers of volunteerism of the general population as examined in the literature (Clary et al., 1998; Sundeen et al., 2007).

The voluntary actions of individuals are motivated by the expected returns from others (Blau, 1964). The social exchange theory (Blau, 1964) has been utilized as a foundational premise for the construct of psychological contracts that individuals associate with organizations (Rousseau, 1995). Nichols and Ojala (2009) researched the volunteer expectations from the organizational perspective, and the recognition a volunteer would receive in return for their service, utilizing the theoretical framework of the psychological contract at sporting events. The findings by Nichols and Ojala (2009) demonstrated that the framework of the psychological contract was valuable in understanding volunteer perspectives in a social relationship.

Volunteers begin to form psychological contracts with organizations based on the perceived expectations of the volunteer during the time that they are recruited by the sporting organization (Kappelides, Cuskelly, \& Hoye, 2019). The research conducted by Hoye and Kappelides (2020) demonstrates a significant relationship between psychological contracts and sport volunteers. The connections that volunteers form during the recruitment process can be related to the role they will contribute for the organization.

Volunteer involvement in a sporting event opportunity has been positively correlated to involvement in a community (Hallman \& Zehrer, 2017). Nonprofit organizations have been able 
to nudge individuals to volunteer by activating personal norms from exposure to peer norms through meeting and observing others who are volunteering for an event or activity (Jackson, 2016). The connection to a nonprofit may be through association alone. Hallett et al. (2020) collected data from individuals who were members of the parkrunning community to identify barriers to volunteering for an event. The sample collected by Hallett et al. (2020) included individuals who had never volunteered in addition to those who had volunteer experience. The ability of an individual to predict their involvement in volunteering for a physical activity program was demonstrated by Kono, Ito, Walker, and Gui (2020) who utilized an independence model in which constraints, negotiation, and motivation were considered as a model.

Major sporting event such as the Olympic games, are supported by nonprofit organizations that require the time, talents, and treasures of a large number of volunteers in order to assist successful completion of the event (Chanavat \& Ferrand, 2010). These supporting organizations may provide recognition, publicity, fundraising, or direct support to the sport itself through a variety of volunteer efforts (Cuskelly, Hoye, \& Auld, 2006). In order to create greater volunteer involvement, these organizations have a need to convert peripheral (nonformal) volunteers to core (formal) volunteers (Ringuet-Riot, Cuskelly, Auld, and Zakus, 2014). Hallmann and Zehrer (2019) concluded that the need for formal event volunteers correlated with the social capital of the individuals. The nature of these types of volunteer services meets many of the characteristics provided by the executive volunteer (Nicholson \& Hoye, 2008; Paik \& Navarre-Jackson, 2011; Wilson \& Musick, 1998). Several nonprofit organizations including: (a) USA Swimming, (b) The American Swimming Coaches Association (ASCA), and (c) The Collegiate Swimming Coaches Association of America (CSCAA) in the United States seek to benefit the sport of swimming in a variety of ways. Swimming coaches are often invited to 
volunteer for events in an executive role to help enhance these organizations that in turn support and grow the sport they themselves are coaching.

The motivators are the forces that drive a volunteer toward assisting with an organization's purpose while barriers prevent one from engaging in service. Klandermans and Oegema (1987) explained that nonparticipation is a collective action from four different grounds including: (a) lack interest, (b) not being invited, (c) not motivated, and (d) presence of barriers. Sundeen et al. (2007) created a set of resources that may determine a person's voluntary abilities. The theoretical framework created by Sundeen et al. (2007) is that an individual must have the necessary resources available in order to successfully provide a volunteer service. The categories of resources are consistent with many volunteers, including those in the executive category (Nicholson \& Hoye, 2008; Paik \& Navarre-Jackson, 2011; Wilson \& Musick, 1998). The barriers to volunteering are not as thoroughly researched as the motivators, which creates a problem in the identification of obstacles for those in the executive category. Additionally, the literature on barriers to volunteerism are primarily theoretical in nature. Identifying concrete barriers may open the door for further research as to how to overcome these barriers. The organizational context of a nonprofit in sport has a direct effect on the necessary roles sought out to achieve the mission (Swierzy, Wicker, \& Breuer, 2018).

\section{Problem Statement and Research Question}

Swimming nonprofit sport organizations should have the ability to recruit high-profile coaches as executive volunteers to participate in an event that supports the sport of swimming. Research has shown that nonprofit sport organizations have a need for volunteers (Wicker \& Breuer, 2013), including those who possess the social capital and social connectedness as demonstrated in the executive volunteer category (Wicker, 2017). Identifiable barriers as to 
executive volunteers' reasoning for not volunteering are unknown in the literature. Utilizing a population of coaches in executive level positions, this study explored the things that were perceived to be barriers, preventing them from participation in a nonprofit organization event that benefited their sport. The research question that guided the study was: What are the most prevalent and impactful barriers preventing collegiate coaches at NCAA Division I swimming programs from utilizing their position as an executive volunteer to participate in a sport awareness program event for a nonprofit organization? The purpose of this study was to gain consensus among a panel of executive level volunteers utilizing collegiate swimming coaches, to (a) create a list of barriers of participation in a volunteer activity with a nonprofit organization that benefits their sport, (b) determine which of the barriers are most prevalent, and (c) determine which of the barriers have the greatest impact on their decision that would prevent them from volunteering in the activity.

\section{Method}

The literature identifying concrete barriers for service of an executive level sport volunteer is virtually non-existent. Therefore, the identification of those barriers would be a logical starting point. The source of these barriers is attached to the executive level volunteers themselves. The variance and complexity in the barriers against volunteerism make the selection of the research design a critical decision. The design must allow for an array of responses while having the ability to rate responses. The Delphi method is designed to account for both requirements. The origin of the Delphi method was to gain consensus through an expert panel and was originated by the RAND Corporation from a series of studies conducted in the 1950's (Dalkey \& Helmer, 1963). The Delphi method has been cultivated over time and is still used for consensus today in a variety of settings. Linstone and Turoff (1975) synthesized many of the 
uses and characteristics of the Delphi method as a group process for dealing with complex issues through structured communication whereby there is: (a) some feedback on individual contributions, (b) some assessment of group judgment, (c) some opportunity for individuals to revisit views, and (d) a degree of anonymity for individual responses. The method has been found to be valid when seeking consensus from a diverse group of experts on a topic or issue related to the individual's practice or field (Powell, 2003). The research methods are explained and detailed in the following order: 1) participants and 2) administrative procedures and data analysis.

\section{Participants}

The identification of the expert group of panelists is the initial step in the creation of a Delphi study. The panelists for this study were experts as to their responses of being invited to participate in an event by being an informed individual, a specialist in their field, or someone with significant knowledge about the subject area (Keeney, McKenna, \& Hasson, 2011). Individuals who have previous volunteer experience and those with no volunteer experience have been utilized in the sport literature to identify barriers to volunteerism (Hallett et al., 2020). The ability to qualify the panelists as experts in the field was the next task. "Expertise implies that the individual panelists have more knowledge about the subject matter than most people, or that they possess certain work experience, or are members in a relevant professional association" (Murray \& Hammons, 1995, p. 428). The membership to a given community as well as the involvement in a community have both been used to predict volunteer involvement in sporting events (Hallett et al., 2020; Hallmann \& Zehrer, 2017).

The homogenous nature of this study focuses on power five collegiate swimming coaches as executive volunteers as designated by their social status and perceived expertise in the sport 
for the respondent population. These executive level volunteers meet the definition set forth by Murray and Hammons (1995), as having the most knowledge of the barriers that prevent them from these opportunities.

The size and scope of the number of expert panelists have varied dramatically over Delphi studies. Recommendations from Rowe and Wright (2001) are to use a homogenous population for each grouping when available and also to use between five and 20 panelists per group, and a total panel consisting of ten to 24 members will meet the minimum recommended amount and maximize the quality of the responses with the highest number (Brooks, 1979; Bulger \& Housner, 2007; Delbecq, Van de Ven, \& Gustafson, 1975; Parentè \& AndersonParentè, 1987). This study selected a single group of 30 panelists to participate in the study to minimize attrition and increase participation as demonstrated by previous works in the literature (Akins, Tolson, \& Cole, 2005; Boyd, 2003; Bulger \& Housner, 2007). The five major sport conferences in the country were selected as the pool of potential panelists based on their participation in the National Collegiate Athletic Association (NCAA) Division I Football Bowl Subdivision (FBS). The budgets, expectations, athletic department sizes, and levels of competition, with regards to swimming teams, are comparable among these institutions. The five conferences included in this cohort were the Big 12 Conference, the Big Ten Conference, the Pacific 12 Conference, the Atlantic Coast Conference (ACC), and the South Eastern Conference (SEC). The continuity of these conferences yielded a potential pool of 205 full-time swimming coaches. The coaching staff at West Virginia University was excluded from the panelist pool due to the personal relationship to the primary researcher.

Diving coaches were excluded from the study. Although, often listed as assistant coaches, associate coaches, or even as the Head Diving Coach, these individuals were not 
eligible for the study as the two sports are viewed as unique and separate, even though they participate in a combined format for the NCAA. In addition to diving coaches, those who may be listed as auxiliary staff were excluded. Examples of auxiliary staff included graduate assistants, volunteer assistants, and directors of operation. These positions are not always fulltime and often have a limited roles and responsibility as compared to those of a full-time paid staff position. The variation in professional responsibilities may have skewed the data of the overall population.

\section{Administrative Procedures and Data Analysis}

Recruitment of participants. Prior to inviting participants each week of the Delphi was mapped out by: (a) tasks to be accomplished, (b) timeframe for completion, and (c) responsible parties. The protocol created by Sandrey and Bulger (2008) was used as a model for the present study. Names were randomly selected from the pool of 205 potential candidates. The potential participants for the study were personally invited to participate via a participant invitation email. The email offered a phone conversation to answer questions, clarify any procedures, address any concerns, and reinforce the importance of their participation and contribution within the study. An introduction email was sent afterward and described the following to prospective participants: (a) study purpose, (b) potential benefit to nonprofit organizations from participation, (c) an explanation of time requirements, and (d) an invitation to participate.

Participants were assigned a random number in each category of head coach, associate coach, and assistant coach. Random numbers from each of the groupings were selected to send the initial email. The invitation to participate was followed by a Qualtrics link to enter the study. Demographic information collected about the participants was: (a) name, age, and gender; (b) coaching information; and (c) volunteering habits. The conclusion of the demographic form 
contained a brief statement thanking the participant for their willingness to participate and preparing them for the opening question for the study. Finally, participants were provided a link to round I and reminded to contact the researcher for any questions, comments, or concerns that they may have regarding the study.

Initial invitations were sent to 54 coaches on the list. A total of 32 coaches responded to the invitation; however, one coach responded that they would not participate due to lack of interest in the subject matter, and one coach responded that they would participate but did not complete the demographic information or respond to multiple reminders. Thirty coaches completed the demographic information, entered the study, and continued until the completion of all three rounds of the data collection. The distribution of coaches was as follows: head coaches $(n=10)$, associate or senior coaches $(n=9)$, and assistant coaches $(n=11)$. The number of panelists who identified as female was eight compared to 22 who identified as male. The age of the overall panel ranged from 27 to 65 years $(M=41.5, S D=11.55)$. The time spent in the coach's current role ranged from 0.5 to 22 years $(M=5.68, S D=5.83)$ at their current position. The years at the current institution had a range of 0.5 to 22 years $(M=6.91, S D=6.72)$. Panelists' participation in nonprofit volunteer events per year ranged from zero to 20 events $(M=3.43$, $S D=4.95)$. Panelists' participation in swimming nonprofit volunteer events ranged from zero to 6.5 events per year $(M=1.28, S D=1.61)$. A complete listing of the demographic information can be found in Table 1.

Round I procedure. The purpose of round I was (a) to collect raw responses from the panelists as to the perceived barriers and (b) to group similar responses into a manageable list via conceptually clustered matrix. The link for the round I landing page provided participants with: 
(a) the study focuses and panelist importance, (b) round I instructions, and (c) study summary. The page concluded with a link to the round I questionnaire.

The questionnaire contained an open-ended question to allow the panel the freedom to interpret and construct their own personal responses. Round I was qualitative in nature by soliciting feedback from the panelists while contextualizing their responses as a collegiate swimming coach. The open-ended question for round I asked the panelists to provide as many personal examples of barriers that prevented them from participating in a volunteer event for a nonprofit organization that has requested the panelist's help for an event due to their role as a collegiate swimming coach of a major athletics department. A list of examples was pulled from the literature to use as thought starters for the panelists. Each of the following categories were defined according to the literature and presented to the panelist just above the open-ended question: (a) personal resources-pertaining to the human capital of the individual and all items related to that individual, i.e. discretionary time, income, education, or job duties, (b) social tiespertaining to the extent that an individual is integrated into the community, i.e. family responsibilities, organizations, groups, or civic, (c) cultural resources-pertaining to the beliefs and values instilled within you as an individual, i.e. cultural upbringing, ethnicity, morals, or notion to help others, (d) mixed resources-pertaining to items that may be pervasive regardless of setting or multiple boundaries, i.e. age, health issues, gender, or roles related to age or gender and, (e) residential context-relating to the community's offerings, attributes, and support, i.e., residential, work, or professional (Sundeen et al., 2007). Panelists were not restricted to these examples but rather encouraged to make them specific to themselves.

Panelists were asked to submit their barriers to participation in a written open text format and to submit as many barriers to the question as they wished. Theoretically, it was possible to 
have three hundred unique responses to the round I questionnaire. Each panelist was given ten spaces to provide their answers to ensure that they have exhausted their barriers. Panelists were also instructed to contact the primary researcher should the number of spaces provided not be enough. The panelists were given one week to respond to the round I questionnaire. After 10 days participants received a reminder email and text message, two days later a phone call was made to prompt their responses and to answer any questions or issues that may be present. If a response was not collected, a contingency communication was in place to ensure participation. The contingency schedule was implemented for those who did not respond within the given time period. After two weeks, panelists would (a) receive an email and text message encouraging their participation in the study and requesting the survey completion, (b) be allotted a seven-day extension for their participation in order to attain the highest participation rate possible, and (c) receive a phone call to reinforce that their participation in the study is important and valued greatly for successful completion of the study (Bulger \& Housner, 2007). The same contingency communication was in place for all three rounds.

Two faculty members at a local institution were asked to participate in the data analysis. The addition of these two individuals was to reduce researcher bias, preconceived framing of statements by the primary researcher, eliminate double-barreled responses, and to check items for clarity (Miles \& Huberman, 1994). The faculty members both hold terminal degrees and have been published in peer-reviewed journals. The additional researchers assisted exclusively during round I of the Delphi. The primary researcher set up a meeting with the two faculty members to explain their role during round I: (a) group similar statements made by the panelists, (b) preserve the integrity of the responses, and (c) to reduce the overall number of items to a manageable list for round II using a conceptually clustered matrix (Keeney et al., 2011). The 
matrix contained the panelist statements along the vertical column of the matrix and the five categories from Sundeen et al. (2007) across the horizontal. Once aligned to a category the group then considered the factors of: (a) scarce resources, (b) skills mismatch, (c) not interested, and (d) lack of community connection, also provided by Sundeen et al. (2007) to further group the items. The matrix allowed the researchers to begin to compare and group similar responses as other studies have done for open responses (Hallett et al., 2020). Each of the researchers were then provided the sheet of results and asked to add them to the appropriate category in the conceptual matrix. The researchers submitted their synthesized matrix to the primary researcher along with the primary researcher's own matrix, and the round II list was created.

The primary researcher set up a meeting with the faculty members in order to further discuss the statements in conflict. The purpose of the meeting was to determine: (a) if statements can be combined, (b) should statements be listed as separate items, (c) that all items are clear to the reader, (d) if there any responses with two or more possible meanings that needed to be clarified, and (e) that the items are in the correct categories according to Sundeen et al. (2007). Statements that could not be resolved past the discussion among the researchers were left as two separate items for the round II list and the reasons and rationales for the disputed items recorded by the primary researcher. The outcome of the round I data analysis resulted in a manageable list of items for the group to rate that was stated in the words of the panelists or at least reflected the panelists' sentiments.

Round I data analysis. The following round I data analysis process was described by Keeney et al. (2011) with the reduction of the data process provided by Miles and Huberman (1994). The categories and groups created by the matrix allowed each researcher to combine statements with the same or very similar wording. Second, statements that may have different 
wording, but the same perceived meaning were combined. The grouping and combining of the statements followed the rules of Keeney et al. (2011) in that the integrity of the statements should be preserved as written by a panelist whenever possible. Any statement that had complete agreement among the three researchers was automatically added to the list. Additionally, any statements that had been removed by all three researchers due to combining or grouping were also removed. The primary researcher then created a list of statements that were in conflict and denoted what category and subcategory each researcher placed the statement. The primary researcher and the two colleagues then met to discuss in person the statements in conflict and determine if the statements should be combined or left as two separate items.

Round II procedures. Panelists received an email from the primary researcher explaining the instructions and timeline for round II and a link to the landing page. The purpose of this round was to rate the items collected from round I on two separate five-point Likert scales, in order to determine those barriers that are the most impactful and prevalent. Each item was rated twice, first in terms of impact and second in terms of prevalence. Impact has been used to explore areas that are meaningful to the panelists (Bulger \& Housner, 2007; Wyant, Tsuda, \& Yeats, 2020), whereas prevalence has been used to explore the prediction of frequency of an item to a panel (Rioja-Lang, Connor, Bacon, \& Dwyer, 2020). The definitions and examples of both impact and prevalence were provided to the panelists on the round II questionnaire. The Likert scale anchors for round II were developed from Vagias (2006). The first prompt for impact states, “This item's impact on my volunteer habit has: (a) No affect, (b) Minor affect, (c) Neutral, (d) Moderate affect, and (e) Major affect.” The responses carried values of one to five. The second prompt for prevalence states, “This item's prevalence is: (a) Never, (b) Rarely, (c) Occasionally, (d) A moderate amount, (e) A great deal." Once again, the 
rating for these values were one to five. Instructions and preparations for round III were included in the round II email so that participants could be aware of the next stage of the procedure. The same timeline and contingency plan used during round I were used for round II to ensure the effectiveness of communication and timeliness of responses.

Round II data analysis. At the conclusion of round II, the average mean scores of each item and the percentage of panelists rating the item at a 4.0 or higher was calculated for all items listed. Each panelist's individual response was recorded along with the total group response for all items on both scales.

Round III procedures. In round III participants were provided an opportunity to reconsider their rankings from round II. They were presented with each item from round II and their personal rating for the item's score of both impact and prevalence. In addition, panelists were provided with the total group's average mean score of each item and the percentage of panelists rating the item at a 4.0 or higher. The explanation and instructions for round III were sent via email to the panelist and a link to the round III landing page. The approach for gaining consensus is one of the most varied and least developed stages of the Delphi method (Crisp, Pelletier, Duffield, Adams, \& Nagy, 1997; McKenna, 1994). Panelists were provided the list of all items from the round II questionnaire for both prevalence and impact. The instructions for round III explained that the threshold for an item to reach consensus (agreement) is a mean score of 4.0 and have a rating of 4.0 or higher on $75 \%$ of the panelist's item rating (Bulger \& Housner, 2007). The 4.0 on both scales represented a trend toward agreement from the ambiguity of 3.0 and not requiring the absolute agreement of 5.0. The rationale for consensus met a higher standard than that of Keeney et al. (2011) who stated agreement could be 51\%. Participants were given the opportunity to keep their score the same, raise, or lower their round III rating. They 
were reassured that it was their choice as to change their response or not. A link to the round III questionnaire was provided at the end of the round III landing page. The same contingency plan used in round I and II was utilized to ensure timely responses.

Round III data analysis. The same data analysis method used in round II was employed in round III. All items reaching a mean of 4.0 for either the rating of impact or prevalence and rated a 4.0 or higher on $75 \%$ of all individuals reached consensus. The level of consensus mirrored the work of Bulger and Housner (2007). This resulted in the creation of four categories: (a) items reaching consensus for both impact and prevalence, (b) items reaching consensus for impact but not prevalence, (c) items reaching consensus for prevalence but not impact, and (d) items not reaching consensus for either impact or prevalence. The primary researcher reviewed the group's response from the panelists to investigate the changes that occurred from round II to round III.

Summary and verification interview procedures. After the panelists rated the items during round III, they were sent a summary of the Delphi results. The summary of results contained: (a) the goal and objectives of the study, (b) a rationale to why the Delphi method was selected, (c) a brief overview of the Delphi procedure as to why they just participated, and (d) the initial findings of the study. Participants were then invited to participate in a verification interview with the primary researcher to discuss the results. The interviews were implemented to add to the validity of the Delphi results and offer clarity that may not be gleaned from a statistical response. The purpose the interview was to provide the panel the opportunity to elaborate on the responses of the group, to provide detail as to the categorization of the items, and to speculate as to possible solutions or interventions that may be attempted to mitigate these barriers in the future. 
Nine of the panelists participated in the semi-structured interviews. Four of the panelists were head coaches, two of the panelists were associate coaches, and three were assistant coaches. Only one of the interviewees identified as female. In this subset of the original panel, the age of the overall panel ranged from 33 to 62 years $(M=45.1, S D=11.27)$. The time spent in the coach's current role ranged from 0.5 to 18 years $(M=5.05, S D=6.29)$ at their current position. The years at the current institution had a range of 0.5 to 18 years $(M=5.94, S D=5.93)$. Panelists' participation in nonprofit volunteer events per year ranged from one to 20 events $(M=5.66$, $S D=6.96)$. The first five questions of the interview sought to allow the interviewee to expand on the findings of the Delphi, the sixth question asked the interviewee to compare the categorization of these findings to that of Sundeen et al. (2007), and the last three questions asked the panelist to speculate as to mitigation of the barriers found by the Delphi. The interviews between the primary researcher and the panelist were recorded via Zoom, and Google Translate was utilized to transcribe the interview as recorded. The time of the interviews ranged from 27 to 45 minutes $(M=32.3, S D=5.10)$. Lastly, panelists were thanked for their participation at the conclusion of the summary email and the verification interview by the primary researcher.

Summary and verification interview analysis. The protocols for the analysis of the interviews followed that of Hycner (1985). The data collected from the interview questions was categorized and coded according to process as follows: (1) transcription, (2) bracketed and phenomenological reduction, (3) listening to the interview for the sense of the whole, (4) delineating units of general meaning, (5) delineating units of meaning relevant to the research question, (6) eliminating redundancies, (7) clustering units of relevant meaning, (8) determining themes from clusters of meaning, (9) writing a summary for each interview, (10) modifying themes and summary, (11) identifying general and unique themes for all interviews, (12) 
contextualizing theme, and (13) composite summary (Hycner, 1985). Nongender specific pseudonyms were assigned to participants to protect anonymity. The primary reason for this protocol selection was the ability of the protocol to analyze both within and between subjects to generate themes.

The primary researcher read the transcript while simultaneously listening to the interview to correct errors in the transcription. The primary researcher then bracketed their preconceived suppositions and biases of the interviews by writing and listing those conscious biases that may have been present. Prior to the interviews occurring the primary researcher took personal notes in three major areas as they related to the research topic: (a) the literature researched for this study, (b) personal experiences with volunteer barriers as a coach in the field, and (c) initial suppositions as related to the data collected throughout the study. The notes were then reviewed to find themes and preconceived biases. The reflexivity of the researcher found three themes of researcher biases: (1) coaches should want to help, (2) the similarity of coaching staffs, and (3) that all coaches find volunteering important.

The interviews were listened to again and notes were taken to record general impressions and perceptions. The review of the transcription allowed for the correction of transcription while being recorded. Additionally, specific units of meaning were noted and recorded for further analysis. The general units of meaning were condensed throughout the individual interviews and each documented according to the specific interviewee. The general units of meaning were then compared to the research question. If the general units of meaning addressed the research question or purpose of the verification interview, it was noted as such.

The researcher then looked at the relevant units of meaning for redundancies within each individual interview. Content validity is typically assured when the participants are 
knowledgeable and have an interest in the subject area, in which case the single interviewer model adds a qualitative clarity to the results (Hasson \& Keeney, 2011; Powell, 2003). The researcher then clustered groups of relevant meaning within interviews for each participant. The groups of relevant meaning were considered to find the central themes that arose across the nine interviews. Summaries of each of the individual interviews were then created. The final step was to identify themes that were common between interviewees that pertained to the research question and that would add clarity and validity to the results of the Delphi.

\section{Results}

The results section contains the data collected from both the Delphi and the verification interviews. The Delphi portion of this section will contain Round I, II, and III. Each round will present the findings and how those findings contribute to the creation of the subsequent rounds. Round I will present the qualitative responses collected from the Delphi and the categorization of the responses. Rounds II and III will show the items that reached consensus. The verification interview portion will put forward the themes and subthemes derived from the interviews and supporting examples from those panelists who participated.

\section{Delphi}

Round I. The completion of the first round of the Delphi yielded 60 unique raw data statements submitted by the 30 panelists in the open-ended probe. The number of responses by panelist ranged from one to five $(M=2.00)$. The 60 raw data statements from round I were reduced to a list of 21 items reflecting the panelist response to the round I probe. During the initial analysis 52 of the raw data statements were agreed upon and reduced to 17 items. Three of those 17 items were examples used as thought starters in the opening scenario: (a) discretionary time, (b) social ties, and (c) family responsibilities. The remaining eight raw data 
statements were discussed by the research team and distilled to four items that produced the round II list of 21 items to be considered. During the reduction, these items were organized into five categories (Table 2): personal resources $(n=9)$, residential context $(n=7)$, social ties $(n=3)$, cultural ties $(n=2)$, and mixed resources $(n=0)$.

Round II. The completion of round II found that five of the nine items in the category of personal resources met the criteria for both impact and prevalence: (a) Primary work responsibilities limiting time availability, (b) Time and availability, (c) Discretionary time, (d) During college season, having to coach practice, and (e) Time of year/season. One item in this category met the criteria for prevalence: (a) Time away from team activity, but it did not reach the criteria for consensus for impact ( $\mathrm{Rd} 2 \mathrm{I}=3.9 / 73.33 \%)$. One item did approach consensus: (a) Length of time being asked for the event $(\mathrm{I}=3.0 / 70 \%, \mathrm{P}=3.93 / 73.33 \%)$ but did not meet the minimum criteria for either impact or prevalence during round II. Two items did not reach consensus during round II: (a) Energy it would cost me and (b) Money it would cost me to help out (Table 3).

Seven of the items were categorized as residential context after the round I responses were received, making it the second largest category. However, none of the items reached criteria for consensus after round II for either impact or prevalence: (a) Does it tie into a cause that the sport of swimming needs, (b) If there is any professional conflict of interest, (c) Is this opportunity going to be of a benefit to my institution to be affiliated with it, (d) Support from university athletics and the city itself, (e) Not beneficial to my professional growth, (f) Program Resources, and (g) Limited to no facility availability (Table 3).

Only one item reached consensus under the category of social ties: (a) Family responsibilities. At the conclusion of round II, this item reached consensus for impact only and 
did not meet the criteria for prevalence $(\mathrm{I}=4.13 / 76.67 \%, \mathrm{P}=4.0 / 70 \%)$. The remaining items did not reach the criteria for either impact or prevalence individually, or both impact and prevalence collectively: (a) Cost of obtaining a babysitter and (b) Social Ties by either not scoring a mean of 4.0 or not being rated as a 4.0 or higher by $75 \%$ of the panelists (Table 3 ).

Neither of the two items reached consensus for impact or prevalence during round II for the category of cultural ties: (a) Whether I agree with the mission of the gathering and (b) Passion for the scheduled event. The item: (a) Passion for the scheduled event did approach consensus during round II for impact (3.87/66.67\%). However, the item did not reach criteria during this round (Table 3).

Three items had the highest ratings on both the scales for impact and prevalence by having a mean rating of at least 4.6 and being rated on at least $93.33 \%$ of the panelist responses: (a) Primary work responsibilities limiting time availability, (b) Time and availability, and (c) During college season, having to coach practice (Table 3). Conversely, the item of: (a) social ties had the lowest rating across all areas $(\mathrm{I}=2.27 / 6.67 \%, \mathrm{P}=2.00 / 10.00 \%)$. Additionally, of the seven items that found some type of agreement during round II, six of the items related to time: (a) Primary work responsibilities limiting time availability, (b) Time and availability, (c) Discretionary time, (d) During college season, having to coach practice, (e) Time of year/season, (f) Time away from team activity. Two items began to approach the requirement for consensus by being rated at least a mean score of 3.8 and a panelist response of at least $70.00 \%$. The item Length of time being asked for the event approached consensus for both impact and prevalence and Time away from team activity approached consensus for impact only.

Round III. The panel reached agreement for both impact and prevalence on seven of the 21 items and one item for prevalence only across all categories (Table 4). The five items that 
reached consensus for both impact and prevalence in the category of personal resources during round II did so again during round III: (a) Primary work responsibilities limiting time availability, (b) Time and availability, (c) Discretionary time, (d) During college season, having to coach practice, and (e) Time of year/season. The item: (a) Time away from team activity reached consensus for prevalence only, as it did during round II, in the category of personal resources. On the rating scale for impact, this item did increase in the group's mean score from 3.90 to 4.00 but fell in the group's total response percentage from $73.33 \%$ to $66.67 \%$, falling short of consensus. The last item to reach consensus in the category of personal resources: (a) Length of time being asked for the event met criteria during round III for both impact and prevalence $(\mathrm{I}=4.00 / 76.67 \%, \mathrm{P}=4.20 / 80.00 \%)$ after trending toward consensus during round II $(\mathrm{I}=3.0 / 70 \%, \mathrm{P}=3.93 / 73.33 \%)$. Seven of the nine items categorized as personal resources reached consensus for at least one rating making it the category with the largest number of items to reach some type of consensus.

Only one item reached consensus under the category of social ties: (a) Family responsibilities. At the conclusion of round II, the item reached consensus for impact only and did not meet the criteria for prevalence. However, after round III the item did reach consensus on both rating scales $(\mathrm{I}=4.10 / 80 \%, \mathrm{P}=4.23 / 83.33 \%)$. Seven of the eight items that found some level of consensus across all categories either contained the word time or related to time: (a) Primary work responsibilities limiting time availability, (b) Time and availability, (c) Discretionary time, (d) During college season, having to coach practice, (e) Time of year/season, (f) Time away from team activity, and (g) Length of time being asked for the event. No other items in any categories reached any level of consensus during round III. The item: (a) 
Passion for the scheduled event did trend closer toward impact consensus (3.90/80\%), however, the item did not reach criteria during either round.

\section{Verification Interview}

The items that gained consensus during the Delphi portion of the study provided the starting point for the verification interview conversations. Interviewees also shared their thoughts as to the items that reached consensus, those that did not meet the minimum standards, and the categorization of those items. Additionally, the panelists speculated as to a coach's willingness and ability to overcome the barriers identified during the Delphi. The following themes emerged from the nine interviewees who participated: (a) time as a main barrier and (b) overcoming barriers.

Time as a main barrier. Time was found by the interviewees as the most impactful and prevalent barrier. All nine participants identified the theme of time as the main barrier for participation as a volunteer. Three main subthemes emerged from the broader theme of time as a main barrier: (a) dedicated time, (b) length of time for participation, and (c) timing of the event during the season or offseason.

Dedicated time. Participant statements during the interviews indicated there was an active decision as to where to place their minutes or hours in a day and have some type of organizational control of their personal schedules. These statements were coded together to create the subtheme of dedicated time. All nine of the panelists discussed their decision-making in determining their time allotment. One participant stated the decision-making process for the typical coaching routine. Coach Sam stated, “As coaches we substitute meetings, practices, or calls where there once was a space in our schedule. It is just the nature of the profession." 
Another participant expressed that time was their most valued resource. Additionally, they equated their success as a coach to their time spent with their team.

Time is the most important resources that I have as a coach. My discretionary time and availability of time are very limited as well, which comes from my personal resources. If you are doing a good job with your team the time is limited (Coach Jordan).

Length of time for participation. Participants also expressed that the amount of time the actual event takes to complete plays a role in the impact of the barrier. Seven of the participants indicated that the length of time for participation effects the barrier. The length of commitment to an event may be related to its impact and prevalence as described by one of the participants. Coach Jordan stated, 'It's an individual choice, if you are willing to step away from the team for any length of time that may be the distinction between impact and prevalence."

Timing of the event during the season or offseason. The time of year the event takes place was indicated by several participants to impact the barrier of time. All nine of the participants indicated that the time of year would affect their decision as to their participation. The participants described their routines and tasks that are required during the season and offseason. One participant explained their daily routine. Coach Avery stated, "I leave at 5:30am and get home at 7:00pm during the season, and that is before recruiting calls."

Overcoming barriers. All nine participants offered some type of idea to overcome the barriers as presented to them and that they themselves would be willing to attempt a suggested strategy to overcome the barriers of time if presented to them by the nonprofit organization. The two emerging subthemes that came from this were strategies and support. Five of the participants had statements that centered around the strategies a coach may utilize to overcome a barrier. Seven of the interviewees indicated a statement that required some type of support or assistance to overcome the barriers presented. 
Strategies. The statements that formed this concept were suggestions that involved the coaches' doing something for themselves. Organizational tools were viewed as scheduling tips, calendars, and planning. Participants stated that keeping a close watch on the budgeting of time during the day and not procrastinating helped to maximize time to dedicate to other activities. Coaches also stressed the importance of recognizing one's weaknesses and strengths can also assist in managing a schedule. One participant explained in more depth in the following statement.

I always viewed myself as a multi-tasker, but after a while I realized that I work much better on one thing at a time. One way I help myself from spinning my wheels is to incorporate a very intricate calendar that maps out my week. I even include my down time in that week (Coach Kennedy).

All nine panelists also indicated that it is possible for a coach to overcome the barrier of time. However, all nine also indicated that there is a personal accountability of the individual to accept the responsibility to overcome the barriers presented.

Support. The participants also stated the need for the support of others in order to overcome barriers. While there are strategies to help oneself, seven of the participants felt there needed to be some intervention from others for the barriers to be mitigated. The strategies for utilizing others came in different forms: the nonprofits organization themselves, the athletic office, and those around the coaches. One participant explained that the organization has a responsibility to assist in the matter by making the task completion as simple as possible. "Making things easy for the coach to participate to where it does not impede my other opportunities or take away from my team, " was stated by Coach Sam. Another participant, Coach Jordan, explained that an individual in the athletic office completes all the ancillary work necessary for the event to take place and the coach needs only to be present and participate, "We 
have a logistics person in the athletic department that sets up the event, from busses, $t$-shirts, and events which makes the event very manageable and easy."

Two other participants explained the importance of relying on the relationships they have with others to help them find time away from work responsibilities: "Make connections and relationships throughout the athletic department. The relationships help to include others in activities," (Coach Avery). While Coach Shawn stated, "Help involve those around you, whether it is staff, administrators, or the team, to make the volunteerism important as well." A panelist felt that it is possible to overcome barriers alone, but other interventions may prove to be more impactful and effective. "The individual may be able to do it themselves, but changes in rules and coaching culture may be more impactful," (Coach Taylor). Another panelist explained that coaches needed to reassess what is important to them. Once that is achieved, they would be free to distribute their time as they see fit.

We need to revalue things as coaches. We as coaches need to trust each other in that when something comes up in our personal lives, we can rely upon one another to help and take over activities or practices. That action will in turn serve as model for our student athletes as well and the cycle will hopefully repeat itself (Coach Kennedy)

\section{Discussion}

The need for nonprofit organizations, including sport nonprofits, to effectively utilize all volunteers but particularly executive level volunteers to link to the general volunteer population is clear in the literature (Hallman \& Zehrer, 2019; Ringuet, Cuskelly, Auld, \& Zakus, 2014). The present study adds to this literature in the areas of volunteer barriers; executive level volunteers, and nonprofit organizations, especially those in the area of sport. The aim of this study was to create a concrete list of barriers that were impactful and prevalent in preventing potential executive level volunteers from participation in a nonprofit event. The following 
section will discuss the major findings of the study, strength and limitations, applications for the field, future directions, and a conclusion.

The motivating factors driving individuals to volunteer has been well researched, while the barriers preventing these individuals from participation are more complicated and have been studied less frequently, including the executive volunteer category (Hameiri, 2018; Swierzy, Wicker, \& Breuer, 2018). The inclination for an individual to serve comes from a set of available resources, regardless if the individual acts upon this inclination or not (Clary et al., 1998; Sundeen et al., 2007). The results from this study suggest that the barrier of time categorized as a personal resource is largely responsible in preventing coaches, in an executive volunteer role, from participation in a nonprofit event that benefits their sport. The category of social ties also contributed a single barrier to the list created by the panelists.

Even though initial barriers were identified for several categories as presented by Sundeen et al. (2007), this study found that many of the barriers that reached consensus were found in the personal resource category. Four of the five categories from Sundeen et al.'s framework (2007) were represented in the responses for this executive-level population, personal resources, social ties, cultural ties, and residential context. There were no items assigned to the category of mixed resources as defined by Sundeen et al. (2007). The 21 unique barriers identified during the opening round of the Delphi matches the complexity studied in the literature identifying motivators, when considering the volunteer's specific situational factors and motivational components (Winniford et al., 1997). The motivational elements of an individual's role, situational context, and personal needs described by Winniford et al. (1997) reciprocate the elements presenting barriers for volunteer involvement found in this study. The final round of the Delphi found that seven items were both impactful and prevalent barriers in preventing 
volunteer efforts: primary work responsibilities limiting time availability, time and availability, discretionary time, during college season, having to coach practice, length of time being asked for the event, time of year/season, and family responsibilities, while one item was found to be a prevalent barrier, time away from team activity.

The barrier of time is consistent with many of the findings in the volunteer literature, identifying time as an important resource for the facilitation of service (Boyd, 2003; Smith, 2010). Time has also been viewed as a barrier for the area of volunteer events involving physical activity and sport (Strazdins, Broom, Banwell, McDonald, \& Skeat, 2011; Weaver, 2015). The theme of time was mentioned in all seven of the items for the personal resource category. Six of the items reached consensus for both impact and prevalence: primary work responsibilities limiting time availability, time and availability, discretionary time, during college season, having to coach practice, time of year/season, and length of time being asked for the event. Only one of the items, time away from team activity, met the criteria for prevalence only. The items of primary work responsibilities limiting time availability and time and availability, which were two of the highest rated items in the study, align with research completed by Krajňáková, Pilinkiene, Grabowska, and Šimkus (2018) that found professional activities would have an effect on a volunteer's ability to participate. The volunteer literature also aligns with the findings of this study that the timing of an event will be a determining factor in volunteer participation (Hallman, Downward, \& Dickson, 2018), as reflected in the next two highest rated items, length of time being asked for the event and time of year/season.

The work completed by Brown, Hoye, and Nicholson (2012) as to decide how to budget your time within your community connected network aligns with the item of time away from team activity which was identified to be a prevalent barrier only. A possible reason that this item 
found consensus for prevalence only may be due to the different definitions of team activity from the interviewees. While all panelists agreed that team activities demand time, there was discussion as to the type of activity, practice, meeting, social event, or service opportunity. The item of discretionary time was found to be both impactful and prevalent regardless of the type of activity. This finding corresponds with the research by Strong and Harder (2010) in that the individual ultimately makes the final decision as to how to dedicate their time to volunteer service.

The factors of considering the potential volunteer's schedule, availability, and time that may be required for the event have been verified in the volunteer literature (Boyd, 2003; Wilson, 2012). The role a coach is perceived to fulfill and recruited by an organization (Swierzy et al., 2018) may drive them to participate, the resources they are able to access determine their actual involvement. The finding from the verification interviews indicated that the coaches had a desire to assist in these types of volunteer activities and that they felt there was an underlying expectation that they should participate in order to support their sport. Nonprofits have a vested interest in making events more accessible and converting informal volunteers to a more formal role (Ringuet-Riot et al., 2014). The interviewees also expressed their close association with these organizations increased their interest in participation, a concept also found by Tidwell (2005) when volunteers were more committed and satisfied with the organizations they were involved.

The consideration of the volunteer's time as an influential factor in the literature (Hallman \& Dickson, 2017) is consistent with the concepts of time identified in the Delphi and verified by the interviewees. The items of primary work responsibilities limiting time and availability, time and availability, length of time being asked for the event, and time of 
year/season identified in the initial round of the Delphi agree with previous studies that found the preparation time an organization may require outside of the actual event and the demands of employment all show indications affecting a person's resources (Brown et al., 2012; Smith, 2010; Strong \& Harder, 2010). The coaches in this study expressed concerns as to how much they may contribute given their busy professional schedule and finding an appropriate amount of time to dedicate to an event. The length of time the actual event would require complemented this concern as they decided whether to become involved in an event or not. Lastly, the interviewees discussed that there are times of the year that they are more likely to assist in these types of events. They expressed that they are more likely to help in the off season, rather than during the competitive phase of their year. For nonprofits, including sport nonprofits, to attract executive-level volunteers they must volunteer and assess organizational needs prior to organizing their event (Brown \& Ferris, 2007; Wicker \& Frick, 2016).

In addition to the personal resource category, the category of social ties contained the one item that reached agreement for both impact and prevalence: family responsibilities. The consensus reached by the group for this item also mirrors the volunteer literature finding family responsibilities a limiting factor for volunteer service (Borgonovi, 2008; Brown et al., 2012; Einolf \& Chambré, 2011). The interviewees confirmed that next to time, the various responsibilities necessary for their families contributed to their decision-making as to whether they may participate in a volunteer event. This role clarity that was verbalized by the coaches is congruent with the work of Einolf and Chambré (2011) and in that it is difficult to uphold the roles of family along with volunteer service. The item within this category aligns with findings of Borgonovi (2008) and Brown et al. (2012) that the volunteer must realize some type of perceived benefit to themselves or their family due to their service, rather than taking additional 
time away from their family responsibilities. The coaches found it difficult to compartmentalize their responsibilities and saw their roles pulling them in multiple directions. Each of the interviewees had slightly a different variation of what the item family responsibilities meant to them. For some it was a further extension of time; for others it was the role that they played in their family.

The category of cultural ties contained items initially identified during round I of the Delphi process. The cultural ties that contribute to the volunteer framework (Sundeen et al., 2007) have influences from an individual's ethnicity, values, spiritual beliefs, and views of a community. One item in the category of cultural ties, passion for the scheduled event, failed to reach the minimum standards of prevalence and impact. This finding is relevant as it runs contradictory to the work of Hallett et al. (2020) that explained that participants of the community would be more likely to volunteer because of their ties. Hager and Brudney (2011) also explained that the participation of a volunteer may increase with the appropriate task assignment and utilizing those within the community to recruit additional volunteers. The lack of agreement on this item may have come from not naming a specific organization's event. While the participants from this study did initially attribute additional items to this category, they did not come to agreement that these items were particularly impactful or prevalent in the scenario related to volunteering.

A similar result was found for the category of residential context, the location, size, and type of community that the potential volunteers reside in will also present a set of barriers that may be difficult to overcome (Brown et al., 2012; Sundeen et al., 2007). The volunteer requirements in the literature for sporting organizations presented by Cuskelly et al. (2006) explained that the program need for fundraising, publicity, and direct support from the 
organization presented in a community setting may be too great and thus prevent the volunteer involvement. Once again, the panelist identified items during round I that corresponded with the work done by Cuskelly et al. (2006), program resources, limited to no facility availability, and support from university athletics and the city itself, but none reached consensus during any of the rounds in which the items were rated by the group. The difference in these two categories not coinciding with the trends found in the literature may be due to the volunteer population selected. The present study used only executive-level volunteers and they were asked to view the volunteer scenario through that specific lens, rather than that of the volunteers used in the studies mentioned from the volunteer literature. Once the interviews confirmed and expanded upon the barriers identified, the panelists were asked to speculate on overcoming these barriers.

The findings from the qualitative interviews indicated there was agreement in that it would be possible to overcome or mitigate the barriers that were found to be impactful and prevalent as well as those that may be prevalent. Panelists offered their thoughts as to how that might be accomplished. All panelists felt that it is ultimately the personal responsibility of the individual coach to overcome the barriers identified. The subthemes found from the interviews were strategies and support. Similar to the personal organization needs of a volunteer found by Hager (2014), the panelists stated that in order for an individual to volunteer, coaches must develop organizational tools and strategies. Additionally, there was an element of support that was sought by the organization hosting the event or the agency of employment to allow the coach to participate, Young's research found agreement with the panel (2001a; 2001b). The ability of an organization run an event efficiently may decrease the impact on the time required for a volunteer to be away from their own professional activities (Krajňáková et al., 2018). The 
use of these executive volunteers and the lack of existing literature in volunteer barriers provided limitations to this study.

\section{Strengths and Limitations}

One of the major strengths of the study was the population itself. Thirty coaches began and completed all rounds of the study. All coaches involved in the study were current members of coaching staffs at large NCAA power five institutions for the sport of swimming. The panelists met the criteria set forth in the volunteer literature to meet the criteria of executive-level volunteers (Nicholson \& Hoye, 2008; Paik \& Navarre-Jackson, 2011; Wilson \& Musick, 1998). The group initially identified many barriers that corresponded with the existing volunteer literature. The present study successfully sampled a specific executive-level volunteer group and identified a list of eight tangible barriers. The specificity of the sample also limited the study results in some areas.

The sample size required for the Delphi method may be a limitation in attempting to generalize the results to a larger community. The selection of 30 panelists for this study allowed for greater participation and completion rates but the small sample size may not have captured a wide enough scope of answers to the initial round I question. By contrast, Clary et al. (1998) surveyed 2, 671 individuals to investigate volunteer motivation through a six-stage survey process at multiple sites and various volunteer types and roles. The small sample size recommended for the Delphi (Rowe \& Wright, 2001) limits the generalizability of the study to those in executive volunteer role. Additionally, requiring the sample of panelists to all have the same previous volunteer experience may have made the group more homogenous. While the research completed by Hallett et al. (2020) does utilize individuals with and without previous volunteer experience to predict barriers, the sample size was much larger. The experiences of 
the lead author, as a member of the larger community of coaches represented in the study, needs to be acknowledged as a potential limitation due to the potential for personal bias. While it may be possible that greater access to these coaches may have been granted by being a member of this overall community, the possibility of researcher bias also exists.

\section{Applications for the Field}

The present study sought to identify the actual constructs perceived by those who were eligible to fulfill the role of executive-level volunteers that may be a barrier to their service at a nonprofit event that benefits their sport. The interviews supported the findings of the Delphi in that the limited nature of the personal resources of coaches are important for the organization to consider when organizing the volunteer event. The focus of the nonprofit organizations should be to directly mitigate these subthemes of time. Packaging volunteer opportunities so that they are easily executed by the volunteer and planning events outside of the playing season may require additional work on the front end for nonprofits but yield a higher executive level volunteer participation as suggested by Hallmann et al. (2018). The need for a nonprofit to be organized and efficient has been stated in the literature (Shilbury \& Moore, 2006; Stebbins, 2005). Specifically, for the area of sport, nonprofit organizations will want to begin conversations with the athletic departments to support the coaches with staff whose responsibility it is to be a liaison with various nonprofit entities. The publicity, recognition, and support from this collaboration may prove mutually beneficial (Cuskelly et al., 2006; Swierzy et al., 2018). Another significant application of the present study is to serve as a springboard for future research in the creation of specific interventions to mitigate the barriers presented in order to facilitate additional executive-level volunteer service.

\section{Future Directions}


Future research is needed in the area of creating interventions to specifically address the barriers of a participant's dedicated time, length of time for participation, and timing of the event during the season or offseason. The organization of the volunteer event itself, support from the organizations employing these individuals, and providing strategies for the volunteers themselves all need to be researched and studied in order to create a more robust field of study. The verification interviews assisted in supporting the findings of the study and demonstrated that further research may be necessary in training coaches at large programs as to how to prepare, organize, and communicate with nonprofit organizations that may seek their volunteer efforts due to their social status (Chanavat \& Ferrand, 2010; Hallmann \& Zehrer, 2019; Ringuet-Riot, 2014). The line of research may extend to other areas in sport coaching, sport management, and nonprofit events.

\section{Conclusion}

Nonprofits will always have a need for volunteers of all types; however, barriers have consistently impeded the participation of volunteers for event participation. In order to remove those barriers preventing participation, it becomes necessary to identify them. The current literature has focused on the motivational reasons for volunteerism, while speculating as to the lack of involvement due to barriers of participation. The present study aimed to begin this discovery by identifying the barrier of time for a specific population, coaches who fill the role of executive volunteers, for a nonprofit sporting event. It becomes incumbent that the nonprofit sport organization begin to form relationships with their communities early during the recruiting process to understand and address the needs of the potential volunteer (Mitchell \& Clark, 2020). The communities present a pool of potential volunteers that are tied to the nonprofit organization (Hallett et al., 2020). The organization may then begin to build a framework to more 
successfully address the efficiency of the event per the needs of the volunteer (Schelling \& Robertson, 2020). The conclusions of the study probably do not come as a surprise to those in the nonprofit sector. However, the conclusions do provide a starting point and reveal a specific set of barriers and recommendations that may contribute to future research and assist in creating strategies and interventions to permit a greater volunteer participation and impact.

The coaches at high profile institutions must be made aware of the social capital associated with their position and the desire of nonprofits to utilize them to fulfill a specific role (Morgan \& Bush, 2016; Wegner et al., 2019). While these activities are not directly tied to their ultimate duties and responsibilities as a professional, the involvement in the overall community may drive these coaches to volunteer for events (Hallett et al., 2020). Those who may fill the role of an executive level volunteer may need access to strategies and programs that will permit them to effectively manage their professional responsibilities while supporting an organization of their choosing (Krajňáková et al., 2018). It may become incumbent upon the nonprofit organization to create this support system to allow specific volunteer roles to decide whether they wish to participate or not (Schelling \& Robertson, 2020). The conclusions reached by this study are significant in that the experts who gave their thoughts as to the barriers are the very same individuals that the nonprofit organizations seek to recruit. 


\section{References}

Akins, R. B., Tolson, H., \& Cole, B. R. (2005). Stability of response characteristics of a Delphi panel: Application of bootstrap data expansion. BMC Medical Research Methodology, 5(1), 37 .

Anheier, H. K. (2005). Nonprofit organizations: an introduction. New York, NY: Routledge.

Blau, P. M. (1964). Justice in social exchange. Sociological Inquiry, 34(2), 193-206.

Borgonovi, F. (2008). Doing well by doing good. The relationship between formal volunteering and self-reported health and happiness. Social Science \& Medicine, 66(11), 2321-2334.

Bouchet, A., \& Lehe, A. (2010). Volunteer coaches in youth sports organizations: Their values, motivations \& how to recruit, \& retain. Journal of Youth Sports, 5(1), 21-24.

Boyd, B. L. (2003). Competencies for leaders of volunteers during the next decade: A national Delphi study. Journal of Agricultural Education, 44(4), 47-56.

Brooks, K. W. (1979). Delphi technique: Expanding applications. North Central Association Quarterly, 53(3), 377-85.

Brown, E., \& Ferris, J. M. (2007). Social capital and philanthropy: An analysis of the impact of social capital on individual giving and volunteering. Nonprofit and Voluntary Sector Quarterly, 36(1), 85-99.

Brown, K. M., Hoye, R., \& Nicholson, M. (2012). Self-esteem, self-efficacy, and social connectedness as mediators of the relationship between volunteering and well-being. Journal of Social Service Research, 38(4), 468-483.

Bulger, S. M., \& Housner, L. D. (2007). Modified Delphi investigation of exercise science in physical education teacher education. Journal of Teaching in Physical Education, 26(1), $57-80$. 
Burgham, M., \& Downward, P. (2005). Why volunteer, time to volunteer? A case study from swimming. Managing Leisure, 10(2), 79-93.

Chanavat, N., \& Ferrand, A. (2010). Volunteer programme in mega sport events: The case of the Olympic Winter Games, Torino 2006. International Journal of Sport Management and Marketing, 7(3-4), 241-266.

Clary, E. G., Snyder, M., Ridge, R. D., Copeland, J., Stukas, A. A., Haugen, J., \& Miene, P. (1998). Understanding and assessing the motivations of volunteers: A functional approach. Journal of Personality and Social Psychology, 74(6), 1516-1530.

Cnaan, R. A., Handy, F., \& Wadsworth, M. (1996). Defining who is a volunteer: Conceptual and empirical considerations. Nonprofit and Voluntary Sector Quarterly, 25(3), 364-383.

Crisp, J., Pelletier, D., Duffield, C., Adams, A., \& Nagy. (1997). The Delphi method? Nursing Research, 46(2), 116-118.

Cuskelly, G., Hoye, R., \& Auld, C. (2006). Working with volunteers in sport: Theory and practice. New York, NY: Routledge.

Dalkey, N., \& Helmer, O. (1963). An experimental application of the Delphi method to the use of experts. Management Science, 9(3), 458-467.

Delbecq, A. L., Van de Ven, A. H., \& Gustafson, D. H. (1975). Group techniques for program planning: A guide to nominal group and Delphi processes (pp. 83-107). Glenview, IL: Scott, Foresman.

Downward, P. M., \& Ralston, R. (2006). The sports development potential of sports event volunteering: Insights from the XVII Manchester Commonwealth Games. European Sport Management Quarterly, 6(4), 333-351. 
Einolf, C., \& Chambré, S. M. (2011). Who volunteers? Constructing a hybrid theory. International Journal of Nonprofit and Voluntary Sector Marketing, 16(4), 298-310.

Hager, M. A. (2014). Engagement motivations in professional associations. Nonprofit and Voluntary Sector Quarterly, 43(2), 39-60.

Hager, M. A., \& Brudney, J. L. (2011). Problems recruiting volunteers: Nature versus nurture. Nonprofit Management and Leadership, 22(2), 137-157.

Hallett, R. J., Mullan, N. K., Tideswell, A. E., Haake, S. J., Graney, M., \& Hurley, M. V. (2020). Community event sustainability: Why don’t people volunteer? Voluntary Sector Review, $11(2), 137-167$

Hallmann, K., \& Dickson, G. (2017). Non-profit sport club members: What makes them volunteer? Voluntary Sector Review, 8(2), 187-204.

Hallmann, K., Downward, P., \& Dickson, G. (2018). Factors influencing time allocation of sport event volunteers. International Journal of Event and Festival Management, 9(3), 316331.

Hallmann, K., \& Zehrer, A. (2017). Event and community involvement of sport event volunteers. International Journal of Event and Festival Management, 8(3), 308-323.

Hallmann, K., \& Zehrer, A. (2019). Volunteers' perceived costs and benefits: The impact of context and their influence on volunteers' satisfaction and behavioral intentions. Event Management, 23(1), 11-26.

Hameiri, L. (2018). Executive-level volunteers in Jewish communal organizations: Their trust in executive professionals as mediating the relationship between their motivation to volunteer and their pursuit of servant leadership. VOLUNTAS: International Journal of Voluntary and Nonprofit Organizations, 30(1), 1-15. 
Hasson, F., \& Keeney, S. (2011). Enhancing rigour in the Delphi technique research. Technological Forecasting and Social Change, 78(9), 1695-1704.

Hoye, R., \& Kappelides, P. (2020). The psychological contract and volunteering: A systematic review. Nonprofit Management and Leadership.

Hustinx, L., Cnaan, R. A., \& Handy, F. (2010). Navigating theories of volunteering: A hybrid map for a complex phenomenon. Journal for the Theory of Social Behaviour, 40(4), 410434.

Hycner, R. H. (1985). Some guidelines for the phenomenological analysis of interview data. Human studies, 8(3), 279-303.

Jackson, S. (2016). Prediction, explanation and big (ger) data: A middle way to measuring and modelling the perceived success of a volunteer tourism sustainability campaign based on 'nudging'. Current Issues in Tourism, 19(7), 643-658.

Kappelides, P., Cuskelly, G., \& Hoye, R. (2019). The influence of volunteer recruitment practices and expectations on the development of volunteers' psychological contracts. VOLUNTAS: International Journal of Voluntary and Nonprofit Organizations, 30(1), 259-271.

Keeney, S., McKenna, H., \& Hasson, F. (2011). The Delphi technique in nursing and health research. West Sussex, UK: John Wiley \& Sons.

Kihl, L. A., Leberman, S., \& Schull, V. (2010). Stakeholder constructions of leadership in intercollegiate athletics. European Sport Management Quarterly, 10(2), 241-275.

Klandermans, B., \& Oegema, D. (1987). Potentials, networks, motivations, and barriers: Steps towards participation in social movements. American Sociological Review, 52(4), 519531. 
Kono, S., Ito, E., Walker, G. J., \& Gui, J. (2020). Predictive power of leisure constraintnegotiation models within the leisure-time physical activity context: A partial least squares structural equation modeling approach. Journal of Leisure Research, 51(3), 325347.

Krajňáková, E., Pilinkiene, V., Grabowska, M., \& Šimkus, A. (2018). Analysis of barriers in sports volunteering. Journal of International Studies. Ternopil: Foundation of International Studies, 2018, 11(4), 255-269

Lewis, D. (2001). The Management of non-governmental development organizations. New York, NY: Routledge.

Linstone, H. A., \& Turoff, M. (1975). The Delphi method: Techniques and applications. Reading, MA: Addison-Wesley.

McKenna, H. P. (1994). The Delphi technique: A worthwhile research approach for nursing? Journal of Advanced Nursing, 19(6), 1221-1225.

Miles, M. B., Huberman, A. M. (1994). Qualitative data analysis: An expanded sourcebook. London, UK: Sage.

Mitchell, S. L., \& Clark, M. (2020). Volunteer choice of nonprofit organisation: an integrated framework. European Journal of Marketing, 55(1), 63-94.

Mook, L., Handy, F., Ginieniewicz, J., \& Quarter, J. (2007). The value of volunteering for a nonprofit membership association: The case of ARNOVA. Nonprofit and Voluntary Sector Quarterly, 36(3), 504-520.

Morgan, H. J., \& Bush, A. J. (2016). Sports coach as transformative leader: Arresting school disengagement through community sport-based initiatives. Sport, Education and Society, 21(5), 759-777. 
Murray Jr, J. W., \& Hammons, J. O. (1995). Delphi: A versatile methodology for conducting qualitative research. The Review of Higher Education, 18(4), 423-436.

Nichols, G., \& Ojala, E. (2009). Understanding the management of sports events volunteers through psychological contract theory. VOLUNTAS: International Journal of Voluntary and Nonprofit Organizations, 20(4), 369.

Nicholson, M., \& Hoye, R. (2008). Sport and Social Capital. New York, NY: Routledge.

Parenté, F. J., \& Anderson-Parente, J. K. (1987). Delphi inquiry systems. Judgmental Forecasting, (pp. 129-156). West Sussex, UK: John Wiley \& Sons.

Paik, A., \& Navarre-Jackson, L. (2011). Social networks, recruitment, and volunteering: Are social capital effects conditional on recruitment? Nonprofit and Voluntary Sector Quarterly, 40(3), 476-496.

Penner, L. A. (2002). Dispositional and organizational influences on sustained volunteerism: An interactionist perspective. Journal of Social Issues, 58(3), 447-467.

Posner, B. Z. (2015). An investigation into the leadership practices of volunteer leaders. Leadership \& Organization Development Journal, 36(7), 885-898.

Powell, C. (2003). The Delphi technique: Myths and realities. Journal of Advanced Nursing, 41(4), 376-382.

Ringuet-Riot C, Cuskelly G, Auld C, \& Zakus D.H. (2014). Volunteer Roles, Involvement and Commitment in Voluntary Sport Organizations: Evidence of Core and Peripheral Volunteers. Sport in Society 17(1), 116-33.

Rioja-Lang, F. C., Connor, M., Bacon, H., \& Dwyer, C. M. (2020). Determining a Welfare Prioritization for Horses Using a Delphi Method. Animals, 10(4), 647. 
Rousseau, D. (1995). Psychological contracts in organizations: Understanding written and unwritten agreements. London, UK: Sage.

Rowe, G., \& Wright, G. (2001). Expert opinions in forecasting: The role of the Delphi technique. In Principles of Forecasting, (pp. 125-144). Boston, MA: Springer.

Sandrey, M. A., \& Bulger, S. M. (2008). The Delphi method: An approach for facilitating evidence-based practice in athletic training. Athletic Training Education Journal, 3(4), $135-142$.

Schelling, X., \& Robertson, S. (2020). A development framework for decision support systems in high-performance sport. International Journal of Computer Science in Sport, 19(1), 123.

Seippel, Ø., Breuer, C., Elmose-Østerlund, K., Feiler, S., Perényi, S., Piątkowska, M., \& Scheerder, J. (2020). In troubled water? European sports clubs: Their problems, capacities and opportunities. Journal of Global Sport Management. Advance online publication. doi: 10.1080/24704067.2020.1806493

Senses-Ozyurt, S., \& Villicana-Reyna, N. (2016). Leadership characteristics and volunteer retention in nonprofit organizations. The Journal of Nonprofit Education and Leadership, 6(4), 350-374.

Shilbury, D., \& Moore, K. A. (2006). A study of organizational effectiveness for national Olympic sporting organizations. Nonprofit and Voluntary Sector Quarterly, 35(1), 5-38.

Smith, V. (2010). Enhancing employability: Human, cultural, and social capital in an era of turbulent unpredictability. Human Relations, 63(2), 279-300. 
Strazdins, L., Broom, D. H., Banwell, C., McDonald, T., \& Skeat, H. (2011). Time limits? Reflecting and responding to time barriers for healthy, active living in Australia. Health Promotion International, 26(1), 46-54.

Stebbins, R. A. (2009). Would you volunteer? Society, 46(2), 155-159.

Strong, R., \& Harder, A. (2010). Master gardeners' teaching efficacy and demographic characteristics as volunteer educators for cooperative extension. Journal of Southern Agricultural Education Research, 60(1), 14-24.

Sundeen, R. A., Raskoff, S. A., \& Garcia, M. C. (2007). Differences in perceived barriers to volunteering to formal organizations: Lack of time versus lack of interest. Nonprofit Management and Leadership, 17(3), 279-300.

Swierzy, P., Wicker, P., \& Breuer, C. (2018). The impact of organizational capacity on voluntary engagement in sports clubs: A multi-level analysis. Sport Management Review, 21(3), 307-320.

Tidwell, M. V. (2005). A social identity model of prosocial behaviors within nonprofit organizations. Nonprofit Management and Leadership, 15(4), 449-467.

Vagias, W. M. (2006). Likert-type scale response anchors. Clemson International Institute for Tourism \& Research Development, Department of Parks, Recreation and Tourism Management, Clemson University.

Weaver, D. (2015). Volunteer tourism and beyond: Motivations and barriers to participation in protected area enhancement. Journal of Sustainable Tourism, 23(5), 683-705.

Wegner, C. E., Jones, G. J., \& Jordan, J. S. (2019). Voluntary sensemaking: the identity formation process of volunteers in sport organizations. European Sport Management Quarterly, 19(5), 625-644. 
Wicker, P. (2017). Volunteerism and volunteer management in sport. Sport Management Review, 20(4), 325-337.

Wicker, P., \& Breuer, C. (2013). Understanding the importance of organizational resources to explain organizational problems: Evidence from non-profit sport clubs in Germany. VOLUNTAS: International Journal of Voluntary and Nonprofit Organizations, 24(2), $461-484$.

Wicker, P., \& Downward, P. (2019). The causal effect of voluntary roles in sport on subjective well-being in European countries. Journal of Sport Management, 34(4), 303-315.

Wicker, P., \& Frick, B. (2016). Recruitment and retention of referees in nonprofit sport organizations: The trickle-down effect of role models. VOLUNTAS: International Journal of Voluntary and Nonprofit Organizations, 27(3), 1304-1322.

Wilson, J. (2012). Volunteerism research: A review essay. Nonprofit and Voluntary Sector Quarterly, 41(2), 176-212.

Wilson, J., \& Musick, M. (1997). Who cares? Toward an integrated theory of volunteer work. American Sociological Review, 62(5), 694-713.

Wilson, J., \& Musick, M. (1998). The contribution of social resources to volunteering. Social Science Quarterly, 13 (3), 799-814.

Winniford, J. C., Carpenter, D. S., \& Grider, C. (1997). Motivations of college student volunteers: A review. NASPA Journal, 34(2), 134-146.

Wyant, J. D., Tsuda, E., \& Yeats, J. T. (2020). Delphi investigation of strategies to develop cultural competence in physical education teacher education. Physical Education and Sport Pedagogy, 25(5), 525-538. 
Young, D. R. (2001). Organizational identity and the structure of nonprofit umbrella associations. Nonprofit Management and Leadership, 11(3), 289-304.

Young, D. R. (2001). Organizational identity in nonprofit organizations: Strategic and structural implications. Nonprofit Management and Leadership, 12(2), 139-157. 


\section{Tables}

Table 1

Participant Demographic Data

\begin{tabular}{lcr}
\hline \multicolumn{1}{c}{ Demographic Information } & Range & \multicolumn{1}{c}{ Mean } \\
\hline Current Age (yrs.) & $27-65$ & 41.50 \\
Number of years at present institution (yrs.) & $.5-22$ & 6.91 \\
Number of years at present institution in your current role (yrs.) & $.5-22$ & 5.68 \\
Number of years coaching at a Power Five Division I institution & $1.5-30$ & 10.83 \\
Number of years coaching (any level) & $4.5-42$ & 18.58 \\
On average, the number of nonprofit (any nonprofit) events that & $0-20$ & 3.43 \\
you typically have volunteered for in given year (\# events) & & 1.28 \\
On average, the number of swimming nonprofit events that you & $0-6.5$ & \\
volunteered for each year (\# events) & &
\end{tabular}

Note. Number of participants in the study, $n=30$. 
Table 2

Condensed Round I Responses and Corresponding Category

Personal Resources
Item 1-Primary work responsibilities limiting time availability
Item 2- Time and availability
Item 3- Discretionary time
Item 4- Energy it would cost me
Item 5- Money it would cost me to help
Item 6- Time away from team activity
Item 7- During college season, having to coach practice
Item 8- Length of time being asked for the event
Item 9- Time of year/season
Social Ties
Item 10- Family responsibilities
Item 11- Cost of obtaining a babysitter
Item 12- Social ties
Cultural Ties
Item 13- Whether I agree with the mission of the gathering
Item 14- Passion for the scheduled event
Residential Context
Item 15- Does it tie into a cause that the sport of swimming needs
Item 16- If there is any professional conflict of interest
Item 17- Is this opportunity going to be of a benefit to my institution to be affiliated with it
Item 18- Support from university athletics and the city itself
Item 19- Not beneficial to my professional growth
Item 20- Program Resources
Item 21- Limited to no facility availability

Note. Categories derived from Sundeen et al. (2007). Mixed Resources, n=0. 
Table 3

Round II Ratings for Impact and Prevalence

\begin{tabular}{|c|c|c|c|c|}
\hline Item & $\begin{array}{l}\text { Impact } \\
\text { Mean }\end{array}$ & $\underset{\%}{\text { Impact }}$ & $\begin{array}{l}\text { Prevalence } \\
\text { Mean }\end{array}$ & $\begin{array}{c}\text { Prevalence } \\
\%\end{array}$ \\
\hline \multicolumn{5}{|l|}{ Personal Resources } \\
\hline $\begin{array}{l}\text { Item 1-Primary work responsibilities limiting } \\
\text { time availability } * \#\end{array}$ & 4.63 & 96.67 & 4.67 & 96.67 \\
\hline Item 2 - Time and availability $* \#$ & 4.73 & 100 & 4.60 & 93.33 \\
\hline Item 3- Discretionary time $* \#$ & 4.23 & 86.67 & 4.30 & 83.33 \\
\hline Item 4- Energy it would cost me & 3.63 & 60.00 & 3.40 & 46.67 \\
\hline Item 5- Money it would cost me to help & 2.63 & 16.67 & 2.53 & 20.00 \\
\hline Item 6- Time away from team activity \# & 3.90 & 73.33 & 4.03 & 76.67 \\
\hline $\begin{array}{l}\text { Item 7- During college season, having to } \\
\text { coach practice } * \#\end{array}$ & 4.70 & 96.67 & 4.63 & 93.33 \\
\hline $\begin{array}{l}\text { Item 8- Length of time being asked for the } \\
\text { event }\end{array}$ & 3.80 & 70.00 & 3.93 & 73.33 \\
\hline Item 9- Time of year/season $* \#$ & 4.37 & 86.67 & 4.43 & 93.33 \\
\hline \multicolumn{5}{|l|}{ Social Ties } \\
\hline Item 10 - Family responsibilities $*$ & 4.13 & 76.67 & 4.00 & 70.00 \\
\hline Item 11- Cost of obtaining a babysitter & 2.43 & 23.33 & 2.07 & 20.00 \\
\hline Item 12- Social ties & 2.27 & 6.67 & 2.00 & 10.00 \\
\hline \multicolumn{5}{|l|}{ Cultural Ties } \\
\hline $\begin{array}{l}\text { Item 13- Whether I agree with the mission of } \\
\text { the gathering }\end{array}$ & 3.43 & 43.33 & 2.93 & 33.33 \\
\hline Item 14- Passion for the scheduled event & 3.87 & 66.67 & 3.17 & 43.33 \\
\hline \multicolumn{5}{|l|}{ Residential Context } \\
\hline $\begin{array}{l}\text { Item 15- Does it tie into a cause that the sport } \\
\text { of swimming needs }\end{array}$ & 3.53 & 50.00 & 2.97 & 33.33 \\
\hline $\begin{array}{l}\text { Item 16- If there is any professional conflict of } \\
\text { interest }\end{array}$ & 3.73 & 63.33 & 2.83 & 26.67 \\
\hline $\begin{array}{l}\text { Item 17- Is this opportunity going to be of a } \\
\text { benefit to my institution to be } \\
\text { affiliated with it }\end{array}$ & 3.27 & 40.00 & 2.83 & 33.33 \\
\hline $\begin{array}{l}\text { Item 18- Support from university athletics and } \\
\text { the city itself }\end{array}$ & 3.13 & 43.33 & 3.03 & 40.00 \\
\hline $\begin{array}{l}\text { Item 19- Not beneficial to my professional } \\
\text { growth }\end{array}$ & 2.43 & 13.33 & 3.00 & 26.67 \\
\hline Item 20- Program Resources & 2.90 & 30.00 & 2.63 & 23.33 \\
\hline Item 21- Limited to no facility availability & 2.60 & 26.67 & 2.63 & 23.33 \\
\hline
\end{tabular}

Note. Items meeting criteria for consensus for impact (4.0/75\%) are indicated with *. Items meeting criteria for consensus for prevalence $(4.0 / 75 \%)$ are indicated with \#. 
Table 4

Round III Ratings for Impact and Prevalence

\begin{tabular}{|c|c|c|c|c|}
\hline Item & $\begin{array}{l}\text { Impact } \\
\text { Mean }\end{array}$ & $\underset{\%}{\text { Impact }}$ & $\begin{array}{l}\text { Prevalence } \\
\text { Mean }\end{array}$ & $\begin{array}{c}\text { Prevalence } \\
\%\end{array}$ \\
\hline \multicolumn{5}{|l|}{ Personal Resources } \\
\hline $\begin{array}{l}\text { Item 1-Primary work responsibilities limiting } \\
\text { time availability } * \#\end{array}$ & 4.57 & 100 & 4.53 & 93.33 \\
\hline Item 2 - Time and availability $* \#$ & 4.70 & 100 & 4.70 & 100 \\
\hline Item 3- Discretionary time $* \#$ & 4.00 & 76.67 & 4.10 & 76.67 \\
\hline Item 4- Energy it would cost me & 3.47 & 50.00 & 3.23 & 40.00 \\
\hline Item 5- Money it would cost me to help & 2.57 & 26.67 & 2.47 & 20.00 \\
\hline Item 6- Time away from team activity \# & 4.00 & 66.67 & 4.27 & 80.00 \\
\hline $\begin{array}{l}\text { Item 7- During college season, having to } \\
\text { coach practice } * \#\end{array}$ & 4.70 & 96.67 & 4.67 & 96.67 \\
\hline $\begin{array}{l}\text { Item 8- Length of time being asked for the } \\
\text { Event } * \#\end{array}$ & 4.00 & 76.67 & 4.20 & 80.00 \\
\hline Item 9- Time of year/season $* \#$ & 4.50 & 90.00 & 4.60 & 96.67 \\
\hline \multicolumn{5}{|l|}{ Social Ties } \\
\hline Item 10- Family responsibilities $* \#$ & 4.10 & 80.00 & 4.23 & 83.33 \\
\hline Item 11- Cost of obtaining a babysitter & 2.07 & 16.67 & 1.93 & 16.67 \\
\hline Item 12- Social ties & 2.27 & 13.33 & 2.40 & 16.67 \\
\hline \multicolumn{5}{|l|}{ Cultural Ties } \\
\hline $\begin{array}{l}\text { Item 13- Whether I agree with the mission of } \\
\text { the gathering }\end{array}$ & 3.73 & 56.67 & 3.40 & 53.33 \\
\hline Item 14- Passion for the scheduled event & 3.90 & 80.00 & 3.37 & 50.00 \\
\hline \multicolumn{5}{|l|}{ Residential Context } \\
\hline $\begin{array}{l}\text { Item 15- Does it tie into a cause that the sport } \\
\text { of swimming needs }\end{array}$ & 3.23 & 43.33 & 3.17 & 43.33 \\
\hline $\begin{array}{l}\text { Item 16- If there is any professional conflict of } \\
\text { interest }\end{array}$ & 3.70 & 60.00 & 2.97 & 30.00 \\
\hline $\begin{array}{l}\text { Item 17- Is this opportunity going to be of a } \\
\text { benefit to my institution to be } \\
\text { affiliated with it }\end{array}$ & 3.10 & 30.00 & 3.00 & 36.67 \\
\hline $\begin{array}{l}\text { Item 18- Support from university athletics and } \\
\text { the city itself }\end{array}$ & 3.63 & 56.67 & 3.17 & 43.33 \\
\hline $\begin{array}{l}\text { Item 19- Not beneficial to my professional } \\
\text { growth }\end{array}$ & 2.60 & 23.33 & 2.77 & 23.33 \\
\hline Item 20- Program Resources & 2.60 & 13.33 & 2.57 & 16.67 \\
\hline Item 21- Limited to no facility availability & 2.80 & 30.00 & 2.57 & 20.00 \\
\hline
\end{tabular}

Note. Items meeting criteria for consensus for impact (4.0/75\%) are indicated with *. Items meeting criteria for consensus for prevalence $(4.0 / 75 \%)$ are indicated with \#. 


\section{Figures}

Figure 1

Item Importance

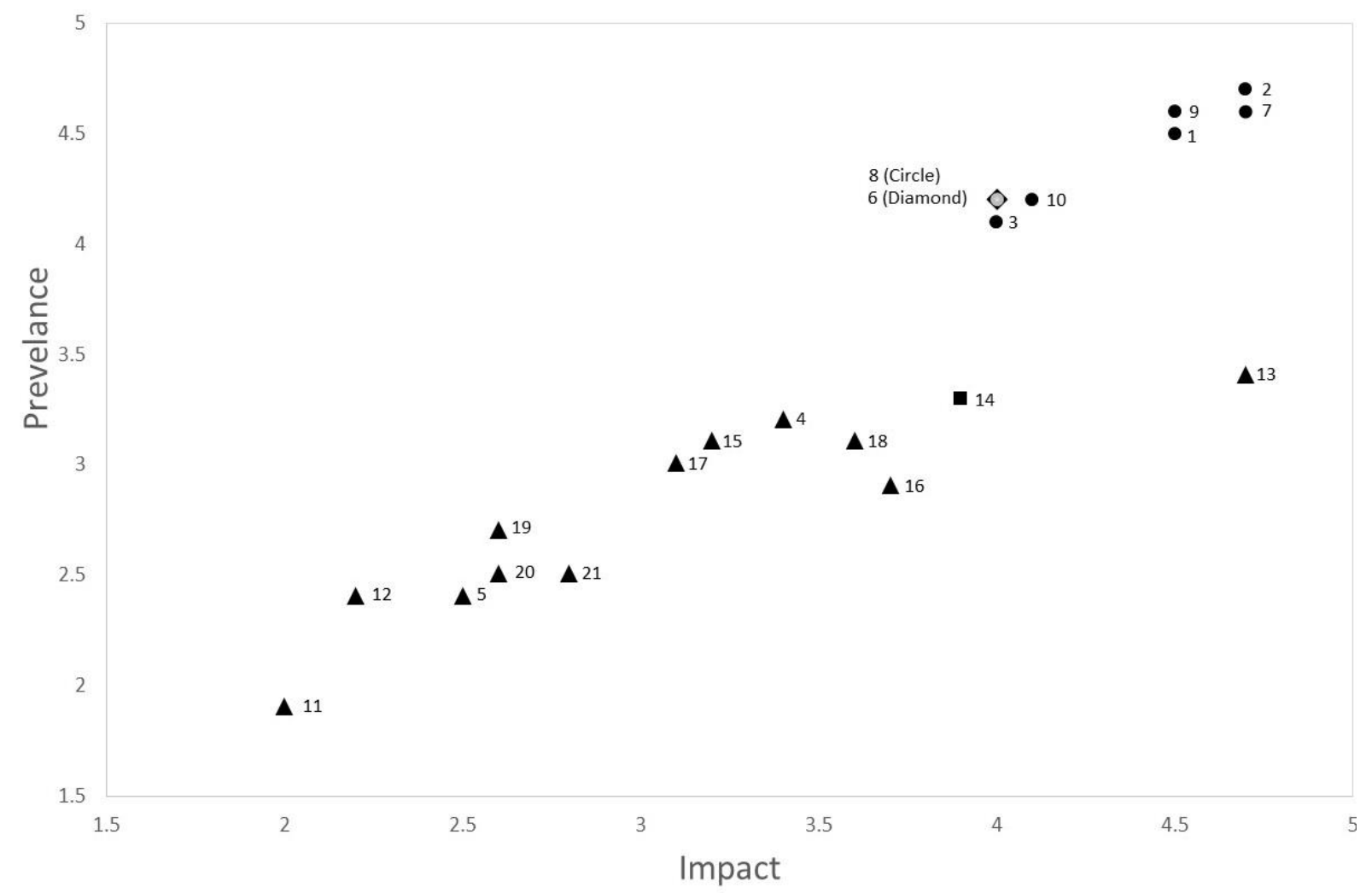

Figure 1: The characters on the graph represent the group mean score for each individual item. The number next to the character represents the items plotted from Table 4. The differentiation in characters represents the percentage of subjects who ranked the item as a 4.0 or higher on the Round III questionnaire.

- -item rated a 4.0 or higher on at least $75 \%$ of respondent questionnaires for both impact and prevalence.

- -item rated a 4.0 or higher on at least $75 \%$ of respondent questionnaires for prevalence but was failed to reach the $75 \%$ threshold for impact.

-item rated a 4.0 or higher on at least $75 \%$ of respondent questionnaires for impact but was failed to reach the $75 \%$ threshold for prevalence.

$\boldsymbol{\Delta}$-item did not rate a 4.0 or higher on $75 \%$ of respondent questionnaires for both impact and prevalence. 


\section{Appendix A: Chapter 1 Introduction \\ CHAPTER 1}

\section{Barriers of Volunteerism for Coaches of Collegiate Division I Swimming Programs}

Volunteers comprise the life's blood of nonprofit organizations and support the mission and purposes of that organization (Anheier, 2005; Lewis, 2001; Mook, Handy, Ginieniewicz, \& Quarter, 2007). The way a volunteer may provide service may come in many forms and has unique opportunities for that service. A volunteer may select to become involved in just one event with a specific opportunity, or the volunteer may choose to serve the organization for a prolonged period of time whereby sustaining their volunteer efforts (Bouchet \& Lehe, 2010; Hustinx, Cnaan, \& Handy, 2010; Penner, 2002; Stebbins, 2009). In either case the length and depth of time by which a volunteer provides service to the nonprofit organization is coupled with the type of specific resources and roles that a volunteer provides the organization, thereby creating a volunteer type or volunteer role (Hustinx et al., 2010; Sundeen, Raskoff, \& Garcia, 2007).

The variations and types of volunteers utilized by nonprofit organizations are as extensive as the tasks themselves (Cnaan, Handy, \& Wadsworth, 1996; Hustinx et al., 2010). The variables of age, gender, cultural heritage, religious affiliation, educational level, socioeconomic status, and physical location have all been used to describe and categorize different indicators of volunteers (Cnaan et al., 1996; Wilson, 2012; Wilson \& Musick, 1997; Stebbins, 2009). The categorical nuances alone do not explain the total depth of the volunteer type. The roles and specific tasks or duties that volunteers provide the organization are meshed with the variables of the individual to describe a more specific volunteer category (Hustinx et al., 2010; Wilson \& Musick, 1997). 
The role of executive volunteer is one type that may be a valuable resource to a nonprofit organization (Bussell \& Forbes, 2002; Cnaan et al., 1996). The resources that categorize an individual as an executive volunteer are social status, influence, and ability to recruit others to the organization or tasks (Brown \& Ferris, 2007; Paik \& Navarre-Jackson, 2011; Wilson \& Musick, 1998). The executive volunteer creates an important link from the general population of volunteers to the organization and the successful fulfillment of that organization's mission (Posner, 2015). The ability of the executive volunteer to use their social standing to attract and recruit additional volunteers affords them a unique attribute (Brown \& Ferris, 2007; Paik \& Navarre-Jackson, 2011). In order for an executive volunteer or any volunteer to act on their compulsion to serve an organization depends upon a complex set of motivators and barriers that when added together result in a decision to volunteer or not (Clary et al., 1998; Sundeen et al. 2007; Winniford, Carpenter, \& Grider, 1997).

The motivators are the forces that drive a volunteer toward assisting with an organization's purpose while the antithesis of these, the barriers, prevent one from engaging in service. Sundeen et al. (2007) created a set of resources a person may determine their voluntary abilities. The theory created by Sundeen et al. (2007) is that an individual must have the necessary resources available in order to successfully provide a volunteer service. The categories of resources are consistent with many volunteers, including those in the executive category (Nicholson \& Hoye, 2008; Paik \& Navarre-Jackson, 2011; Wilson \& Musick, 1998). The executive volunteer must then ascertain if the motivators or barriers provide a more compelling avenue in the use of their resources for volunteerism or select to not volunteer in the scenario for that event. The barriers to volunteering are not as thoroughly researched proportionally as the motivators, which creates a difficult problem in the identification of 
obstacles of those in the executive category volunteering for a nonprofit organization.

Additionally, the literature on barriers to volunteerism are primarily theoretical in nature.

Identifying concrete barriers may open the door for further research as to how to overcome these barriers.

Olympic sporting clubs and organizations, nonprofit or profit, like many other groups in the United States are reliant upon support from a variety of resources produced by the organization, subsidies from the government, or in-kind funding or services from others (Anheier, 2005). The nonprofit sport organization's activity and health rely on these support measures to sustain and grow especially those coming from the volunteer sector (Burgham \& Downward, 2005; Downward \& Ralston, 2006). One of the populations necessary for this growth is that of the executive volunteer (Bussell \& Forbes, 2002; Cnaan et al., 1996). The nonprofit sector of sport relies heavily on the efforts of executive volunteers to serve the mission and identity of the sport itself and utilize their social status and standing to move the organization forward (Nicholson \& Hoye, 2008).

In the area of sport, the coach of a team or organization may often be viewed as this executive individual who can provide the necessary volunteer service. Coaches at different levels have unique spheres of influence and visibility. Those who may be at the pinnacle of the sport's highest competition level place those coaches in a much more highlighted role and thereby increase their social standing, social status, and visibility. The coach of a high-profile team or organization then meets the criteria of the executive volunteer due to the nature of their position (Wicker \& Frick, 2016). The individual then acts as an executive volunteer of their sport when presented with the opportunity to provide service, and they are possibly susceptible 
to the same barriers of the general population examined in the literature (Clary et al., 1998; Sundeen et al., 2007).

Olympic sports are often supported by nonprofit organizations that require the time, talents, and treasures of volunteers in order to assist in their performance (Anheier, 2005). These support organizations may provide recognition, publicity, fundraising, or direct support to the sport itself in a variety of manners utilizing volunteer efforts (Cuskelly, Hoye, \& Auld, 2006). The nature of these types of volunteer services meets many of the characteristics provided by the executive volunteer (Nicholson \& Hoye, 2008; Paik \& Navarre-Jackson, 2011; Wilson \& Musick, 1998). In the case of a coach, he or she themselves may benefit from those executive volunteer functions and actions as those efforts typically strengthen and benefit the sport overall. The sport of swimming cooperates with several nonprofit organizations in the United States that directly benefit the sport in a variety of ways. Swimming coaches are often asked to volunteer in an executive role to help enhance these organizations that in turn support and grow the sport they themselves are coaching.

\section{Problem Statement and Research Question}

Ideally high-profile coaches, as executive volunteers, would make themselves available to provide their service and resources to nonprofit sport organizations in order to benefit the sport overall. The reality is that nonprofit sport organizations have a need for volunteers, especially those in the executive categories to fulfill specific roles and duties due to a lack of volunteers. Identifiable practical barriers as to these individuals' reasoning for not volunteering is unknown in the literature. One possible solution is to uncover the most prevalent and impactful barriers for an executive coaching population for a nonprofit organization that benefits their sport. The purpose of this study was to gain consensus among a panel of executive level 
volunteers utilizing collegiate swimming coaches, to (a) create a list of barriers of participation in a volunteer activity with a nonprofit organization that benefits their sport, (b) determine which of the barriers are most prevalent, and (c) determine which of the barriers have the greatest impact on their decision that would prevent them from volunteering in the activity, utilizing a Delphi study. The research question guiding this discovery throughout the study; What are the most prevalent and impactful barriers preventing collegiate coaches at Division I swimming programs from volunteering in an executive role to participate in a sport awareness program for a nonprofit organization? 


\section{Appendix B: Chapter 2 Extended Literature Review}

\section{Chapter 2}

\section{Extended Review of Literature}

\section{Nonprofit Organizations}

Nonprofit organizations are unique entities that possess a specific framework of characteristics, guided by a mission, led by a board, and powered by volunteers. A nonprofit organization is only as impactful as the volunteers who participate and donate their personal resources to the cause of the group (Sundeen et al., 2007; Young, 2001a; Young, 2001b). Each volunteer has a specific set of characteristics and duties that enhance their purpose for the nonprofit entity (Cnaan et al., 1996). These characteristics and duties form the volunteer types. For nonprofit organizations to successfully implement their mission they require various volunteer types to achieve their goals one of these is the executive volunteer (Anheier, 2005; Cnaan et al., 1996; McDonald, 2007).

The executive volunteer has the social status to attract additional volunteers, due to their notoriety (Wilson \& Musick, 1998). The characteristics of volunteerism for nonprofits in the general population have transferability to the volunteerism in sport as well (Cuskelly et al., 2006; Nicholson \& Hoye, 2008). The organizational need of sport nonprofits for volunteers to participate is consistent, especially for those volunteers who may attract interest from others as in the case of the executive volunteer (Brown \& Ferris, 2007; Wicker \& Frick, 2016). In sport, the coach has a dual role as a natural stakeholder and potential executive volunteer who may contribute to a nonprofit's goals. In the sport of swimming, the American Swimming Coaches Association and the College Swimming Coaches Association (See appendices A \& B) are both 
examples of nonprofit organizations that have a need for executive coach participation to support the overall sport (Carman, Leland, \& Wilson, 2010).

The coaches at large universities are often viewed as the executive coaches who may volunteer for these organizations. The need for these individuals to participate is as important as the need in the general population; however, not all coaches volunteer and therefore create a need (Winand, Rihoux, Qualizza, \& Zintz, 2011). The uniqueness of the characteristics of the executive volunteer to possess a high enough social stature and to allow that person to recruit additional volunteers to the organization, limits the individuals who could fulfill this role. Due to the limited number of persons in this category, it is imperative that all may be able to participate within a nonprofit. The examination of the barriers preventing this volunteer action may prove valuable for nonprofits that wish to overcome said barriers preventing participation.

Characteristics of nonprofit organizations. The first step in explaining the importance and value for nonprofit organizations is to define their role in a community and their contribution to society. The purpose of a nonprofit organization is directly tied to the mission and service it provides to the constituency. Anheier (2005) describes the nonprofit sector as the "third sector" of organizational business. The first sector comes from government and the subsidiary agencies, while the second sector comes from business and the world commerce organizations. The third sector which Anheier (2005) describes was predominantly created for the purposes of education and research. The space in which the nonprofit organization operates is defined by the contributions it makes to the members of the community.

Anheier (2005) describes five conceptual characteristics of a nonprofit organization: (1) organized as an institution to one extent or another, (2) private, meaning separate from the government, (3) self-governing as to control their own activities, (4) non-profit-distributing, 
meaning they do not make a profit for the owners or directors, and (5) voluntary which constitutes some level of meaningful volunteer activity. The specifics of these five concepts could vary from organization to organization, but the overarching themes can be found in almost every entity. Several authors have utilized the work conducted by Anheier (2005) as the foundation for their concepts and theories in non-governmental organizations, influences of professionalism in nonprofits, and volunteer management practices (Cuskelly et al., 2006; Hwang \& Powell, 2009; Lewis, 2001). The characteristics of the nonprofit organization described by Anheier (2005) provide a framework to describe these entities that is supported in the literature.

The first concept held by Anheier (2005) is the characteristic of being organized as an institution. The concept of being organized as an institution shows that there is some type of clear thread or purpose of the organization. The typical instrument of this is the mission statement. Lewis (2001) explains that the policies and common goals of the organization are the foundation of the institutional variables. While Lewis's (2001) work focuses on the management of the organization, the other areas of the literature support this concept. Young (2001a) explained that a clear identity is essential in solving issues for the organization. The identity of the organization is provided within the mission statement. Young (2001b) also comes into agreement with Lewis (2001) in explaining that organizational effectiveness and management improve when there is clear identity. The mission of the nonprofit must contribute to the entity's autonomy and thereby fulfill Anheier's (2005) second characteristic of the framework, independence.

Both Anheier (2005) and Lewis (2001) explain the private nature of a nonprofit and therefore categorize the organizations into the third sector. The fact that a nonprofit is not tied to 
a governmental agency or seeking to make a profit for shareholders does not absolve it from organization or fiscal responsibility. The example of a national Olympic sport organization researched by Shilbury and Moore (2006) explains an organization that is not tied to either a government-run agency or a profit-centric group. The study explains that this type of nonprofit needs to be especially effective in planning and being productive (Shilbury \& Moore, 2006). The self-sufficient nature of organizations focuses on two specific variables, effective planning and productivity of the organization. The lack of endless government subsidies or large profits to reinvest back into to the structure make it necessary for an organization like the ones studied by Shilbury and Moore (2006) to be especially efficacious. The characteristics described are found to be common in many third-sector organizations (Anheier, 2005; Lewis, 2001). The governance of the nonprofit requires some type of independent leadership.

Nonprofit organizations' ability to self-govern and police their own activities is one of the hallmark characteristics of these organizations. The structure of a board of directors or a board-run organization sets the framework of a self-governing organization and complies with Anheier's (2005) third characteristic within the framework. Billis and Harris (1992) collected data from a decade of activities from local nonprofit agencies. The bureaucracy formed by these organizations provides a hierarchy that helps to run the nonprofit (Billis \& Harris, 1992). The organizational structure of the nonprofit is such that the board provides the direction for the services provided while following the mission. Members of the organization then carry out the services provided by that group. The cycle is then complete, by the board members volunteering themselves.

Boards are more effective when the members have a higher social prestige (Herman \& Renz, 1998). Board members often have a responsibility to use that social status and prestige to 
recruit and entice others to become involved in the organization and meet the needs of a specific volunteer category (Cnaan et al., 1996; Herman \& Renz, 1998). The executive types of functioning that are demonstrated by board members are often associated with their abilities as recruiters and their social status in the community (Herman \& Renz, 1998; Wilson \& Musick, 1998).

The fourth area as described by Anheier (2005) is to provide financial direction for the nonprofit. In many cases the effectiveness of the board/leadership and the members is measured by the financial security provided to the organization. Even though a nonprofit board is not measured as effective by the dividends earned as in the private sector, there is still a fiduciary responsibility for the members. McDonald (2007) explains that nonprofit organizations are expected to be as financially sustainable as their private counterparts. He goes on to explain that organizations who have a clear mission tend to be more innovative in their financial endeavors (McDonald, 2007). One of methods in which organizations increase their innovation is by utilizing their volunteer capital. The appearance of this volunteer effort may not always show in an organization's bottom line; however, a board of directors is responsible for this aspect of the organizational success as well (Mook et al., 2007). Mook et al. (2007) explained that the volunteer service provided contributes to the overall financial health of the nonprofit.

Volunteer activities and reasons for volunteering are mixed throughout the nonprofit literature and comprise the fifth and final characteristic of Anheier's (2005) framework. The role of a volunteer is a combination of their skills and the role they see themselves participating in the organization. Penner (2002) explained that the individual's dispositional values and traits combined with their role identity within the organization will help to produce a sustained volunteer. He also made the point that a volunteer's initial experience with an organization will 
also contribute to the overall experience and sustained service (Penner, 2002). The cycle of a nonprofit is constructed by the interaction individuals have as they recognize or engage in the service the organization provides, participate as volunteers, and refine the policies of the entity itself. The two driving factors that lead these nonprofits are the mission of the organization and the boards who lead them.

Mission and boards. The education, research, and/or services conducted by the nonprofit are driven by the direction of the organization. The mission of the organization and the board governing it are responsible for the execution of the nonprofit services (Balser \& McClusky, 2005; Lewis, 2001; McDonald, 2007). These drivers and the service that the organization provides will define the purpose and role in society. The mission of a nonprofit is the conceptual foundation by which the organization derives the purpose (Anheier, 2005; Lewis, 2001). The board governing the organization is constructed of volunteers who are dedicated to implementing the mission through the services provided (Anheier, 2005; Lewis, 2001). The more direct link in defining a nonprofit's importance and reason for existence is then tethered to the mission.

The mission of the nonprofit becomes the foundational piece that must be initially researched to explain and define the organization's importance and reasons for existence. The clarity of a well-constructed mission can improve an organization's identity, strategy, innovation, and structural choices for the nonprofit (McDonald, 2007; Young, 2001a; Young, 2001b). A clear mission then allows a volunteer board to implement the organizational functions to provide services. Lewis (2001) explained the link of a clear mission to a well-run board structure has far reaching benefits and effectiveness of the board's actions. Anheier (2005) confirms that the mission of an organization influences the goals and objectives of the organization and thereby 
the actions executed by the volunteers. An organization's mission clarity can have a direct influence on the outcomes of the group.

The identity of an organization is encapsulated in the service of the volunteers and the programs it supports within the community. A mission guides the sense of identity of the organization by providing a direction for service (Anheier, 2005). The research has also shown that there is an increase in the opportunity for dilemmas within the nonprofit if the identity of the organization is not clear and defined as described by Young (2001a). The programs and services created by an organization are conducted and executed by volunteers. Should the mission identity become unclear or lack focus there could be a negative impact on volunteer participation and effectiveness (Lewis, 2001; Young, 2001a). The structural choices and strategies a nonprofit select to implement are also impacted by the clarity a mission provides.

A nonprofit organization makes decisions concerning board members, services to provide, and any type of monetary appropriations (Anheier, 2005). The structure of an organization along with the strategies implemented in operations, is directly related to an organizational identity that is clear (Young, 2001a; Young, 2001b). The mission provides that identity and roadmap for the group and the strategies to implement the mission are then executed. Politics, goal alignment, and internal identities are all structural dilemmas that may change or deviate an organization from the intended purpose therefore an internal examination of organizational identity becomes important in order to stay true to the mission (Lewis, 2001; Young, 2001a; Young, 2001b.). The structural decisions and strategies created by the organization may also be tied to the innovation and creativity of the nonprofit.

Creativity and innovation allow for a group or organization to implement their services in a manner that can be exciting and contagious. An organization with a clear mission has more of 
an opportunity to be innovative according to McDonald (2007). He explains that nonprofit organizations are pressured more and more to behave and conduct themselves in a businesslike manner (MacDonald, 2007). The issue in contorting to this model is a potential deviation from the mission and potentially from the third sector Anheier (2005) spoke of. The more clarity in a mission, the more innovative the organization can become with the strategies and structural decisions made by the leaders (McDonald, 2005; Young, 2001a). The mission-driven nonprofit entity that can implement innovative methods for providing service has the potential for a greater amount of volunteer activity. One of the major potential roles of this activity is providing leadership by becoming a board member or executive volunteer.

The value a nonprofit provides is driven by the implementation of the mission and the direction of the board of directors. The scenario becomes a difficult conundrum, as both a clear mission for identity and effective board are necessary for organizational success. Organizational success helps to attract an effective board member that in turn assists in successful management of the nonprofit (Herman \& Renz, 1998; Herman \& Renz, 2008; Penner, 2002). Individuals viewed as successful with a high social standing as those described by Cnnan et al. (1996) may also contribute to those responsibilities typically charged to board members. The cycle of attracting and recruiting effective board members and executive volunteers distills down to the experiences and awareness the potential volunteers have with the organization and the organization's ability to attract executive volunteers that specialize in recruitment.

The volunteers for these roles may be recruited for the organization as explained by Anheier (2005) or have a connection to the organizational goals and services the nonprofit provides as defined by Lewis (2001). The likelihood of an individual volunteering their time for a philanthropic endeavor can be linked to their confidence in the organization. Herman and Renz 
(1998) showed that stakeholders found nonprofits to be more effective when they had more effective boards. The efficacy of the board often comes from the visibility of the organizational actions. In the same article by Herman and Renz (1998) they explained that stakeholders often viewed their boards as more effective when the board members held a higher social status. The effectiveness of a board can also assists in managing and guiding the professional staff of a nonprofit.

The article by Herman and Renz (1998) also explains that effective boards utilize practitioner-identified correct management procedures. The board itself and organizational leaders may consist of former practitioners who help to pass along their experiences to the professional staff that organize and execute the mission of the organization. An alternative possibility is that the board utilizes the suggestions and experiences of the professional staff coupled with the intention of the mission to direct their decisions for the policies directing the organization. Each of these scenarios describes a board that is nimble in terms of the ability to make decisions. Shilbury and Moore (2006) found in their study that a national sport organization's ability to be flexible in their resources, planning, and productivity allowed for a more effective organization. The availability of information to a board and the stability of board members also provide for a more effective organization (Shilbury \& Moore, 2006). The stakeholders of these organizations are comprised of several individuals, including those who volunteer.

\section{Value of Volunteers within Nonprofit Organizations}

The value of a volunteer to a nonprofit organization is nearly immeasurable. The service an individual may provide can come in various forms and degrees of commitment. The section to follow explains the types of volunteering needed for an organization and the types of 
individuals who may fulfill those roles. Formal and informal volunteers arise as the two predominant volunteer pathways in which volunteer activities are segmented. The impact and advantages that a formal and an informal volunteer offer to an organization are specific to the volunteer's role and type along with the type of event or activity being held by the organization.

Types of volunteering. A key to defining volunteers and their responsibilities within a nonprofit organization is to explain their status. The nature of a professional, or someone who is paid for their work, demonstrates an implicit motivator in the payment. The paid professional may have additional motivating factors to their involvement in the activity beyond monetary gain, such as prestige, power, or control (Nistler, Lamm, \& Stedman, 2011). In contrast, an unpaid volunteer possesses myriad reasons for the initial and continued service to the organization outside the contextual prospects of payment being rendered for the service. The collection of activities these individuals perform is known in the literature as "volunteering" (Stebbins, 2009; Wilson, 2012). Conversely, the lack of participation in volunteer activity would put an individual in the nonvolunteer category (Boezeman \& Ellemers, 2008). The next step in defining volunteer activities and duties is to explain the types of roles a volunteer may fulfill within the organization.

The levels of volunteering in this manner could be varied in terms of formal, semiformal, or informal depending upon the amount of oversight provided by the organization. Formal volunteering takes place in an organization when a given structure and operation exists (Stebbins, 2009). Formal volunteering opportunities may or may not require some type of active education or training process followed by an oversight constructed by the organization. Conversely, the lack of supervisory structure or organization is the most informal level of 
volunteering (Stebbins, 2009). The general categories explained by Stebbins (2009) coincide with those of the sport volunteers studied by Cuskelly et al. (2006).

There are two volunteer types according to Bouchet and Lehe (2010). "A spot volunteer is a person who will volunteer very rarely and usually only when asked" (Bouchet \& Lehe, 2010, p. 23). An example of this might be a timer at a swim meet or a line official at a recreational soccer game or volleyball match. "The formal volunteer is a person who has a personal commitment to the organization and gains a sense of work accomplishment and gratification from doing their work" (Bouchet \& Lehe, 2010, p. 23). The examples provided by Bouchet and Lehe (2010) find agreement with the sport literature provided by Cuskelly et al. (2006) and the volunteer literature from Stebbins (2009). Given the type of event the organization is sponsoring, one or both types of volunteers may be required or preferred depending on need for the event or organization. Both types of volunteers are highly sought after, as spot volunteers are quick to participate, and formal are valued for commitment to the organization and/or cause (Bouchet \& Lehe, 2010).

Wilson and Musick (1997) developed a widely accepted theory that volunteer work is based upon, first, productive work that requires human capital, second, collective behavior that requires social capital, and third, ethically guided work that requires cultural capital. The combination of these three areas dictates the type of volunteers and volunteerism required to provide the service of the nonprofit agency. The statistical trends discovered by Wilson and Musick (1997) may indicate who is volunteering but lack the why factor. The why factors lend themselves to the motivation of certain volunteer types rather than the mere categorization of volunteer variables. Balser and McClusky (2005) went on to explain that organizations that discussed their actions in terms of mission and value, that built relationships with the 
constituency, and that demonstrated solid external relationships were viewed as more effective by the stakeholders. The relationship of the volunteer to the organization then helps to determine the impact of the volunteer.

The impact of formal volunteers. Mook et al. (2007) explained that the benefit of formal volunteers to the overall health of an organization lies in the ability to contribute to the organization's bottom line. In this manner, formal volunteers can have a significant impact on a nonprofit organization. The work by Cuskelly et al. (2006) complements that of Mook et al. (2007). Cuskelly et al. (2006) explained that the contribution made by volunteers to an organization has the potential to increase the organizational value and worth. The ability of a volunteer to participate at both an institutional level and at an event sponsored by the organization can have a lasting impact. Cuskelly et al. (2006) described the institutional-level volunteer as a formal volunteer.

Formal volunteers are often those who make up the boards and governing bodies of the sport organizations and have a lasting interest in the nonprofit (Cuskelly et al., 2006). The organizational characteristics of these nonprofit boards described by Anheier (2005) coupled with the fiduciary responsibility of Mook et al. (2007) build into the work by Wicker, Feiler, and Breuer (2013). The formal volunteers comprising the boards running the organization execute the mission of the nonprofit and an important responsibility of a board is the fiscal planning. Wicker et al. (2013) studied German sport nonprofits and found that the diversification in funding strategies was largely determined by the mission of the organization. The intention and execution of that mission are demonstrated in the impact of the organization. The formal volunteers in the work completed by Wicker et al. (2013) complement the executive volunteer characteristics (Brown \& Ferris, 2007; Paik \& Navarre-Jackson, 2011; Wilson \& Musick, 1998). 
The impact of informal volunteers. Formal volunteers are more connected to an organization over a more consistent period compared to their informal volunteer counterparts who may be involved only for a single event or activity. The volume of informal volunteers at a single event can impact the organization tremendously. A key to understanding participation is to understand what influences a participant in an event. The four components of achievement, involvement, status, and socialization found by Taylor and Shanka (2008) were very similar to those factors of purposive, leisure, external influences, material, and egotistic found by Strigas and Jackson (2003) as to characteristics of volunteer motivation. Each of the studies centered around large sport events and gathered data from the informal volunteers. Strigas and Jackson (2003) found that egotistic motivations were the greatest in their study. The concept of doing an activity for oneself is like that of executing the mission for a formal board.

The informal sport event volunteer findings from Strigas and Jackson (2003) and Taylor and Shanka (2008) are consistent with those of other authors who sought a more generalized population. Bang, Ross, and Reio (2012) surveyed over 200 individuals on their interaction with nonprofit volunteering. The group found that volunteer role satisfaction, personal value alignment, and personal volunteer experience all created a greater commitment level for these volunteers (Bang et al., 2012). The personal connection and perspective of the volunteer experience coincide with the findings of the previous studies (Strigas \& Jackson, 2003; Taylor \& Shanka, 2008). In addition to the personal interest of the individual, it also becomes necessary that the individual possess the proper resources to participate in a sport-related activity.

Interest in a sporting event alone may not be enough to garner a volunteer effort from a population. Dawson and Downward (2013) discuss the importance of time as a personal resource for volunteers to participate in events. The willingness to participate and benefit is a 
portion of the equation, but the individual must also have the time to contribute as well.

Community resources also become a necessity for events to take place. Wicker, Breuer, and Pawlowski (2009) explain that the infrastructure a community maintains can also significantly contribute to a sporting nonprofit event. As an example, a community-swimming league must have at least the aquatic facility in order to host an event. The combination of the individual's interest and time and the community's infrastructure can significantly impact the ability of a nonprofit sport organization to achieve its mission (Bang et al., 2012; Dawson \& Downward, 2013; Wicker et al., 2009).

Wicker and Hallmann (2013) discuss the multiple levels of interests, characteristics, and resources that sport organizations need in order to achieve success. The need for formal volunteers to guide the institution and see the mission of the organization through is important from a guidance and organizational perspective. The institutional direction is complemented by the informal volunteer participation in events as they occur. The interplay between the two groups then distills into the institution's ability to meet the personal needs of the informal volunteer while conducting the event in a community that houses the necessary resources.

The link between the formal volunteers who guide the organization and the spot volunteers who may become mobilized for an event calls for an individual who has a high social profile and has the ability to recruit others for events (Cuskelly et al., 2006; Strigas \& Jackson, 2003; Taylor \& Shanka, 2008). The type of volunteer needed would be a hybrid. The volunteer would be one who could connect with spot volunteers and perhaps participate in the nonprofit event. The final characteristic of this volunteer would be that they have an invested long-term interest in the organization. This role may be filled by a type described by Cnaan et al. (1996) and Nicholson and Hoye (2008). The executive volunteer is a type that could utilize their social 
capital and influence on others (Cnaan et al., 1996; Nicholson \& Hoye, 2008). These

characteristics coupled with the ability to recruit provide a hybrid volunteer to connect the informal spot volunteers to the formal volunteers (Wilson \& Musick, 1998).

\section{The Executive Volunteer Category and their Role}

The variations of volunteer types and their connection to certain projects is well studied and well categorized. Cnaan et al. (1996) reviewed several definitions of volunteers and identified the key dimensions in the literature: 1) the voluntary nature of the activity, 2) the type of reward the individual receives, 3 ) the context of the activity, and 4) who benefits from the service provided. In order to categorize and organize the types of volunteers and link them to volunteer activities, Cnaan et al. (1996) expanded the four criteria into a continuum with shared common denominators and variables. The study then drew upon the perceptions of individuals as to how they viewed volunteers. Twenty-one volunteer examples were presented to 514 participants who rated the examples and likelihood of volunteering (Cnaan et al., 1996). One of the categories presented in the study was the Chief Executive Officer (CEO).

A convenience sample was used from six sites including libraries, volunteer training workshops, manufacturing sites, and universities to complete the Likert scale of the 21 volunteer descriptions and scenarios (Cnaan et al., 1996). The examples given to the participants contained elements of the dimensions in the literature presented earlier paired with a volunteer type such as baby, child, teenager, parent, college student, doctor, or hourly worker (Cnaan et al., 1996). Each of these types was paired with a scenario to contextualize their scenario. In the examples of the CEO or executive, they were the heads of organizations like the United Way or a computer company and in some cases had assistants that reported to them. The overall feeling 
reported from the participant questionnaires was that the executives would not do the work themselves but rather delegate to someone else or not participate at all (Cnaan et al., 1996).

The researchers used additional clarifying indicators to describe the individuals, but the examples of executive were always associated with some type of higher responsibility or influence. The distinction among the volunteer types expanded past that of just male and female or age and extended into that of the social capital and intuitive responsibility of the position. The underlying influence and scope of a higher social capital suggest that the executive category is more specific than that of volunteer. In the other examples, the individuals' qualifying statements were more related to the person themselves rather than their profession. The example of an older sister or a parent of an individual who is involved with the organization was used to describe one of the items (Cnaan et al., 1996). In the case of the hourly worker, the qualifier implied that the worker had a position, but it was not important enough to mention where or what kind of position (Cnaan et al., 1996). Additionally, the CEO example in the research was rated as one of the least likely to volunteer by the subjects (Cnaan et al., 1996) even though there is a need for this category.

Social capital and networks. Nicholson and Hoye (2008) examined the factors of influence that accompanied social capital and how social capital translated into monetary benefits and volunteer services in sport. The implication of social capital for executives stated by Cnaan et al. (1996) couples with the definitions put forth in the book by Nicholson and Hoye (2008). There are several definitions and theories surrounding social capital. In addition to the multiple definitions, there are several implications and benefits associated with levels of social capital. Nicholson and Hoye (2008) concluded from their survey of the literature that social capital is the resources that are available to and accessed by an individual or community through 
social networks. The authors expand the definition of resource to be not only a financial mechanism but to also include trust, sympathy, and reciprocity (Nicholson and Hoye, 2008). The introduction of the variable of social capital delineates some volunteers and communities as there are stratifications of social capital depending upon the individual and their placement in society.

The strata associated with social capital allow those in a more executive role in their community to assist and participate in a uniquely influential manner. Wilson and Musick (1998) examined the variables of human capital, social class, and social capital in combination to increase volunteerism. The study showed a correlational relationship between the social capital and the capital of the individual (Wilson \& Musick, 1998). The importance of this discovery is the influence an individual may have on an organization is proportional to their social and individual capital. Therefore, an executive volunteer who has a high amount of individual resources can augment those resources due to that individual's social resources. Wilson and Musick went on to explain that an individual's human capital may be augmented with their high social status (1998). The executive volunteer may use their social capital to advance their volunteer efforts for an organization.

The social capital defined by Nicholson and Hoye (2008) and the impact explained by Wilson and Musick (1998) help to build the executive volunteer category. Two of the major factors within that social capital influence explained by Wilson and Musick (1998) are the individual's associational networks and their trust in others and in the community (Brown \& Ferris, 2007). The authors used the Social Capital Community Benchmark Survey (SCCBS) and determined that the factors of social capital and network-based social capital influence both religious and secular giving among volunteers and participants (Brown \& Ferris, 2007). The 
authors further concluded that associational relationships are key for giving regardless of the type of organization (Brown \& Ferris, 2007). The link among the studies begins to show that executive volunteers who possess a high social status have the potential to give more due to those associational relationships that are forged due to their status in the community.

Responsibility of executive volunteers. The executive volunteer can be a useful pillar in maintaining a nonprofit organization's sustainability. The same holds true for a coach who may act as an executive volunteer. Vail (2007) explained that there are three key elements in her model to maintain a community tennis program. She explained that each organization needs a champion of the community, to develop collaborative partnerships, and to deliver quality sport programming (Vail, 2007). The executive coach volunteer is appropriately suited to these needs as they have a vested interest in the sport in which they participate. The combination of their social status and their involvement in the overall sport-specific community fulfills the first requirement, and the ability to develop collaborative partnerships can be mediated by networking and their associational habits. Ideally, the executive volunteer could also contribute to the delivery of quality sport as well. One of the major factors that Vail (2007) cited of the community champion was the ability to recruit individuals to the organization. This call to action fits in well with the characteristics of the executive volunteer.

The recruitment and retention of executive volunteers already has examples in the sport community. Wicker and Frick (2016) examined the recruitment and retention habits of soccer referees in Germany. The specific variable was the trickle-down effect of role models on retention of active referees and recruitment of new referees (Wicker \& Frick, 2016). While the referees were not coaching, the cultural aspect of sport provides a backdrop for these volunteer activities. The links between the study and the executive volunteer were the characteristics of 
the role model: outstanding performance, worthiness of imitation, and similarity (Wicker \& Frick, 2016). The recognition associated with performance in sport often accompanies social stratification. If a coach or executive volunteer is worthy of imitation, it may enhance their ability to recruit others to participate in volunteer efforts. The last category of similarity described by Wicker and Frick (2016) explains the community connection that a group feels toward the coach or executive volunteer. Those connections provide the trickle-down effect that enhances both retention and recruitment of others.

In the 2015 study by Posner, he investigated the characteristics of an effective leader by surveying 569 leaders across national youth sport organizations. The study states that there are differences between leaders who serve in a volunteer role and those who are paid to lead (Posner, 2015). Leadership behaviors were found more frequently in those who volunteered as opposed to those who were paid (Posner, 2015). The altruistic nature of volunteering for an organization to assist in the organization's growth and development rather than being paid for this service provides an opportunity for leaders to distinguish themselves. The leadership behaviors discovered by Posner (2015) coupled with the literature on the characteristics of executive volunteers creates a dynamic of responsibility, need, and impact from these individuals.

\section{The Need for and Impact of Volunteers who Hold Executive Professional Positions}

The executive volunteer may fulfill specific duties and tasks necessary for the nonprofit organization. The social capital, leadership, and relationships that constitute their makeup help to make them a desirable volunteer category (Brown \& Ferris, 2007; Nicholson \& Hoye, 2008; Vail, 2007). The next stage in examining this group is to look at their impact on an organization and their need as a population. The impact comes from their social exposure and visibility along with their relationships to others. The need comes from those very same abilities, connections, 
and how inviting and recruiting others can position the executive volunteer as a catalyst for building a volunteer workforce.

Executive volunteer impact. The impact of the executive volunteer for a nonprofit organization can best be explained by their ability to recruit others and raise the volunteer exposure due to their high social status. Bussell and Forbes (2002) explain that volunteer and more pointedly, specific volunteer groups are important to an organization's success. The recruitment and retention of additional volunteers are both critical to the long-term success of the organization (Bussell \& Forbes, 2002). The traits of the executive volunteer fulfill this needed role of volunteer organizations.

Winand et al. (2011) explained two key areas that executive volunteers may benefit or impact sport governing bodies. The first category explained that large governing bodies may utilize the individual's knowledge or expertise to deliver a higher-level program (Winand et al., 2011). In the first category, the volunteer may have the ability to provide additional innovative programs for the membership. The second involves innovative and important activities being provided when the group may be small or unable to meet the necessary resources (Winand et al., 2011). The executive coach can then make an impact by fulfilling these needs and assisting to provide quality programming or events by volunteering for the membership (Vail, 2007; Winand et al., 2011). The executive volunteer may find that they impact the have on one organization may benefit other organizations as well.

Executives who participate in volunteering do so often in a similar capacity as their own (Weil \& Kimball, 2010). The healthcare executives in the study volunteered for other organizations at the rate of more than 90 percent and did so in a similar fashion to that of their organization, on committees and boards for example (Weil \& Kimball, 2010). The executive 
volunteer has demonstrated the tendency to make themselves available to volunteer at a level they may be effective. In the same study Weil and Kimball (2010) explained that higher executives were more likely to volunteer for activities that involved their skill set as in fund raising, policy setting, and professional standards. The executive volunteer showed a propensity to volunteer for activities that enhance the individual's recognition, for high-level positions, and to gain rewards (Weil \& Kimball, 2010). The recruitment of high-level and high-achieving executive volunteers can impact an organization in a specific manner needed for the organization (Bussell \& Forbes, 2002; Winand et al., 2011). The available volunteers are likely to volunteer for these positions as is their habit (Weil \& Kimball, 2010; Winand et al., 2011).

Volunteers who exhibit executive skills in their field may have an opportunity for additional involvement. In the study by Gibleman and Sweifach (2008) social workers were studied. The field of social work often coordinates with nonprofit organizations and volunteer efforts. The social workers surveyed indicated that they felt that volunteering was important and that they had done so most of their adult lives (Gibleman \& Sweifach, 2008). Respondents in the study by Gibleman and Sweifach (2008) indicated that they did so in organization and activities that utilized their expertise and talents. Even in professions that associate with and have a need for volunteers, it can be possible that those professionals do not always continue to volunteer on their own. The social workers in the study indicated that they no longer volunteer for a variety of complex reasons including previously volunteering, work-life balance, and the culture of the time (Gibleman \& Sweifach, 2008). The findings indicate that even though volunteering may be important for the executive volunteer's profession, they themselves may no longer volunteer, thereby creating a need. 
Executive volunteer need. Nonprofits have a need for every type of volunteer including that of the executive category. Freeman (1997) studied the size and scope of volunteering and found that volunteers account for a sizeable amount of financial activity for organizations and that volunteers contribute significant skills and time but do so most often when asked or invited by the organization. The invitation of the nonprofit organization to seek out the specific type of required volunteers helps to meet the needs of the organization. The executive volunteer can fulfill this need specifically and help to move the organization forward with their efforts. Freeman (1997) suggests that volunteering is associated as a moral activity and something that individuals will participate in when asked but may stand aside to let someone else do if not approached. It then becomes imperative that the organization understands the type of volunteer they can best utilize and to develop a relationship with those individuals. The executive volunteer could recruit and attract others in the community to become involved, thereby fulfilling this need (Brown \& Ferris, 2007).

To determine an executive volunteer's involvement in an organization, the commitment, engagement, and psychological well-being can be examined. Vecina, Chacón, Marzana, and Marta (2013) examined these variables in 232 volunteers surveyed by 18 different nonprofits. The researchers found that the relationship between engagement and intention to remain within the organization is mediated by commitment to the organization (Vecina et al., 2013). The volunteer dynamic shows the need of the volunteer to be connected and committed to the mission of the organization. Vencina and her colleagues (2013) also found that the relationship between commitment and psychological well-being is mediated by engagement. The findings by Vecina et al. (2013) correlate with those of Wilson and Musick (1998) in the individual's relationships and their community ties (Brown \& Ferris, 2007). The importance of the executive 
volunteer is to recruit others who can contribute at the level necessary for the task (Wicker \& Frick, 2016).

Volunteers and their organizations often fit as a lock and key. The example is to illustrate that volunteers each possess a unique set of talents that may benefit an organization specifically. Valeau, Migonac, Vandenberghe, and Gatignon Turnau (2013) found that the turnover rate for volunteers was related to the affective and normative commitment to the beneficiaries of the organization. The volunteer's affective and normative commitment to the individuals they were assisting led to higher organizational commitment rather than a higher affective commitment to the organization itself (Valeau et al., 2013). The contribution found by Valeau (2013) and his partners connects with the executive volunteer literature in the sense that their specific skill sets may benefit the stakeholders for which they were intended. The area of need is exposed due to organizations' attempts to build relationships with the volunteers rather than connect them to the beneficiaries (Brown \& Ferris, 2007; Valeau et al., 2013).

Carman et al. (2010) found in their study that communities may have a possible crisis in executive leadership in nonprofit organizations. The apathy that is felt to take over leadership positions often cause young professionals to not step into open roles and positions (Carman et al., 2010). The breakdown in the leadership of executives in volunteer organizations risks the relationships that the organization may have with executive volunteers and their commitment to the organization (Carman et al., 2010; Vail, 2007; Valeau et al., 2013). The gap in executive leadership of the organization as cited by Carman et al. (2010) then increases the need of executive volunteers to remain committed to the organization and its principles and mission.

Sport organizations effort to produce both small and large-scale events require volunteer efforts of all types including that of the executive volunteer. Downward and Ralston (2006) 
explored the relationships of volunteers that participated in sport and those who were non-sport volunteers for the XVII Commonwealth Games in Manchester, England. The first discovery was that volunteering for a major sporting event can increase interest, participation, and volunteering for sport (Downward \& Ralston, 2006). The importance of this is the snowball effect that has the potential to take place when an influential executive volunteer participates, and their relationships and social capital attract additional volunteers. Downward and Ralston (2006) also found that personal development was increased by participation in a major sporting event volunteer opportunity that directly affected the ability to recruit additional volunteers. The natural phenomena that Downward and Ralston (2006) uncovered may be enhanced by the executive volunteer. The need of this type of volunteer then becomes more targeted when the area of emphasis is sport and recreation.

Collegiate swimming coaches as executive level volunteers. Collegiate swimming coaches' involvement in nonprofits that benefit the sport of swimming is an example of an executive volunteer whose social status and social impact are enhanced by their social and associational ties. They in turn can use this influence to garner involvement from other individuals. Researchers Paik and Navarre-Jackson (2011) extended the research that confirmed social ties, diversity, the number of social ties, and religious involvement all enhance a volunteer's involvement. The researchers went a step further to explain that these factors also enhance recruitment of additional volunteers (Paik \& Navarre-Jackson, 2011). The combination of the social capital and the recruitment enhance the likelihood of volunteering and gathering others to volunteer. The study showed three prominent contributions, 1) networks for volunteering are conditional upon recruitment, 2) bridging personal networks is important, and 3) social capital effects depend upon recruitment (Paik \& Navarre-Jackson, 2011). 
A sport-specific example of volunteer need comes from the literature for the sport of swimming. Burgham and Downward (2005) studied the needs and policies of volunteers for swimming clubs in the United Kingdom. The authors asked the simple question as to whether to volunteer or not as well as what policies may be created or introduced to facilitate the volunteering of individuals (Burham \& Downward, 2005). The types of volunteers that were sought out were categorized and defined. The terms of formal and informal volunteers were consistent with those of Stebbins (2009) and Cuskelly et al. (2006) stated earlier. Burgham and Downward (2005) concluded that there is in fact a need for volunteers for a variety of activities in the sport of swimming and that need included spot volunteers and those with characteristics matching those of the executive volunteers. The instinctive desire to simply collect more volunteers was not seen as a valid response to this need because the simple increase of volunteers is not likely to reap the executive volunteer needed to recruit, socially impact, and give expertise to the sport (Burgham \& Downward, 2005). The skills and specific traits possessed by the executive volunteer create a need for these individuals. The decrease in volunteer activity, and more specifically executive volunteers in the sporting arena creates a gap for nonprofit sport organizations (Burgham \& Downward, 2005; Downward \& Ralson, 2006). The next logical progression in solving this need is to examine the motivations and barriers related to volunteerism of the individual.

The category expert coach (Cote et al., 1995; Cote \& Gilbert, 2009) is distinctly different from the traits of the executive level volunteer. The expert coach reaches a level of effectiveness in their knowledge, athlete outcomes, and coaching context (Cote \& Gilbert, 2009). The executive level volunteer draws their effectiveness from social ties, ability to recruit others, and social capital (Burgham \& Downward, 2005; Paik \& Navarre-Jackson, 2011). The collegiate 
coach because of their public visibility meet the criteria executive level volunteer. The public persona and perception of the coach's position at a large university system contribute to this social impact.

\section{Motivators and Barriers for Volunteering}

Handy et al. (2000) extended the work completed by Cnaan et al. (1996) by taking perceptions of the executive category and extending out to six different regions and cultures. The work done in this study by Handy et al. (2000) compared the executive volunteer to a doctor, student, and teacher like the earlier study completed by Cnaan et al. (1996). The perceptions were that even though the volunteer efforts may be appreciated from the executive they were more appreciated and expected in those who may not be as affluent and have a greater attachment to the nonprofit organization (Handy et al., 2000). The perception of need was higher for the executive volunteer versus those who may be more motivated to participate when more intimately involved with the nonprofit (Handy et al., 2000).

The motivators and barriers are the ultimate variables separating an individual from a non-volunteer to becoming a volunteer. The category of the volunteer invariably comes down to forces that move the individual. The motivators of being asked or recruited, connection to a community, being educated and prepared for the task, and fitting into the schedule all facilitate and motivate individuals to volunteer (Dorsch, Riemer, Sluth, Paskevich, \& Chelladurai, 2002). These variables are opposing the barriers hypothesized in the framework by Sundeen et al. (2007) of volunteer resources. The framework explains that individuals possess resources in a variety of areas, each with the potential to block or cause an individual not to participate in each activity. The sum of the collection of the motivators and barriers then create a social equation by which the individual selects to participate or not in volunteerism. 
Motivation for volunteerism. The motivators and facilitators that are perceived to be important by a nonprofit organization often guide the recruitment process of necessary volunteers for an activity or sustained service. After determining the needs of the organization; the type of volunteer, spot or formal, and the type of volunteering activity; formal, semi-formal, or non-formal; the recruitment process begins to build the volunteer network to support the organization's needs. Effectively identifying which motivator moves the participant to volunteer and then accentuating those motivators is a function of the organization analyzing their population and services (Clary et al., 1998). The decision then becomes the volunteers to determine if they have enough resources to support the organization. The motivation to participate in the activity for the nonprofit moves the potential volunteer along the volunteer continuum from a non-volunteer to a volunteer.

The act of being asked or invited to participate may be the most basic of stages for the organization to motivate, engage, and recruit new volunteers. Volunteers tend to increase their volunteer activity after being asked by the organization (Wilson \& Musick, 2007). The volunteer may have the feeling that they are not wanted or needed by the organization and thereby lose interest in the activity. The act of asking or inviting an individual to participate allows the organization to formally declare and define needs. The volunteer then could self-assess their personal resources to determine if they are an appropriate fit or match for the tasks needed. By opening a dialogue of need for assistance to the organization, the volunteer may determine if their sets of skills are serviceable to the group. The typical reasons for accepting a volunteer role in a leadership capacity are the need for affiliation, the need for achievement, and the need for power (Nistler et al., 2011). The role or status that the participation in the organization may 
yield to the volunteer could possibly interest them for various reasons, including increasing their status in the community.

The connection the individual feels to their community possibly has a great impact on the amount of resources they are willing to contribute for volunteer services. The term community could mean their physical residence but also the sociological meaning as well, to encompass their shared experiences and viewpoints. The need for individuals to contribute to the overall benefit of the community at large can be very motivating to a prospective volunteer. The connection the potential volunteer has to a community can have a profound impact on their ability to overcome various barriers, especially if a community member feels that the organization and the service to the organization are important to continued prosperity of that community (Boezeman \& Elllemers, 2008; Borgonovi, 2008).

Additionally, the commitment to the organization and the causes of the organization can be closely tied to the focus of the volunteer. The volunteer does not always have to be connected closely to the organizational goals and mission, but instead, the volunteer may be tied to the beneficiaries of the nonprofit. In a case like this, the volunteer will remain in high contact with the organization to ensure that the beneficiaries of the nonprofit's work see the reward (Valeau et al, 2013). The connection one feels to the organization via their community ties can allow the volunteer to provide time within their schedule.

The motivation of the volunteer not only comes from the specific and general expectations of the organization but also the expectations from themselves. Lee, Piliavin, and Call (1999) explained the donation of volunteer time and money comes from a perceived expectation and the modeling of other volunteers for the organization. The internal moral obligations for donating time and/or money are high for those in a secular nonprofit compared to 
the religious affiliation felt by those in a religious organization (Lee et al., 1999). The results by Lee and partners were conclusive with that of Choi and DiNitto (2012) in that those giving their resources did so because of their abilities and what they can offer the organization. The result was different than that of the religious affiliation, where people volunteered due to obligation.

The requisite skills needed for the nonprofit can also determine the pool of potential volunteers it should pull from. The individual may self-select based upon the needs of the group, or it is possible that the person is willing to undergo training or some type of educational process in order to more effectively serve. The recruitment of a person may first come from the initial invitation and/or by aligning the mission and purpose to a community or residential area, but the confidence that accompanies a volunteer will come from a feeling of competence in completing the task. Organizations may have a difficult time finding an educated individual to create or conduct appropriate volunteer trainings (Boyd, 2003). It then becomes incumbent upon the organization to either find those who already have the necessary skills to perform the tasks or to educate a group via a training, school, or information session. The feeling of support that can come from this type of service from the organization back to the volunteers may also act as a facilitator for service opportunities.

The support that a volunteer or group of volunteers feels from an organization can not only contribute to the recruitment of new members but can also contribute to the retention of existing members as well. The feeling of support and respect (Boezeman \& Ellemers, 2008) can augment the service experience and thereby create a positive relationship. The more prepared and skilled the volunteer feels about their contribution, the stronger the bond to the organization. Poor organizational practices and volunteer management can often be more of a barrier than personal or family needs (Hager, 2014). The opportunity of the barriers to outweigh the 
facilitators is then opened. The support created by the organization may help to facilitate an identification or alignment of the volunteer to the organization itself. Individuals who closely identify with organizations are more likely to engage in volunteer activities or financially committing to the organization (Tidwell, 2005). One of the factors that can contribute to feelings of support may be to consider the schedule and availability of the service provider population.

The mechanics of the physical time of service or the delivery of the educational training to provide support to the volunteer population can facilitate the cooperation of a population. It becomes necessary for the nonprofit organization to strongly consider the schedule of the potential volunteers so that they may participate and cooperate with the desired activity. Additionally, the organization may require the potential volunteer to participate in a session which does not appropriately meet the needs of the volunteer's schedule (Wilson, 2012). The requirements, method of delivery, and time needed for the educational system may prove to be too costly for the individual's personal resources (Boyd, 2003). Should the organization not pay attention to the availability of time in a person's schedule it could prove to be costly to the cause.

The recent study by Hameiri (2018) connects the motivators of the lay volunteer in executive-level functioning positions to that of the motivators of the general population. The study breaks out two specific categories of the volunteer activity in that of executive-level volunteerism and servant-level volunteerism (Hameiri, 2018). It is explained that servant volunteers are those who provide stewardship to the entity whereas the executive leader operates on a more organizational level (Hameiri, 2018). One of the purposes of the study was to compare the motivators of these two distinct types of volunteers. Hameiri (2018) found that in Jewish communal organizations there was a match in motivations between both executive and servant types of volunteering, especially when the mission of the organization was clearly stated. 
The motivations in the study matched those of the Volunteer Function Index; however, barriers preventing such service were not researched (Clary et al, 1998).

Barriers of volunteerism. The motivation for volunteers has been researched in a variety of aspects and environments and has been found to be complex and multifaceted (Winniford et al., 1997). The antithesis is also true; several factors constitute the rationale for preventing volunteers from engaging in service for any given organization. The complexity of the volunteer barriers is often difficult to identify due to the absence of the volunteer's participation. Sundeen et al. (2007) identified five general categories in their study of perceived barriers for volunteers. A deficiency in the areas of personal resources, social ties, cultural resources, mixed resources, and residential context (Sundeen et al., 2007) may potentially prevent an individual from volunteering for an organization, thereby creating a non-volunteer rather than a volunteer. The gap in the literature is not only due to the lack of research in barriers to volunteerism but additionally the theoretical nature of the research that has been completed.

Hameiri (2018) connected the motivators of the executive category to those of the general volunteer literature but a gap exists for the executive barriers. Sundeen and colleagues' (2007) categories, while general in nature, certainly have a narrative that is relevant to executive coaching volunteers for nonprofit organizations. The categories themselves do not necessarily indicate a person's disinclination to volunteer, but rather the categories may capture the core of an individual's unwillingness to volunteer. The combination of all the variables within a given category may well give some indication as to whether a certain barrier may deter an executive coaching volunteer from becoming involved.

The personal resources an individual possess often mark their ability or willingness to move from a non-volunteer, to a pre-service volunteer, to an engaged volunteer. The factors of 
personal time dedicated to a non-work environment, the educational level of the individual, and the status of employment all show indications affecting a person's resources (Brown, Hoye, \& Nicholson, 2012; Smith, 2010; Strong \& Harder, 2010). The resource of education may have either a positive or negative effect on the volunteer practices of an executive coach. The person's formalized education has shown to be an indicator in an individual's willingness to volunteer (Brown et al., 2012; Forbes \& Zampelli, 2014; Strong \& Harder, 2010). If the potential volunteer lacks a more formalized or complete education, a potential barrier has been created for that individual.

The service aspects of a formal education setting may familiarize the individual with the practices and thereby open the possibility to their involvement. The more educated the individual, the stronger the correlation is that they will serve in a volunteer capacity (Brown et al., 2012; Smith, 2010); however, there is a point of diminishing returns when a decrease in volunteer efforts is seen in those with more advanced degrees (Forbes \& Zampelli, 2014). The increase in the volunteer's formalized education may also increase the demands brought upon them related to a more complex and time-consuming profession and thereby create a greater demand on other personal resources such as time.

The resource of time is often one of the more influential factors when considering the decision to dedicate service to an organization (Sundeen et al., 2007; Wilson, 2012). When volunteers gain either a social or cultural benefit from their service, one of the determining factors is the amount of time available to be spent on these additional activities (Wilson, 2012). The lifestyle and responsibilities in the executive coaching profession may also display a similar theme. The demands of practices, travel, after-hours meetings, and irregular work hours could 
contribute to a schedule that is not consistent enough for the individual to participate in an organization that would need consistent participation.

The personal resource of employment of the pre-service volunteer may indicate their inability to provide service, not due solely to the family income but rather to the schedule of the position itself (Brown et al., 2012; Smith, 2010). Those who are unemployed and those who have a job that has high or inconvenient time constraints tend not to volunteer. Those with incomes that are in the upper ranges are also less likely to volunteer than those who have a moderate income or one closer to the median family income (Forbes \& Zampelli, 2014). In this example the potential executive volunteer may be overemployed compared to their unemployed counterparts. The elements that are created from the personal resources of education, time, and level of employment then link directly to the lifestyle and personal decisions that are reflected and represented in the individual's social ties.

The social ties that bind one to the community may take on several forms, each with varying levels of importance. The variables of marital status, family obligations, and social obligations all may influence an individual's propensity to volunteer and maintain a volunteer lifestyle (Sundeen et al., 2007). In the first instance of marital status, it has been found that individuals who are married have a higher incidence of volunteering than their non-married counterparts (Brown et al., 2012; Smith, 2010). The family obligations are not solely restricted to married couples and individuals with children. Individuals may select to volunteer to enhance or strengthen their social ties (Clary \& Snyder, 1999). The volunteer must realize some type of perceived benefit that will come to themselves or their family due to their service (Borgonovi, 2008; Brown et al., 2012). The source of the barrier exists within the construct of family obligations, but the compounding factor often mentioned is the personal resource of time. The 
social connectedness that comes from being a greater part of the community is high for the executive volunteer and is one of the reasons they are so coveted. The conundrum of a limited number of social resources as an individual is paired with the executive's naturally high social connectedness.

The social category combines many of the roles and resources an individual fulfills with the duties and responsibilities outside their social area. The roles that an individual upholds as a community member and family member are difficult to isolate (Einolf \& Chambre, 2011). However, each link that an individual must another in their family or community has the potential to enhance their willingness to volunteer or provide some type of service. The social bridges that a person creates have the potential to enhance their ability to volunteer or provide a barrier to participation. The social networking and commitment are a fluid and varying bond that binds the individual to their surroundings (Einolf \& Chambre, 2011). The social ties for the executive volunteer then become a labyrinth of contextual facilitators and barriers for the individual's service possibilities.

The intensity or commitment to religion may also affect the amount of volunteerism the individual contributes to the community. Involvement in a spiritual or religious organization which has altruistic intentions has a natural tendency to align with service to others. Forbes and Zampelli (2014) found that the greater the religious participation and the more intense the religious affiliation, the more likely the individual is to volunteer and provide service. However, as in the case of education, there is a point of diminishing returns when it comes to religious affiliations. Becker and Dhingra (2001) explain that often individuals provide service related to religious affiliation for the social and community aspects of the task. Those who are participating in service as a part of their spiritual group may not typically or normally do so in each civic 
setting and therefore participate for only if time permits (Becker \& Dhingra, 2001). The lingering barrier of time, as well as the decision as to how to manage and distribute that time, becomes an overriding factor in the potential volunteer's life. The categorization of an individual to a religious or spiritual affiliation accounts for only a portion of what defines the individual themselves.

The cultural resources that contribute to the volunteer framework (Sundeen et al., 2007) have influences from an individual's ethnicity, values, spiritual beliefs, and views of a community. The perceived interaction an individual has regarding a volunteer experience will have a profound influence on their willingness to participate (Wilson, 2012). The sum of the experiences, both real and perceived, constructs the points of view of volunteer work. The builtin antecedents of volunteer service are portions of the decision to participate in the activity (Wilson, 2012).

An individual's actions and behaviors may be significantly altered based on the implications of their cultural background and heritage (Forbes \& Zampelli, 2014). In the study conducted by Forbes and Zampelli (2014), it was found that the Latino and African American populations were less likely to volunteer than their Caucasian counterparts. Though the exact rationale as to how ethnicity affects volunteerism is unclear, there are patterns of service that are predictable. The ethnicity does not apply only to those who are citizens of the United States. Those thoughts and implications could be strongly influenced as to the naturalization of an individual as a citizen of that region or as someone is who new to the area or region (Gilster, 2012). The parenting and guidance of the potential volunteer also have a cultural context to the possibility of participation. The upbringing and cultural morals that are instilled into an individual via their ethnicity can be represented in many forms including their values. 
The values that have been instilled in the individual who may potentially volunteer may come about via their cultural norms or the values they associate with the interaction with the organization itself. Evidence suggests that the likelihood of volunteering does have cultural ties (Wilson, 2012). The upbringing of a child in a neighborhood or within cultural parameters may augment or impede the potential volunteer's participation. The values passed down through the generations may place a greater emphasis on volunteering in one culture's views versus another. Additionally, the actions of the organization itself may help to instill certain feelings or emotions that also activate a person's values to volunteer. The feelings of pride and respect have been found to motivate an individual when contemplating volunteer service (Boezeman \& Ellemers, 2008). The organization's reputation for their treatment of their volunteers can prove to be a barrier in the recruitment and retention of their volunteers. The perception of the importance placed upon the volunteer work completed by an organization precedes the individual's pride in the work performed for the organization (Boezeman \& Ellemers, 2008). The importance that an individual's culture places on values like pride, respect, and self-worth may have long-lasting outcomes to their willingness to volunteer or provide service to an organization.

Lastly, the perception of an organization's support of their individuals' volunteer service precedes a volunteer's feeling of respect (Boezeman \& Ellemers, 2008). The potential volunteer must feel that there is a value added to their community or general society in order to spend their time in the service of others. Should the culture or community not support the organization as a necessary piece of the community, it becomes unlikely that those in the community will volunteer their efforts with the organization (Legg, Wells, \& Barile, 2015). In the area of sport this need for individuals is also evident. The need for volunteers becomes a systemic need throughout the community, not just for coaches but also for game organizers, officials, and 
sponsors (Nistler et al., 2011). The connection a community feels towards an organization relates to the support that will be expressed. Should a community not see the need to support the organization a barrier becomes apparent for the coaching population and the overall outlook and stigma of that group (Legg et al., 2015). The values placed upon feelings like pride and respect and how those feelings are supported by the cultural heritage of the individual and community can prove to impact a volunteer's commitment and service.

The age, gender, gender-related roles, age-related roles, and problems related to a given individual are combined into a category called mixed resources (Sundeen et al., 2007). The physical health and wellbeing related to one's chronological age may prevent participation in highly active events like youth sports, as there is a negative trend to volunteer as individuals reach advanced ages (Forbes \& Zampelli, 2014). The array of illnesses, physical conditions, and susceptibility to injury that come with advanced age may contribute to the natural trend of this group. There have been studies that indicate that individuals who volunteer tend to be happier and healthier as in the study completed by Borgonovi (2008). While it has not been found that improved health is attributed to volunteering, a reverse causality has been found to be the case in that individuals who volunteer tend to be healthier than those who do not (Borgonovi, 2008).

The natural barrier of health issues then arises for volunteer services. The older population may not be the only group affected by the natural hindrance of their age. Potential volunteers who are younger in age may be just as affected but possibly not for the reasons of health concerns but rather schedules and time. Community members who are still in school or studying may also prove to be deterred if the individual's personal schedule or experience may prevent them from volunteering (Aoyagi et al., 2013). The schedules that are kept with 
schooling, sport and activities, and social schedules have the potential to become barriers to those of a much younger age who may provide service.

Roles and responsibilities often associated with mothers, fathers, brothers, sisters, and other family members often have gender-related specificity as well. Women are more likely than men to volunteer in some service situations (Forbes \& Zampelli, 2014). However, the roles of mothers are expansive and all-encompassing. The wide array of responsibilities and activities that mothers fulfill creates an ever-increasing strain on their resource of time and creates a natural barrier for volunteering. Mothers are sometimes categorized by their time needs and constraints in a triad model of mother-worker-volunteer (Leberman \& LaVoi, 2011). In their study Leberman and LaVoi (2011) found the pertinent skills required to fulfill their duties as mothers and workers translated into the role of volunteer. Even though the resources these women have developed and cultivated are relevant to the volunteer needs the personal resource of time may impede their opportunity to show those skills. Men tend to have more resources in the areas of education, income, and secular social networks that would lend themselves to volunteer, but they typically volunteer less time than their female counterparts (Einolf \& Chambre, 2011).

Women have demonstrated the ability to combine or pool their resources into one larger segment. Women combine their community and social resources and when available link them to their religious groups as well (Einolf \& Chambre, 2011). However, in the case of sporting events, there is a slight trend away from the norm. Men tend to volunteer at higher rates than women when it comes to sporting activities (Skirstad \& Hanstad, 2013). The rationale and reasons for men to do so are different than their female counterparts. Men tend to volunteer for social capital while women tend to volunteer in sport for intrinsic reasons (Skirstad \& Hanstad, 
2013). While the tendencies demonstrate that females are more likely to volunteer than males in most cases, it is not the lone factor in determining a volunteer nor is being a male necessarily a barrier to volunteer service, especially in the example of sport.

The final category of the framework comes from the individual's residential context (Sundeen et al., 2007). The location, size, and type of community that the potential volunteers reside in will also present a set of barriers that may be difficult to overcome (Brown et al., 2012). The residential context has an impact on the size and nature of the organization. The increase or decrease of the importance residential context supports has an impact on the resources that organizations may access from that volunteer. In this case the volunteer may not have the desire to overcome the other perceived barriers. Should a potential volunteer be a transient individual or not have a strong cultural tie to a given area, the sense of community may be strained (Brown et al., 2012).

The community connection may in many cases augment or erode a potential participants involvement. The lack of support that comes from a community perception also creates a barrier for the potential volunteer. If a community or supporting organization does value the effort being produced, the barrier for volunteers could increase significantly (Cuskelly et al., 2006). The potential volunteer may perceive certain resources as not being available or certain obstacles as being too difficult to overcome before committing their service to an organization. The sum of all the resources that are available to a volunteer will help to indicate their willingness and availability to volunteer. The barriers that are created by various factors can deplete the volunteer's resources available to them.

The categories and framework laid out by Sundeen et al. (2007) allow an organization to see the complexity of the factors that may prevent certain populations of volunteers from 
serving. The group theorizes that there are four general barriers that prevent an individual from utilizing the resources mentioned. The scarcity of a given resource, a skills mismatch, a lack of interest, and a lack of community connection may all prevent an individual from providing their services to an organization (Sundeen et al., 2007). When a person who may become a volunteer lacks the resources to provide their service, a barrier exists in preventing that individual from volunteering. The lack of resources may extend into an improper mismatch of the skills one possesses versus the skills needed for the organization or event to be successful. The lack of a connection to the residential or theoretical community may also present a barrier to the volunteer work being conducted. Lastly, the lack of interest in the organization or the cause of the organization could be the final barrier.

The study conducted by Sundeen et al. (2007) studied results from United States Census data and found that the most common barriers were lack of time, lack of interest, and ill health. The pre-volunteer will assess their resources available and then compare that to the benefit of service. It will ultimately be the responsibility of the organization to show the importance of the service. If the needs of the volunteer are not being met or satisfied by the organization in terms of happiness, self-fulfillment, pride, respect, or community status, it becomes likely that they will not burden themselves to a point that the relationship with their family, profession, comfort, or community status could be damaged or negated (Boezeman \& Ellemers, 2008; Borgonovi, 2008). Expanding these categories to define the specific barriers of elite and professional coaches may assist sport organizations in utilizing their resources effectively to overcome these barriers.

The personal resource framework of Sundeen et al. (2007) complements that of Grube and Piliavin (2000) whose study stated that a volunteer's specific role identity within the 
organization begins with and is related to their general role identity or relationship with the organization. Grube and Piliavin (2000) went on to explain that the demands of a specific duty or role within an organization may be too great and cause the sustained volunteering of the individual to decrease. An additional conflict described by Grube and Piliavin (2000) is if the conflict is due to a discrepancy between the specific and general expectations and role of the organization. The roles and/or expectations of the nonprofit could possibly create a barrier with the volunteer should the demand be too high. The study by Grube and Piliavin (2000) is also consistent with the study by Young (2001a) in that the identity of the organization, which is derived from the mission, plays an integral role in any potential conflict with the volunteer.

\section{Conclusion}

Volunteers are the life's blood of a nonprofit organization. They are invaluable to the success and sustainment of an organization. Volunteers may take on many roles and responsibilities with an organization or event. Each role of volunteerism has a specific set of duties and responsibilities that contribute to the organization in unique ways. The role of executive volunteer could use their social status and standing to influence others to join them in their volunteer efforts. The executive volunteer then becomes an important resource for nonprofits as they may enhance the overall volunteering of others. Every person who may volunteer for an organization, either accepts the motivation to participate or yields to the barriers that prevent them from assisting. The literature for motivation is well researched and explained however, little is known about the barriers. The rationale for this is the absence of a captive population for a volunteer event. Identifying barriers for a specific population may be the first step in creating solutions for those barriers. 
Ideally high-profile coaches, as executive volunteers, would make themselves available to provide their service and resources to nonprofit sport organizations in order to benefit the sport overall. The reality is that nonprofit sport organizations have a need for volunteers, especially those in the executive categories to fulfill specific roles and duties due to a lack of volunteers. Identifiable barriers as to these individuals' reasoning for not volunteering are unknown in the literature. One possible solution is to uncover the most prevalent and impactful barriers for an executive coaching population for a nonprofit organization that benefits their sport. The literature presented builds to the research question for this study: What are the most prevalent and impactful barriers preventing collegiate coaches at Division I swimming programs from volunteering in an executive role to participate in a sport awareness program for a nonprofit organization? 


\section{Appendix C: Chapter 3 Methods \\ CHAPTER 3}

\section{Method}

The purpose of this study was to gain consensus among a panel of executive-level volunteers utilizing collegiate swimming coaches to (a) create a list of barriers of participation in a volunteer activity with a nonprofit organization that benefits their sport, (b) determine which of the barriers are most prevalent, and (c) determine which of the barriers have the greatest impact on their decision that would prevent them from volunteering in the activity, utilizing a Delphi study. The research methods in this chapter include the following sections: (a) participants, (b) research design, (c) administrative procedures and data analysis.

\section{Participants}

The identification of the expert group of panelists is the initial step in the creation of a Delphi study. The panelists employed for the service of the Delphi study are each an expert by being informed individuals, specialists in their field, or someone with significant knowledge about the subject area (Keeney, Hasson, \& McKenna, 2011). The ability to qualify the panelists as experts in the field was the next task. "Expertise implies that the individual panelists have more knowledge about the subject matter than most people, or that they possess certain work experience, or are members in a relevant professional association" (Murray \& Hammons, 1995, p. 428). The homogenous nature of this study focuses on collegiate swimming coaches as executive volunteers as designated by their social status and perceived expertise in the sport for the respondent population.

Coaches employed by large NCAA Division I institutions are those executive-level individuals in the public eye and among those who follow their sport. The coaches' association 
with the institution assists in elevating their social status and perception of expertise by others in the sport they coach. It should be noted that the criterion as an expert panelist for the Delphi is distinctly different than the term "expert coach," a category in effectiveness as by defined Côté and Gilbert (2009). The involvement of these collegiate coaches in nonprofit organizations, supporting their sport, helps to complete the loop of self-sustainment for that sport. Asking these collegiate coaches directly would give one the greatest insight to the barriers preventing their involvement with these nonprofit organizations. These executive-level volunteers meet the definition set forth by Murray and Hammons (1995), as having the most knowledge of the barriers that prevent them from these opportunities.

The size and scope of the number of expert panelists have varied dramatically over Delphi studies, anywhere from ten to 1685 panelists (Reid, 1988). Recommendations from Rowe and Wright (2001) were to use a homogenous population for each grouping when available and also to use between five and 20 panelists per group, and a total panel consisting of ten to 24 members will meet the minimum recommended amount and maximize the quality of the responses with the highest number (Brooks, 1979; Bulger \& Housner, 2007; Delbecq, Van de Ven, \& Gustafson, 1975; Parentè \& Anderson-Parentè, 1987). A high rate of completion of all the rounds of the study strengthens the consensus results and validity. This study invited a single group of 30 panelists to participate in the study to minimize attrition and increase participation as demonstrated by previous works in the literature (Akins, Tolson, \& Cole, 2005; Boyd, 2003; Bulger \& Housner, 2007). Although 30 panelists were invited, it was the expectation that a minimum of 24 panelists would complete the study to ensure less than an $20 \%$ mortality rate. The selection of the coaches gave preference to head coaches, associate coaches, and finally assistant coaches in that order. The preference given to the head coach was due to their 
higher social capital and more prominent role in their organization as a potential executive-level volunteer (Nicholson \& Hoye, 2008; Wilson \& Musick,1998). Every attempt was made to secure all head coaches for the panel. However, the priority was to secure enough coaches to fulfill the panel requirements. In addition to the level of coach, the type of institution was considered as well. The five major sport conferences in the country were selected based on their participation in the NCAA Division I Football Bowl Subdivision (FBS). The budgets, expectations, athletic department size, and level of competition, with regards to swimming, are comparable among these institutions. The five conferences included in this cohort were the Big 12 Conference, the Big 10 Conference, the Pacific 12 Conference, the Atlantic Coast Conference (ACC), and the South Eastern Conference (SEC). The continuity of these conferences yielded a potential pool of 205 full time swimming coaches. The coaching staff at West Virginia University was excluded from the panelist pool due to the personal relationship to the primary researcher.

The most homogenous population, in terms of duties and responsibilities, came from a group of coaches who are members of the conferences provided. Additionally, the coaches in this population are often viewed as the high-profile coaches in their region and the sport in general, allowing them to fulfill the executive volunteer criteria. Many of the swimming programs at these institutions house the largest and most advanced facilities in the area, and those facilities are utilized by many of the club programs in those regions. The head coaches of these programs are viewed as the figureheads of the sport in their areas and, due to their link within the athletic department, often have a higher social profile than many of their club counterparts. Additionally, the participation in the NCAA allows for a greater amount of exposure. 
Diving coaches were excluded from the study. Althoug, often listed as assistant coaches, associate coaches, or even as the Head Diving Coach, these individuals were not eligible for the study as the two sports are viewed as unique and separate, even though they participate in a combined format for the NCAA. In addition to diving coaches, those who may be listed as auxiliary staff were excluded. Examples of auxiliary staff included: graduate assistants, volunteer assistants, and directors of operation. These positions are not always full-time and often have a limited roles and responsibility as compared to that of a full-time paid staff position. The variation in professional responsibilities may have skewed the data of the overall population.

\section{Research Design}

The variance and complexity in the barriers against volunteerism make the selection of the research design a critical decision. The design must allow for an array of responses while having the ability to rate responses. The origin of the Delphi method was to gain consensus through an expert panel and was originated by the RAND Corporation from a series of studies conducted in the 1950's (Dalkey \& Helmer, 1963). The Delphi method has been cultivated over time and is still used for consensus today in a variety of settings. Linstone and Turoff (1975) synthesized many of the uses and characteristics of the Delphi as a group process for dealing with complex issues through structured communication whereby there is: (a) some feedback on individual contributions, (b) some assessment of group judgment, (c) some opportunity for individuals to revisit views, and (d) a degree of anonymity for individual responses. The method has been found to be valid when seeking consensus from a diverse group of experts on a topic or issue related to the individual's practice or field (Powell, 2003).

The research for this study mirrors the complexity of the data collected for the Delphi method. The aim was to reach consensus by conducting a Delphi study to identify the most 
impactful and prevalent barriers collegiate swimming coaches may encounter and prevent them from participating in volunteer activities for a nonprofit organization that benefits their sport.

First the group submitted their responses for an open-ended probe sent to all panelists. During the round II the participants rated the responses to determine those items that proved to be prevalent and impactful barriers for participation. During the round III the panel had the opportunity to review their responses, compare them to the overall group, and rerate them if necessary. Items reaching consensus were shared with the group at the conclusion of rounds II and III. A voluntary verification interview was utilized to further qualify their answers and provide methods for overcoming barriers.

\section{Administrative Procedures and Data Analysis}

The administrative procedures for this study had been adapted from the protocol developed by Bulger and Housner (2007). The Delphi is a method that builds upon itself round by round. The following section will describe those procedures and analysis in chronological order to show the complementary nature of the rounds of data. The administrative procedures and data analysis will be described within the following sections: (a) recruitment of participants, (b) round I procedures, (c) round I data analysis, (d) round II procedures, (e) round II data analysis, (f) round III procedures, (g) round III data analysis, (h)summary and verification interview procedures, and (i) summary and verification interview data analysis.

Recruitment of participants. Names were randomly selected from the pool of 205 available candidates. The potential participants for the Delphi study were personally invited to participate by the researcher via a participant invitation email (Appendix $\mathrm{H}$ ). The email offered a phone conversation to answer questions, clarify any procedures, address any concerns, and reinforce the importance of their participation and contribution within the study. Should the 
participant not desire a phone conversation, they responded directly to the participant invitation email (Appendix H) in the positive and received the introduction email (Appendix I). The introduction email described the following to prospective participants: (a) study purpose, (b) potential benefit to nonprofit organizations from participation, (c) an explanation of time requirements, and (d) an invitation to participate (Appendix I).

The invitation to participate was followed by a Qualtrics link to the participant letter of consent (Appendix J). The letter contained: (a) study purpose and potential benefits, (b) brief description of the Dephi method, (c) disclosure that participation is optional and voluntary, (d) brief summary of the Delphi rounds, and (e) timelines and expectations (Appendix J). The letter concluded with a link to the participant consent form (Appendix K). The consent form contained confirmation tabs that the participant: (a) confirmed understanding of the study, (b) willingness to participate in all rounds, (c) participation was voluntary, (d) will remain anonymous, and (e) data security (Appendix K). The participant was asked to electronically sign the participant consent form (Appendix K) and provided a linked to the demographic information (Appendix L). The demographic information captured data about the participants: (a) name, age, gender, (b) coaching information, and (c) volunteering habits (Appendix L). The conclusion of the demographic form contained a brief statement thanking the participant for their willingness to participate and preparing them for the opening open-ended question for the study. Finally, participants were provided a link to round I and reminded to contact the researcher for any questions, comments, or concerns that they may have regarding the study.

A total of 32 coaches responded to the invitation; however, one coach responded that they would not participate due to lack of interest in the subject matter, and one coach responded that they would participate but did not complete the demographic information or respond to 
multiple reminders. Thirty coaches completed the demographic information, entered the study, and continued until the completion of all three rounds of the Delphi. The distribution of coaches was as follows: head coaches $(n=10)$, associate or senior coaches $(n=9)$, and assistant coaches $(\mathrm{n}=11)$. The number of panelists who identified as female was eight compared to 22 who identified as male. The age of the overall panel ranged from 27 to $65(\mathrm{M}=41.5)$ years old. The time spent in the coach's current role ranged from ( .5 years $)$ to 22 years $(M=5.68)$ at their current position. The years at the current institution had a range of (.5 years) to 22 years $(\mathrm{M}=6.91)$. Panelists participation in nonprofit volunteer events per year ranged from zero to $20(M=3.43)$. A complete listing of the demographic information can be found in Table 1.

Round I procedure. The purpose of the first round was (a) to collect raw responses from the panelists as to the perceived barriers and (b) to group similar responses into a manageable list via conceptually clustered matrix. The first round of the Delphi consisted of an open-ended question to allow the panel the freedom to interpret the survey question and construct their own personal responses. The initial round was qualitative in nature by soliciting feedback from the panelists while contextualizing their responses as a collegiate swimming coach. The open-ended question asked the panelists to provide as many examples of barriers that prevented them from participating in the volunteer activity described. The following categories and examples of thought starters were pulled from the literature: (a) personal resources, i.e. discretionary time, income, education, or job duties, (b) social ties, i.e. family responsibilities, organizations, groups, or civic, (c) cultural resources, i.e. cultural upbringing, ethnicity, morals, or notion to help others, (d) mixed resources, i.e. age, health issues, gender, or roles related to age or gender, (e) residential context, i.e. residential, work, or professional (Sundeen et al., 2007). The raw responses were gathered and condensed. 
The link for the round I landing page (Appendix M) provided participants with: (a) the study focuses and panelist importance, (b) round I instructions, and (c) study summary. The page concluded with a link to the round I questionnaire (Appendix N). Each panelist was given ten spaces to provide their answers to ensure that they have exhausted their barriers. Panelists were also instructed to contact the primary researcher should the number of spaces provided not be enough.

The panelists were given one week to respond to the round I questionnaire (Appendix N). After 10 days participants received a reminder email, text message, and phone call to prompt their responses and to answer any questions or issues that may be present. If a response was not collected, a contingency communication was in place to ensure participation. The contingency schedule was implemented for those who do not respond within the given time period. After two weeks panelists would (a) receive an email and text message encouraging their participation in the study and requesting the survey completion, (b) be allotted a seven-day extension for their participation in order to attain the highest participation rate possible, and (c) receive a phone call to reinforce that their participation in the study is important and valued greatly for successful completion of the study (Bulger \& Housner, 2007).

Once the panelist responses were collected, both the panelist and each response were coded. Three categories were created for the participants that reflected their positions of employment as head coaches, associate coaches, and assistant coaches. The coding provided anonymity for the panelists and their responses. Numbers were assigned to each individual in the three categories to complete the coding process. The primary researcher collected data from the round I responses, coded, and listed them on a cumulative Excel spreadsheet by denoting the panelist by number (i.e. Head Coach 1) and numbering their responses (i.e. Head Coach 1-Item 
1). The anonymity provided by coding facilitated the data being interpreted by individuals other than the primary researcher.

Two faculty members at a local teaching institution were asked to participate in the data analysis. The addition of these two individuals was to reduce researcher bias and preconceived framing of statements by the primary researcher, to eliminate double-barreled responses, and to check items for clarity (Miles \& Huberman, 1994). The faculty members both hold terminal degrees and have been published in peer-reviewed journals. The additional researchers assisted exclusively during round I of the Delphi. The primary researcher set up a meeting with the two faculty members to explain their role during round I: (a) group similar statements made by the panelists, (b) preserve the integrity of the responses, and (c) reduce the overall number of items to a manageable list for round II using a conceptually clustered matrix (Keeney, McKenna, \& Hasson, 2011). The matrix contained the panelist raw data statements along the vertical column of the matrix and the five categories from Sundeen et al. (2007) across the horizontal. Once aligned to a category, the group then considered the factors of: (a) scarce resources, (b) skills mismatch, (c) not interested, and (d) lack of community connection also provided by Sundeen et al. (2007) to further group the statements. Each of the researchers where then provided the sheet of results and asked to add them to the appropriate category in the conceptual matrix. The researchers submitted their synthesized matrix to the primary researcher along with the primary researchers' own matrix, and the round II list was created.

Once the initial data analysis concluded, the primary researcher set up a meeting with the faculty members in order to further discuss the raw data statements in conflict. The purpose of the meeting was to determine: (a) if statements can be combined, (b) should statements be listed as separate items, (c) that all items are clear to the reader, (d) if there are any responses with two 
or more possible meanings that needed to be clarified, and (e) whether the items are in the correct categories according to Sundeen et al. (2007). Statements that could not be resolved past the discussion among the researchers were left as two separate items for the round II list and the reasons and rationales for the disputed items recorded by the primary researcher. The outcome of the round I data analysis resulted in a manageable list of items for the group to rate that was stated in the words of the panelists or at least reflected the panelists' sentiments.

Round I data analysis. The following round I data analysis process was described by Keeney, McKenna, and Hasson (2011) with the reduction of the data process provided by Miles \& Huberman (1994). The categories and groups created by the matrix allowed each researcher to combine statements with the same or very similar wording. Second, statements that may have different wording but the same perceived meaning were combined. The grouping and combining of the statements followed the rules of Keeney, McKenna, \& Hasson (2011) in that the integrity of the statements should be preserved as written by a panelist whenever possible. Any item that had complete agreement among the three researchers was automatically added to the list. Additionally, any statements that had been removed by all three researchers due to combining or grouping were also removed. The primary researcher then created a list of statements that were in conflict and denoted in what category and subcategory each researcher placed the statement. The primary researcher and the two colleagues then met to discuss in person the statements in conflict and to determine if the statements should be combined or left as two separate items.

Round II procedures. Panelists received an email from the primary researcher explaining the instructions and timeline for round II and a link to the landing page (Appendix O). The purpose of this round was to rate the items collected from round I on two separate five-point Likert scales, in order to determine those barriers that are the most impactful and prevalent. 
Each item was rated twice, first in terms of impact and second in terms of prevalence. The definitions and examples of both impact and prevalence were provided to the panelists on the round II questionnaire (Appendix P). The Likert scale anchors for round II were developed from Vagias (2006). The first prompt for impact states, “This item's Impact on my volunteer habit has: (a) No affect, (b) Minor affect, (c) Neutral, (d) Moderate affect, and (e) Major effect." The responses carried values of one to five. The second prompt for prevalence states, "This item's Prevalence is: (a) Never, (b) Rarely, (c) Occasionally, (d) A moderate amount, (e) A great deal." Once again, the rating for these values were one to five. Instructions and preparations for round III were included in the round II email so that participants could be aware of the next stage of the procedure. Once again, the same timeline and contingency plan were used during round II to ensure the effectiveness of communication and timeliness of responses.

Round II data analysis. At the conclusion of round II, the mean score of each item and the percentage of panelists rating the item at a 4.0 or higher were calculated for all items listed. Each panelist's individual response was recorded along with the total group response for all items on both scales.

Round III procedures. In round III participants were provided an opportunity to reconsider their rankings from round II. They were presented with each item from round II and their personal rating for the item's score of both impact and prevalence. In addition, panelists were provided with the total group's mean score of each item and the percentage of panelists rating the item at a 4.0 or higher. The explanation and instructions for round III were sent via email to the panelists along with a link to the round III landing page (Appendix Q). The approach for gaining consensus is one of the most varied and least developed stages of the Delphi method (Crisp, Pelletier, Duffield, Adams, \& Nagy, 1997; McKenna, 1994). Panelists 
were provided the list of all items from the round II questionnaire for both prevalence and impact. The instructions for round III explained that the threshold for an item to reach consensus (agreement) is a mean score of 4.0 and have a rating of 4.0 or higher on $75 \%$ of the panelists' item ratings (Bulger \& Housner, 2007). The rationale for consensus meets a higher standard than that of Keeney, McKenna, and Hasson (2011) who stated agreement could be $51 \%$. Panelists were shown their individual score for each item and for both rating scales and the aggregate scores of the panel rating each item for both scales and asked to reconsider. Panelists were asked to keep their score the same, raise, or lower their round III rating. They were reassured that it was their choice as to change their response or not. A link to the round III questionnaire (Appendix R) was provided at the end of the round III landing page (Appendix Q). The same contingency plan used in round I and II was utilized to ensure timely responses.

Round III data analysis. The same data analysis as round II was again conducted in round III. All items reaching a mean of 4.0 for either the rating of impact or prevalence and rated a 4.0 or higher on $75 \%$ of all individuals reached consensus. There would then be four categories created: (a) items reaching consensus for both impact and prevalence, (b) items reaching consensus for impact but not prevalence, (c) items reaching consensus for prevalence but not impact, and (d) items not reaching consensus for either impact or prevalence. The primary researcher considered the group's response from the panelists to investigate the changes that occurred from round II to round III.

Summary and verification interview procedures. After the panelists rated the items during round III they were sent a summary of the Delphi results (Appendix S). The summary of results contained: (a) the goal and objectives of the study, (b) a rationale to why the Delphi method was selected, (c) a brief overview of the Delphi procedure in which they just 
participated, and (d) the initial findings of the study. Participants were then invited to participate in a verification interview with the primary researcher to discuss the results (Appendix T). The interviews were implemented to add to the validity of the Delphi results and offer clarity that may not be gleaned from a statistical response. The purpose of the interview was to provide the panel the opportunity to elaborate on the responses of the group, provide detail as to the categorization of the items, and to speculate as to possible solutions or interventions that may be attempted to mitigate these barriers in the future. The verification interview (Appendix T) was conducted as a semi-structured Zoom interview by the primary researcher.

Nine of the panelists participated in the semi-structured interviews. Four of the panelists were head coaches, two of the panelists were associate coaches, and three were assistant coaches. Only one of the interviewees identified as female. The first five questions of the interview sought to allow the interviewee to expand on the findings of the Delphi, the sixth question asked the interviewee to compare the categorization of these findings to that of Sundeen et al. (2007), and the last three questions asked the panelist to speculate as to mitigation of the barriers found by the Delphi (Appendix O). Lastly, panelists were thanked for their participation at the conclusion of the summary email and the verification interview by the primary researcher.

Summary and verification interview analysis. he protocols for the analysis of the interviews followed that of Hycner (1985). The data collected from the interview questions were categorized and coded according to the process as follows: (1) transcription, (2) bracketed and phenomenological reduction, (3) listening to the interview for the sense of the whole, (4) delineating units of general meaning, (5) delineating units of meaning relevant to the research question, (6) eliminating redundancies, (7) clustering units of relevant meaning, (8) determining themes from clusters of meaning, (9) writing a summary for each interview, (10) modifying 
themes and summary, (11) identifying general and unique themes for all interviews, (12) contextualizing theme, and (13) composite summary (Hycner, 1985). The primary reason for this protocol selection was the ability of the protocol to analyze both within and between subjects to generate themes.

The interviews between the primary researcher and the panelist were recorded via Zoom, and Google Translate was initially utilized to transcribe the interview as recorded. The primary researcher then read the transcript while simultaneously listening to the interview to correct errors in the transcription. In order to alleviate researcher bias, the primary researcher then bracketed the preconceived suppositions and bias of the meaning of the interviews by writing and listing those conscious biases that may have been present. The major themes that arose from the preconceived researcher bias were: (1) coaches should want to help, (2) coaching staffs are similar among schools, and (3) that all coaches find volunteering important. A portion of the bias came from the introspection of the researcher and conversations that took place during the proposal meeting. Once the bracketing had taken place the primary researcher then listened to the interviews again, and took notes recording general impressions and perceptions. The primary researcher then began to condense the general units of meaning throughout the various individual interviews and documenting each according to the specific interviewee. After each of the general units of meaning were assessed, they were then compared to the research question. If the general units of meaning addressed the research question or purpose of the verification interview, it was noted as such.

The researcher then looked at the relevant units of meaning for redundancies within each individual interview. Content validity is typically assured when the participants are knowledgeable and have an interest in the subject area, in which case the single interviewer 
model adds a qualitative clarity to the results (Hasson \& Keeney, 2011; Powell, 2003). After the redundancies were identified and documented, the researcher clustered groups of relevant meaning within interviews for each participant. The groups of relevant meaning were considered to find the central themes that arose across the nine interviews. The researcher then wrote summaries of the individual interviews. The final step was to identify themes that were common between interviewees that pertained to the research question and that would add clarity and validity to the results of the Delphi. 


\section{Appendix D: Chapter 4 Extended Results \\ CHAPTER 4}

\section{Results}

The results section contains the data collected from both the Delphi and the verification interviews. The data analysis from round I will explore the qualitative responses collected from the Delphi and the categorization of the responses. Rounds II and III will show the items that reached statistical consensus. The item's specific categorization and level of consensus in each round is listed according to the category. The verification interview portion lists the themes derived from the interviews and supporting examples from the panelists.

\section{Round I}

The completion of the first round of the Delphi yielded 60 unique raw data statements submitted by the 30 panelists in the open-ended probe. The 60 raw data statements from round I were reduced to a list of 21 items reflecting he panelist responses to the round I probe. These items organized into five categories (Table 2): personal resources $(n=9)$, social ties $(n=3)$, cultural ties $(n=2)$, residential context $(n=7)$, and mixed resources $(n=0)$.

\section{Round II}

The completion of the second round found that five of the 21 items met the previously mentioned criteria for both impact and prevalence. One item met the criteria for impact only, while another item met the criteria for prevalence only (Table 3). The remaining item's ratings did not reach the criteria for either impact or prevalence individually, or both impact and prevalence collectively by either not scoring a mean of 4.0 or not being rated as a 4.0 or higher by $75 \%$ of the panelists.

\section{Round III}


The panel reached agreement for both impact and prevalence on seven of the 21 items and one item for prevalence only (Table 4). The results of each round of the Delphi utilized the conceptual framework from the volunteer literature to categorize the items and compare as to how the responses of this population on this topic aligned.

Personal resources. Seven of the items reaching consensus were previously categorized as personal resources after the round I responses were received. Five of these items reached consensus in both impact and prevalence after both rounds II and III of the study: (a) Primary work responsibilities limiting time availability, (b) Time and availability, (c) Discretionary time, (d) During college season, having to coach practice, and (e) Time of year/season. One item did not reach consensus for impact or prevalence during round $\mathrm{II}(\mathrm{I}=3.0 / 70 \%, \mathrm{P}=3.93 / 73.33 \%)$ but did reach consensus during round III on both rating scales ( $\mathrm{I}=4.0 / 76.67 \%, \mathrm{P}=4.20 / 80 \%)$ : (a) Length of time being asked for the event. One item reached consensus for prevalence only at the conclusion of both round II and round III: (a) Time Away from team activity, but it did not reach the criteria for consensus in either round for impact ( $\mathrm{Rd} 2 \mathrm{I}=3.9 / 73.33 \%, \mathrm{Rd} 3 \mathrm{I}=4.0 / 66.67 \%)$. Two items that were categorized as personal resources did not reach consensus during round II or round III: (a) Energy it would cost me and (b) Money it would cost me to help out.

Social ties. Only one item reached consensus under the category of social ties: (a) Family responsibilities. At the conclusion of round II, the item reached consensus for impact only and did not meet the criteria for prevalence $(\mathrm{I}=4.13 / 76.67 \%, \mathrm{P}=4.0 / 70 \%)$. However, after round III the item did reach consensus on both rating scales $(\mathrm{I}=4.10 / 80 \%, \mathrm{P}=4.23 / 83.33 \%)$. The remaining two items in this category did not reach consensus during either round for impact or prevalence: (a) Cost of obtaining a baby sitter and (b) Social ties. 
Cultural ties. Neither of the two items reached consensus for impact or prevalence during round II or round III for the category of cultural ties: (a) Whether I agree with the mission of the gathering and (b) Passion for the scheduled event. Item 14 Passion for the scheduled event did approach consensus during round II for impact (3.87/66.67\%). During round III the item trended closer toward impact consensus as well (3.90/80\%). However, the item did not reach criteria during either round. The interviewees did lend some thought to this item during their verification interview as will be discussed later.

Residential context. Seven of the items were categorized as residential context after the round I responses were received, making it the second largest category. However, none of the items reached criteria for consensus after round II or round III for either impact or prevalence: (a) Does it tie into a cause that the sport of swimming needs, (b) If there is any professional conflict of interest, (c) Is this opportunity going to be of a benefit to my institution to be affiliated with it, (d) Support from university athletics and the city itself, (e) Not beneficial to my professional growth, (f) Program resources, and (g) Limited to no facility availability.

\section{Verification Interview}

The following themes (a) perception of the concept of time as the main barrier, (b) the category of personal resources as the most utilized category, (c) overcoming barriers, and (d) willingness and ability to overcome barriers were presented during the interviews.

Perception of the concept of time as the main barrier. The theme of time was found by the interviewees as the most impactful and prevalent barrier. All nine participants identified time as the main barrier for participation. Three main concepts emerged from the broader concept of time: (a) dedicated time, (b) length of time for participation, and (c) timing of the event during the season or offseason. 
Dedicated time. The coach making the active decision as to where to place their minutes or hours in a day and have some type of organizational control of their personal schedule created the theme of dedicated time. All nine of the panelists discussed their decision-making in determining their time allotment. One participant stated the decision-making process for the typical coaching routine.

As coaches we substitute meetings, practices, or calls where there once was a space in our schedule. It is just the nature of the profession (HC 10, Q1).

Another participant expressed that time is their most valued resource. Additionally, they equated their success as a coach to their time spent with their team.

Time is the most important resources that I have as a coach, my discretionary time and availability of time are very limited as well which comes from my personal resources. If you are doing a good job with your team the time is limited (Assoc. 1, Q2).

Length of time for participation. Coaches also expressed that the amount of time the actual event takes plays a role in the impact of the barrier. Seven of the participants indicated that the length of time for an event affects the barrier. The length of commitment to an event may be related to its impact and prevalence as described by one of the participants.

It's an individual choice, if you are willing to step away from the team for any length of time that may be the distinction between impact and prevalence (Assoc. 1, Q4).

Timing of the event during the season or offseason. The time of year the event takes place was indicated by several participants to impact the barrier of time. All nine of the coaches indicated that the time of year would affect their decision as to their participation. The coaches described their routines and tasks that are required during the season and off-season. One participant explained their daily routine.

I leave at 5:30am and get home at 7:00pm during the season, and that is before recruiting calls (HC 9, Q1). 


\section{The category of personal resources as the most utilized category. All nine}

participants found agreement that time is a personal resource, and time was often described as one of their most valuable resources. Six of the nine coaches indicated that their family is the recipient of the time that becomes available after job responsibilities. Once the tasks of the job were complete, the distribution of time then went to family, and lastly other functions they decide to dedicate their time. Two participants expressed those sentiments.

Time is my most valuable personal resource. It is not a matter of an unwillingness or lack of interest to participate in something. Family becomes a second priority for receiving my open time (Assoc 1, Q1).

The time I have to myself is precious. I make every effort to spend that time with my spouse and child and to ensure that those times are meaningful (Asst. 1, Q1).

Overcoming barriers. All nine coaches offered ideas about overcoming the barriers that were presented. The two emerging concepts that came from this were strategies and support. Five of the coaches made statements that centered around the strategies a coach may utilize to overcome a barrier. Seven of the interviewees indicated a statement that required some type of support or assistance to overcome the barriers presented.

Strategies. The statements that formed this concept were suggestions that involved the coaches' doing something for themselves. Organizational tools were viewed as scheduling tips, calendars, and planning. Coaches stated that keeping a close watch on the budgeting of time during the day and not procrastinating helped to maximize time to dedicate to other activities. Coaches also stressed the importance of recognizing one's weaknesses and strengths can also assist in managing a schedule. One coach explained in more depth in the following statement.

I always viewed myself as a multi-tasker, but after a while I realized that I work much better on one thing at a time. One way I help myself from spinning my wheels is to incorporate a very intricate calendar that maps out my week. I even include my down time in that week (Asst. 1, Q8). 
Support. The coaches also stated the need for support of others in order to overcome barriers. While there are strategies to help oneself, seven of the coaches felt there needed to be some intervention from others in order for the barriers to be mitigated. The strategies for utilizing others came in different forms: the nonprofit organization themselves, the athletic office, and those around the coaches. One coach explained that the organization has a responsibility to assist in the matter by making the task completion as simple as possible.

Making things easy for the coach to participate to where it does not impede my other opportunities or take away from my team (HC10,Q 8).

Another coach explained that an individual in the athletic office completes all of the ancillary work necessary for the event to take place, and the coach needs only to be present and participate.

We have a logistics person in the athletic department that sets up the event, from busses, t-shirts, and events which makes the event very manageable and easy (Assoc. 1, Q8).

Two other coaches explained the importance on relying on the relationships they have with others to help them find time away from work responsibilities.

Make connections and relationships throughout the athletic department. The relationships help to include others in activities (HC 6, Q8).

Help involve those around you, whether it is staff, administrators, or the team, to make the volunteerism important as well (HC 5, Q8).

Willingness and ability to overcome barriers. All nine interviewees indicated that they themselves would be willing to attempt a suggested strategy to overcome the barriers of time if presented to them by the nonprofit organization. All nine panelists also indicated that it is possible for a coach to overcome the barrier of time. However, all nine also indicated that there is a personal responsibility of the individual to accept the responsibility to overcome the barriers presented. 
A panelist felt that it is possible to overcome barriers alone, but other interventions may prove to be more impactful and effective.

The individual may be able to do it themselves, but changes in rules and coaching culture may be more impactful (Assoc. 7, Q7).

Another panelist explained that coaches needed to reassess what is important to them.

Once that is achieved they would be free to distribute their time as they see fit.

We need to revalue things as coaches. We as coaches need to trust each other in that when something comes up in our personal lives we can rely upon one another to help out and take over activities or practices. That action will in turn serve as model for our student athletes as well and the cycle will hopefully repeat itself (Asst. 1, Q9). 


\section{Appendix E: Extended Reference List \\ References}

Akins, R. B., Tolson, H., \& Cole, B. R. (2005). Stability of response characteristics of a Delphi panel: application of bootstrap data expansion. BMC Medical Research Methodology, $5(1), 37$.

Alexandrov, A. V., Pullicino, P. M., Meslin, E. M., \& Norris, J. W. (1996). Agreement on disease-specific criteria for do-not-resuscitate orders in acute stroke. Stroke, 27(2), 232237.

Anheier, H. K. (2005). Nonprofit organizations: an introduction. New York, NY: Routledge.

Aoyagi, K., Ishii, K., Shibata, A., Arai, H., Hibi, C., \& Oka, K. (2013). Correlates of engagement in school-based extracurricular sports activities among registrants of sports leader banks. Journal of Physical Education and Sport, 13(2), 127.

Balser, D., \& McClusky, J. (2005). Managing stakeholder relationships and nonprofit organization effectiveness. Nonprofit Management and Leadership, 15(3), 295-315.

Bang, H., Ross, S., \& Reio Jr, T. G. (2012). From motivation to organizational commitment of volunteers in non-profit sport organizations: The role of job satisfaction. Journal of Management Development, 32(1), 96-112.

Becker, P. E., \& Dhingra, P. H. (2001). Religious involvement and volunteering: Implications for civil society. Sociology of Religion, 62(3), 315-335.

Billis, D., \& Harris, M. (1992). Taking the strain of change: UK local voluntary agencies enter the post-Thatcher period. Nonprofit and Voluntary Sector Quarterly, 21(3), 211-225.

Boezeman, E. J., \& Ellemers, N. (2008). Pride and respect in volunteers' organizational commitment. European Journal of Social Psychology, 38(1), 159-172. 
Borgonovi, F. (2008). Doing well by doing good. The relationship between formal volunteering and self-reported health and happiness. Social Science \& Medicine, 66(11), 2321-2334.

Bouchet, A., \& Lehe, A. (2010). Volunteer Coaches in Youth Sports Organizations: Their Values, Motivations \& How to Recruit, \& Retain. Journal of Youth Sports, 5(1), 21-24.

Boyd, B. L. (2003). Competencies for leaders of volunteers during the next decade: A national Delphi study. Journal of Agricultural Education, 44(4), 47-56.

Brooks, K. W. (1979). Delphi technique: Expanding applications. North Central Association Quarterly, 53(3), 377-85.

Brown, E., \& Ferris, J. M. (2007). Social capital and philanthropy: An analysis of the impact of social capital on individual giving and volunteering. Nonprofit and Voluntary Sector Quarterly, 36(1), 85-99.

Brown, K. M., Hoye, R., \& Nicholson, M. (2012). Self-esteem, self-efficacy, and social connectedness as mediators of the relationship between volunteering and well-being. Journal of Social Service Research, 38(4), 468-483.

Bulger, S. M., \& Housner, L. D. (2007). Modified Delphi investigation of exercise science in physical education teacher education. Journal of Teaching in Physical Education, 26, 57 -80 .

Burgham, M., \& Downward, P. (2005). Why volunteer, time to volunteer? A case study from swimming. Managing Leisure, 10(2), 79-93.

Bussell, H., \& Forbes, D. (2002). Understanding the volunteer market: The what, where, who and why of volunteering. International Journal of Nonprofit and Voluntary Sector Marketing, 7(3), 244-257. 
Carman, J. G., Leland, S. M., \& Wilson, A. J. (2010). Crisis in leadership or failure to plan? Nonprofit Management and Leadership, 21(1), 93-111.

Choi, N. G., \& DiNitto, D. M. (2012). Predictors of time volunteering, religious giving, and secular giving: Implications for nonprofit organizations. Journal of Sociology \& Social Welfare, 39, 93.

Clary, E. G., \& Snyder, M. (1999). The motivations to volunteer: Theoretical and practical considerations. Current Directions in Psychological Science, 8(5), 156-159.

Clary, E. G., Snyder, M., Ridge, R. D., Copeland, J., Stukas, A. A., Haugen, J., \& Miene, P. (1998). Understanding and assessing the motivations of volunteers: a functional approach. Journal of Personality and Social Psychology, 74(6), 1516.

Cnaan, R. A., Handy, F., \& Wadsworth, M. (1996). Defining who is a volunteer: Conceptual and empirical considerations. Nonprofit and Voluntary Sector Quarterly, 25(3), 364-383.

Côté, J., \& Gilbert, W. (2009). An integrative definition of coaching effectiveness and expertise. International journal of sports science \& coaching, 4(3), 307-323.

Côté , J., Saimela, J., Trudel, P., Baria, A., \& Russell, S. (1995). The coaching model: A grounded assessment of expert gymnastic coaches' knowledge. Journal of sport and exercise psychology, 17(1), 1-17.

Crisp, J., Pelletier, D., Duffield, C., Adams, A., \& Nagy, S. U. E. (1997). The Delphi method? Nursing research, 46(2), 116-118.

Cuskelly, G., Hoye, R., \& Auld, C. (2006). Working with Volunteers in Sport: Theory and Practice. New York, NY: Routledge.

Dalkey, N., \& Helmer, O. (1963). An experimental application of the Delphi method to the use of experts. Management Science, 9(3), 458-467. 
Dawson, P., \& Downward, P. M. (2013). The relationship between participation in sport and sport volunteering: An economic analysis. International Journal of Sport Finance, 8 (1), $75-92$.

Delbecq, A. L., Van de Ven, A. H., \& Gustafson, D. H. (1975). Group Techniques for Program Planning: A Guide to Nominal Group and Delphi Processes (pp. 83-107). Glenview, IL: Scott, Foresman.

Dorsch, K. D., Riemer, H. A., Sluth, V., Paskevich, D. M., \& Chelladurai, P. (2002). What Affects a Volunteer's Commitment? Toronto, ON: Canadian Centre for Philanthropy.

Downward, P. M., \& Ralston, R. (2006). The sports development potential of sports event volunteering: Insights from the XVII Manchester Commonwealth Games. European Sport Management Quarterly, 6(4), 333-351.

Einolf, C., \& Chambré, S. M. (2011). Who volunteers? Constructing a hybrid theory. International Journal of Nonprofit and Voluntary Sector Marketing, 16(4), 298-310.

Forbes, K. F., \& Zampelli, E. M. (2014). Volunteerism: The influences of social, religious, and human capital. Nonprofit and Voluntary Sector Quarterly, 43(2), 227-253.

Freeman, R. B. (1997). Working for nothing: The supply of volunteer labor. Journal of Labor Economics, 15(1, Part 2), 140-S166.

Gibelman, M., \& Sweifach, J. (2008). Acting on our values: Do social workers Volunteer? Social Work, 53(1), 53-64.

Gilster, M. E. (2012). Comparing neighborhood-focused activism and volunteerism: psychological well-being and social connectedness. Journal of Community Psychology, 40(7), 769-784. 
Grube, J. A., \& Piliavin, J. A. (2000). Role identity, organizational experiences, and volunteer performance. Personality and Social Psychology Bulletin, 26(9), 1108-1119.

Hager, M. A. (2014). Engagement motivations in professional associations. Nonprofit and Voluntary Sector Quarterly, 43(2), 39-60.

Hameiri, L. (2018). Executive-level volunteers in Jewish communal organizations: Their trust in executive professionals as mediating the relationship between their motivation to volunteer and their pursuit of servant leadership. Voluntas: International Journal of Voluntary and Nonprofit Organizations, 1-15.

Handy, F., Cnaan, R. A., Brudney, J. L., Ascoli, U., Meijs, L. C., \& Ranade, S. (2000). Public perception of "who is a volunteer": An examination of the net-cost approach from a cross-cultural perspective. Voluntas: International Journal of Voluntary and Nonprofit Organizations, 11(1), 45-65.

Hasson, F., \& Keeney, S. (2011). Enhancing rigour in the Delphi technique research. Technological Forecasting and Social Change, 78(9), 1695-1704.

Herman, R. D., \& Renz, D. O. (1998). Nonprofit organizational effectiveness: Contrasts between especially effective and less effective organizations. Nonprofit Management and Leadership, 9(1), 23-38.

Herman, R. D., \& Renz, D. O. (2008). Advancing nonprofit organizational effectiveness research and theory: Nine theses. Nonprofit Management and Leadership, 18(4), 399-415.

Hustinx, L., Cnaan, R. A., \& Handy, F. (2010). Navigating theories of volunteering: A hybrid map for a complex phenomenon. Journal for the Theory of Social Behaviour, 40(4), 410434. 
Hwang, H., \& Powell, W. W. (2009). The rationalization of charity: The influences of professionalism in the nonprofit sector. Administrative Science Quarterly, 54(2), 268298.

Hycner, R. H. (1985). Some guidelines for the phenomenological analysis of interview data. Human studies, 8(3), 279-303.

Keeney, S., McKenna, H., \& Hasson, F. (2011). The Delphi Technique in Nursing and Health Research. West Sussex, UK: John Wiley \& Sons.

Leberman, S. I., \& LaVoi, N. M. (2011). Juggling balls and roles, working mother-coaches in youth sport: Beyond the dualistic worker-mother identity. Journal of Sport Management, $25(5), 474-488$.

Lee, L., Piliavin, J. A., \& Call, V. R. (1999). Giving time, money, and blood: Similarities and differences. Social Psychology Quarterly, 276-290.

Legg, E., Wells, M. S., \& Barile, J. P. (2015). Factors related to sense of community in youth sport parents. Journal of Park and Recreation Administration, 33(2), 73-86.

Lewis, D. (2001). The Management of Non-Governmental Development Organizations. New York, NY: Routledge.

Linstone, H. A., \& Turoff, M. (Eds.). (1975). The Delphi Method: Techniques and Applications (Vol. 29). Reading, MA: Addison-Wesley.

McDonald, R. E. (2007). An investigation of innovation in nonprofit organizations: The role of organizational mission. Nonprofit and Voluntary Sector Quarterly, 36(2), 256-281.

McKenna, H. P. (1994). The Delphi technique: a worthwhile research approach for nursing? Journal of advanced nursing, 19(6), 1221-1225. 
Miles, M. B., Huberman, A. M., Huberman, M. A., \& Huberman, M. (1994). Qualitative data analysis: An expanded sourcebook. London, UK: Sage.

Mook, L., Handy, F., Ginieniewicz, J., \& Quarter, J. (2007). The value of volunteering for a nonprofit membership association: The case of ARNOVA. Nonprofit and Voluntary Sector Quarterly, 36(3), 504-520.

Murray Jr, J. W., \& Hammons, J. O. (1995). Delphi: A versatile methodology for conducting qualitative research. The Review of Higher Education, 18(4), 423-436.

Nicholson, M., \& Hoye, R. (Eds.). (2008). Sport and Social Capital. New York, NY: Routledge.

Nistler, D. L., Lamm, A. J., \& Stedman, N. (2011). Evaluating the influences on extension professionals' engagement in leadership roles. Journal of Agricultural Education, 52(3), $110-121$.

Parenté, F. J., \& Anderson-Parente, J. K. (1987). Delphi inquiry systems. Judgmental Forecasting, (pp. 129-156). West Sussex, UK: John Wiley \& Sons.

Paik, A., \& Navarre-Jackson, L. (2011). Social networks, recruitment, and volunteering: Are social capital effects conditional on recruitment? Nonprofit and Voluntary Sector Quarterly, 40(3), 476-496.

Penner, L. A. (2002). Dispositional and organizational influences on sustained volunteerism: An interactionist perspective. Journal of Social Issues, 58(3), 447-467.

Posner, B. Z. (2015). An investigation into the leadership practices of volunteer leaders. Leadership \& Organization Development Journal, 36(7), 885-898.

Powell, C. (2003). The Delphi technique: Myths and realities. Journal of Advanced Nursing, 41(4), 376-382. 
Reid, N. (1988). The Delphi technique: Its contribution to the evaluation of professional practice. Professional Competence and Quality Assurance in the Caring Professions, 230-262.

Rowe, G., \& Wright, G. (2001). Expert opinions in forecasting: The role of the Delphi technique. In Principles of Forecasting, (pp. 125-144). Boston, MA: Springer.

Shilbury, D., \& Moore, K. A. (2006). A study of organizational effectiveness for national Olympic sporting organizations. Nonprofit and Voluntary Sector Quarterly, 35(1), 5-38.

Skirstad, B., \& Hanstad, D. V. (2013). Gender matters in sport event volunteering. Managing Leisure, 18(4), 316-330.

Smith, V. (2010). Enhancing employability: Human, cultural, and social capital in an era of turbulent unpredictability. Human Relations, 63(2), 279-300.

Stebbins, R. A. (2009). Would you volunteer? Society, 46(2), 155-159.

Strigas, A. D., \& Jackson Jr, E. N. (2003). Motivating volunteers to serve and succeed: Design and results of a pilot study that explores demographics and motivational factors in sport volunteerism. International Sports Journal, 7(1), 111.

Strong, R., \& Harder, A. (2010). Master gardeners' teaching efficacy and demographic characteristics as volunteer educators for cooperative extension. Journal of Southern Agricultural Education Research, 60(1), 14-24.

Sundeen, R. A., Raskoff, S. A., \& Garcia, M. C. (2007). Differences in perceived barriers to volunteering to formal organizations: Lack of time versus lack of interest. Nonprofit Management and Leadership, 17(3), 279-300.

Taylor, R., \& Shanka, T. (2008). Cause for event: not-for-profit marketing through participant sports events. Journal of Marketing Management, 24(9-10), 945-958. 
Tidwell, M. V. (2005). A social identity model of prosocial behaviors within nonprofit organizations. Nonprofit Management and Leadership, 15(4), 449-467.

Vagias, W. M. (2006). Likert-type scale response anchors. Clemson International Institute for Tourism \& Research Development, Department of Parks, Recreation and Tourism Management, Clemson University.

Vail, S. E. (2007). Community development and sport participation. Journal of Sport Management, 21(4), 571-596.

Valéau, P., Mignonac, K., Vandenberghe, C., \& Gatignon Turnau, A. L. (2013). A study of the relationships between volunteers' commitments to organizations and beneficiaries and turnover intentions. Canadian Journal of Behavioural Science/Revue Canadienne des Sciences du Comportement, 45(2), 85.

Vecina, M. L., Chacón, F., Marzana, D., \& Marta, E. (2013). Volunteer engagement and organizational commitment in nonprofit organizations: what makes volunteers remain within organizations and feel happy? Journal of Community Psychology, 41(3), 291-302.

Weil, P. A., \& Kimball, P. A. (2010). The volunteer activities of healthcare executives. Journal of Healthcare Management, 55(2), 115-131.

Wicker, P., Breuer, C., \& Pawlowski, T. (2009). Promoting sport for all to age-specific target groups: the impact of sport infrastructure. European Sport Management Quarterly, 9(2), 103-118.

Wicker, P., Feiler, S., \& Breuer, C. (2013). Organizational mission and revenue diversification among non-profit sports clubs. International Journal of Financial Studies, 1(4), 119-136. 
Wicker, P., \& Frick, B. (2016). Recruitment and retention of referees in nonprofit sport organizations: The trickle-down effect of role models. Voluntas: International Journal of Voluntary and Nonprofit Organizations, 27(3), 1304-1322.

Wicker, P., \& Hallmann, K. (2013). A multi-level framework for investigating the engagement of sport volunteers. European Sport Management Quarterly, 13(1), 110-139.

Wilson, J. (2012). Volunteerism research: A review essay. Nonprofit and Voluntary Sector Quarterly, 41(2), 176-212.

Wilson, J., \& Musick, M. (1997). Who cares? Toward an integrated theory of volunteer work. American Sociological Review, 694-713.

Wilson, J., \& Musick, M. (1998). The contribution of social resources to volunteering. Social Science Quarterly, 13 (3), 799-814.

Winand, M., Rihoux, B., Qualizza, D., \& Zintz, T. (2011). Combinations of key determinants of performance in sport governing bodies. Sport, Business and Management: An International Journal, 1(3), 234-251.

Winniford, J. C., Carpenter, D. S., \& Grider, C. (1997). Motivations of college student volunteers: A review. NASPA Journal, 34(2), 134-146.

Young, D. R. (2001). Organizational identity and the structure of nonprofit umbrella associations. Nonprofit Management and Leadership, 11(3), 289-304.

Young, D. R. (2001). Organizational identity in nonprofit organizations: Strategic and structural implications. Nonprofit management and leadership, 12(2), 139-157. 


\section{Appendix F}

\section{Nonprofit Organization Summary 1}

American Swimming Coaches Association (ASCA). ASCA is a nonprofit organization that was started in 1958 and it lists the mission of the organization on the organizational website. "The American Swimming Coaches Association provides leadership to American and World Swimming at all levels. ASCA develops and supports professional coaches and quality career opportunities in collaboration with its partners in the world aquatics community. We are an independent professional association based on a central theme of: 'Leadership, Education, and Certification.' We are dedicated to creating and enhancing solutions that are effective in strengthening and improving the coaching profession. American Swimming and World Swimming." The mission of the organization is implemented by the volunteer board of directors and the professional support staff. The board is comprised of many of the leaders in the field. These leaders could be classified in the executive volunteer category.

The methods for achieving the mission are listed in the 14 purposes set forth by ASCA are listed on their website. The organization attempts to meet the needs of the coaching population by offering certifications, clinics, fellowships, and connecting coaches to one another. Educationally ASCA has dual armed five level certification process. The first arm is educational in nature. The coursework begins with basic coaching fundamentals then to rule and stroke basics and progresses into the physiology of swimming, leadership, and administration. Each course is administered by ASCA in a take home format or may be taken at in a clinic setting. The second arm of ASCA is performance related. The higher and more frequently the coach's athletes are successful at specified meets the higher the coach may progress in a performance setting. 


\section{Appendix G}

\section{Nonprofit Organization Summary 2}

\section{The College Swimming Coaches Association of America (CSCAA). The College}

Swimming Coaches Association of America is comprised of collegiate coaches and supporters from all three levels of the NCAA and the National Association of Intercollegiate Athletics (NAIA). Rather than a specific mission statement, the organization lists a purpose statement on their website, "The mission of the corporation shall be to promote collegiate swimming and diving and provide educational, professional and competitive services and opportunities to the membership; and to those generally interested in collegiate aquatic activities." Similar to both ASCA, CSCAA is governed by a board of directors with a paid support staff. One unique caveat to this organization is that membership is restricted to those who are currently coaching in a collegiate environment or honorary, life, or associate memberships that have been granted by the board. The pool of potential volunteers for both board and event activities then diminishes due to the limits placed on the membership. The membership traits for the CSCAA are very unique compared to the other organizations and thereby make them the smallest of the three organizations with approximately 2000 members.

Many of the volunteers for these boards, activities, and events fit the description of the executive volunteer. The social status and recognition of the coaches and volunteers fit the definitions and descriptions outlined. The coaches are typically well-known, from a large school, and have had some level of success in the field. The question that is then postulated becomes, what barriers may prevent one of these executive coaches from volunteering for an event that may help a nonprofit organization in which they are a stakeholder and thereby help them as their sport grows. 


\section{Appendix H}

\section{Participant Invitation Email}

Dear Swimming Coach,

My name is Rick West and I am an assistant swimming coach at WVU. You may have seen or met me at the various meets in which we have crossed paths. I am also a doctoral student in Coaching and Teaching Studies at WVU. I am asking your help and expertise as a swimming coach to complete my dissertation. Your input as an active coach on a Division I coaching staff will lend great value to my study and require very little of your time. Your participation will be completely confidential and you will be a part of a panel of other swimming coaches at similar institutions.

I am conducting a study to identify barriers that Division I swimming coaches feel prevent them from volunteering for nonprofit organization events (i.e. ASCA, CSCAA, USA Swimming...) that may benefit the sport of swimming. Your views on this subject will be collected along with several of your peers in order to reach a consensus (agreement). The information will be gathered electronically via email.

Should you agree to participate in this research you will receive a series of emails (3-4 total) over the next several weeks asking your input as to these barriers that prevent volunteering. Each email may take up to 15 minutes each to answer. Your responses to each email are extremely valued and important, as they are combined with the rest of the panel. The nature of the process makes it very important that you complete each phase of the email responses.

Should you have any questions about the research, wish to voice concerns about this study, or to know more about your rights as a participant you may contact either Dr. Kristen Dieffenbach (Committee Chair), kristen.dieffenbach@mail.wvu.edu or WVU's Office of Research and Integrity at (304)-293-7073 or email at ORIC@ mail.wvu.edu.

I truly do value your input and hope that you are willing and able to participate. If you are interested, you may simply respond to this email. I am also happy to set up a phone call with you to explain the study design and address any questions or concerns. Please respond if you are willing to participate and indicate a day and time that may be appropriate for me to call, if you wish me to explain the rest of the process verbally. Thank you in advance for your help.

Respectfully yours,

Richard (Rick) A. West, MS

Assistant Swimming Coach/Doctoral Student, WVU

304-692-9145

rwest2@mix.wvu.edu 


\section{Appendix I}

\section{Introduction Email}

\section{Swimming Coach,}

Thank you very much for participating in this study. I want to take this opportunity to explain the purpose and processes in which you will be taking part. The objective of this study is to identity barriers of volunteering for collegiate swimming coaches for nonprofit organizations (i.e. ACSCA, CSCAA, USA Swimming...) that may benefit their sport. You have been asked to participate in this study due to your experiences, expertise, and the fact that you represent a potential executive level volunteer.

The potential benefits to nonprofit organizations that support the sport of swimming, is to identify barriers that may prevent a coach from volunteering for an activity and begin to research strategies to mitigate these barriers. Future research may seek methods to overcome those barriers, but the first step is to collectively identify the problem. You have been selected due to your value and position as a Division I swimming coach of a major athletics department.

You will first be asked demographic questions to assist in further categorization of your responses, however, your information will always remain confidential. You will next be asked to identify your personal barriers for participating in the nonprofit example. The prompt will be linked via email and your answers will remain confidential and categorized with additional similar responses. Once all of the participants have responded, I will categorize the data and create a list for the next email.

Second, you will receive an email with all of the responses compiled and asked to rate them according to impact and prevalence. Once again, I will collect all of the responses from everyone and create descriptive statistical data analysis to share with you for the next round.

You will then be presented with the group's cumulative responses to each item and be asked to compare those to your original response. You will then be asked if you would like to alter your original response or keep it the same. Depending upon the results, this final process may be repeated. Your individual time spent on responses will be fairly brief (approximately 15 minutes for each email), however, the length of time the study may last is dependent upon the timeliness of the responses from the coaches.

You will be asked to complete each email prompt within a week. After 10 days I will email and text you to remind you about the prompt. After 2 weeks I will send one final reminder to encourage you to continue with the study. It is imperative that each participant complete all phases of the study to ensure success. Once again, I truly value your input and appreciate your consideration of participation. Now that you are aware of all of the steps and time commitments, if you are still willing to participate in the study I would like you to click on the link below to view the Participant Letter of Consent, fill out the Participant Consent Form, and provide your Demographic Information. Thank you for your willingness to participate and I appreciate your time.

Have a great day!

$\underline{\text { Participant Letter of Consent }}$ 


\section{Appendix J}

\section{Participant Consent Letter}

\section{Participant Letter}

You are being invited to take part in a Delphi research study. Before deciding whether to participate, it is important for you to understand why the research is being conducted and what is involved. Please read the following information carefully. If there is anything that is not clear or you would like any additional information, please let me know before you officially decide whether you would like to join the study.

The purpose of this study is to identity barriers of volunteering for collegiate level coaches for nonprofit organizations that may benefit their sport. The potential benefits to nonprofit organizations that support the sport of swimming, is to identify barriers that may prevent a coach from volunteering for an activity and begin to research strategies to mitigate these barriers. Future research may seek methods to overcome those barriers, but the first step is to collectively identify the problem.

You have been asked to participate in this Delphi study due to the fact that you represent a potential executive level volunteer. Your position as a Division I swimming coach of a major athletics department align with the traditional characteristics of an individual who would be deemed an executive level volunteer.

It is up to you whether or not you participate in the study and there is no obligation. If you decide to participate you will complete this partcipant form, consent form, and demographics information. If you decide to take part in the study and subsequently withdraw you will not have to give a reason and be permitted to withdraw.

The research will be carried out using the Delphi technique consisting of questionnaires (known as rounds) aimed to achieve consensus of a panel of experts. After receipt of the consent form you will be sent to the first questionnaire. Simple and specific instructions will accompany each questionnaire

The amount of time to complete each questionnaire will vary with each round and panelist; but should range from 15-20 minutes for Round 1, 10-15 minutes for Round 2, and 5-10 minutes for Round 3. There is no right or wrong answer for the questions provided, the study seeks your expert opinion. At the conclusion you will be asked to participate in a short interview to further clarify your responses. Once again, your participation will be optional.

The following are points to remember: 
- Your participation is entirely voluntary.

- You may withdraw from the study at any time.

- You will remain anonymous to other experts (panelists) throughout the study and only the researcher will know your identity.

- All records are confidential. Your name will only be recorded on the consent form; it will not be recorded on the questionnaire. The information will only be available to members of the research team. All information will be destroyed 5 years after the research is complete.

- Any information that you provide will be confidential and when the results of the study are reported, you will not be identifiable in the findings.

- Following the study information gathered will be sent for publication in a professional journal and sent for submission at professional conferences. All details about those who participated in the study will be kept anonymous.

- You only have to complete the consent form once; return of completed Delphi questionnaires implies your continued consent.

There are no known risks or complications associated with the Delphi or your taking part in this study. If you decide to take part in the study you will be given the names and contact information for those with whom you may wish to log a complaint. As the principle investigator you may always contact me with any administrative or organizational questions that you may have during the process.

Richard (Rick) A. West

WVU Assistant Swimming Coach/Doctoral Student

rwest2@ $\underline{\text { mix.wvu.edu }}$

304-692-9145

If you have any complaints or issues regarding this study you may contact:

Dr. Kristen Dieffenbach (Committee Chair)

kristen.dieffenbach@ mail.wvu.edu

304-293-0847 or

WVU's Office of Research and Integrity

(304)-293-7073

ORIC@mail.wvu.edu.

*West Virginia University's Review Board approval of this project is on file.

Approved:10-Oct-2019 Expires: 9-Oct-2024 Number:1909714263 


\section{Appendix K}

\section{Participant Consent Form}

\section{Conditions for Study Participation:}

1. I Confirm that I have read and understood the Participant Letter of Consent for the study. I have had the opportunity to consider the information, ask questions and have had these answered satisfactorily.

2. I am willing to participate in all rounds of the Delphi study and the follow-up stages.

3. I understand that my participation is voluntary and that I am free to withdraw at any time, without giving reason. However, I understand that the success of this study depends on all participants completing all rounds.

4. I understand that I will remain anonymous to the other participants (or experts) throughout this Delphi study and only the researchers will be able to identify my specific answers.

5. I understand that the researcher will hold all information and data collected in a secure and confidential manner.

I agree to the above conditions.

I do not wish to participate in the study. 


\title{
Letter of Consent
}

\author{
Principal Investigator (PI) $\mid$ Richard A. West \\ Department College of Physical Activity and Sport Science \\ WVU IRB Protocol \# $\quad 1909714263$ \\ Study Title $\quad$ Barriers of Volunteerism for Coaches of Collegiate Division I Swimming Programs
}

\section{Why is this research being done and what is involved?}

\begin{abstract}
The purpose of this study is to identify barriers that Division I swimming coaches feel prevent them from volunteering for nonprofit organization events (ie. ASCA, CSCAA, USA Swimming...) that may benefit the sport of swimming. Your views on this subject will be collected along with several of your peers in order to reach a consensus (agreement). Should you agree to participate, you will receive a series of emails (4) with links to surveys for your completion. Each survey may take up to 10-15 minutes to complete. Your information and answers will be entirely confidential from other participants. The emails will come to you every 5-7 weeks, depending upon how quickly surveys are completed and information analyzed. The last email will ask you to complete a voluntary interview to discuss the results of the study. Once again, the interview will be completely confidential.
\end{abstract}

\section{Do I have to participate and what are the risks?}

Participation in this research study is completely voluntary and you are free to withdraw from the research at any time. You may or may not directly benefit from participating in this research.

Risks from participation in this study include, a lack of interest in this topic or the time required to complete the process.

\section{Will I be compensated for my participation?}

You will not be paid or otherwise compensated for this research.

Your personal information is confidential and all indicators att aching you to your specific data will be kept confidential. Your data, health information, research results, specimens, or any and all other information related to this research study used in this research study may contribute to a new discovery or treatment. In some instances, your data, your health information, your research results, your specimens, these discoveries or treatments, or any other information related to this research study, even if identifiers are removed, may be of commercial value and may be sold, patented, or licensed by the investigators and West Virginia University for use in other research or the development of new products. You will not retain any property rights, nor will you share in any money or commercial profit that the investigators, West Virginia University, or their agents may realize.

\section{What will happen to my research information and data?}

All of your information will remain anonymous to other experts (panelists) throughout the study and only the researcher will know your identity. All records are confidential. Your name will only be recorded on the consent form; it will not be recorded on the questionnaire. The information will only be available to members of the research team. All information will be destroyed 5 years after the research is complete. All information that you provide will be confidential and when the results of the study are reported, you will not be identifiable in the findings.

Any information about you that is obtained as a result of your participation in this research will be kept as confidential as legally possible. Your research records and test results, just like hospital records, may be subpoenaed by court order or may be inspected by the study sponsor or federal regulatory authorities without your additional consent.

In addition, there are certain instances where the researcher is legally required to give information to the appropriate authorities. These would include mandatory reporting of infectious diseases, mandatory reporting of information about behavior that is imminently dangerous to you or to others, such as suicide, child abuse, etc.

Audiotapes or videotapes will be kept locked up and will be des troyed as soon as possible after the research is finished. In any publications that result from this research, neither your name nor any information from which you might be identified will be published without your consent. 
Who can I talk to if I have questions or concerns?

Richard (Rick) A. West

WVU Assistant Swimming Coach/Doctoral Student

rwest2@mix.wvu.edu

304-692-9145

If you have any questions or concerns about this research, you can contact Dr. Kristen Dieffenbach during office hours (Monday, 11:00am-Noon, Wednesday, 2:00pm-3:00pm, or Friday, 9:30am-11:00am) at 304-293-7073 or email at kristen.dieffenbach@mail.wvu.edu . Dr. Kristen Dieffenbach is a member of the College of Physical Activity and Sport Science, at West Virginia University.

For information regarding your rights as a participant in resea rch or to talk about the research, contact the WVU Office of Human Research Protection (OHRP) at (304) 293-7073 or by email at IRB@ mail.wvu.edu.

\section{Signatures}

You have been given the opportunity to ask questions about the research and you have received answers concerning areas you did not understand. Upon signing this form, you will receive a copy.

\section{Participant Signature}

I willingly agree to participate in this research.

I am not willing to participate in this research. 
Appendix L

\section{Demographic Information}

\section{Demographic Information}

Please provide the following demographic information. Once again, any personal information that may identify you will remain confidential.

To which gender identity do you most identify:

Male

Female

Other

Prefer not to answer

What is your current age (You may leave blank if you prefer not to answer):

Number of years at present institution:

Number of years at present institution in your current role:

Number of years coaching at a power five division I institution:

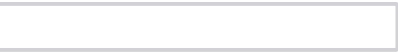

Number of years coaching (any level):

On average, the number of nonprofit (any nonprofit) events that you typically have volunteered for in given year. A nonprofit organization is one that is not tied to government or seeking to 
make a profit for shareholders:

On average, the number of swimming nonprofit events that you volunteered for in a given year. A nonprofit organization is one that is not tied to government or seeking to make a profit for shareholders: 


\section{Appendix M}

\section{Round I Survey Landing Page}

Swim Coach, thank you once again for your participation in this research.

The purpose of this study is to identity barriers of volunteering for collegiate level swimming coaches for nonprofit organizations that may benefit their sport. The potential benefits to nonprofit organizations that support the sport of swimming, is to identify barriers that may prevent a coach from volunteering for an activity and begin to research strategies to mitigate these barriers. Future research may seek methods to overcome those barriers, but the first step is to collectively identify the problem.

You have been asked to participate in this Delphi study due to the fact that you represent a potential executive level volunteer. Your position as a Division I swimming coach of a major athletics department align with the traditional characteristics of an individual who would be deemed an executive level volunteer. You are a part of a larger panel of your peers completing this study.

\section{Round I}

The amount of time to complete each questionnaire will vary with each panelist; but should range from 15-20 minutes for Round 1. You will be asked to respond to a prompt asking about a scenario in which you may volunteer and what barriers may prevent you from volunteering. You will be permitted to provide as many responses as you like to the scenario. There are no right or wrong answers for the question. The study seeks your expert opinion as to barriers that may prevent your participation.

\section{Study Schedule Summary}

In order to keep the study on track, you are asked to respond to the round I questionnaire within one week. If you have not responded after 10 days you will receive a reminder email, text message, and phone call to encourage your responses and to answer any questions or issues that may be present.

If there is no response after two weeks, (a) you will receive an email and text message encouraging your participation in the study and requesting the survey completion, (b) allotted an extension for participation in order to attain the highest participation rate possible, and (c) a phone call to reinforce participation in the study.

Round II will be sent in approximately 5-7 weeks and contain the grouped version of all the panelists round I responses. You will then be asked to rate the collected items on two distinct scales.

Round III will occur once the Round II data is collected and analyzed. 
If you have questions regarding the administrative process or procedures, you may contact the doctoral student:

Richard (Rick) A. West

WVU Assistant Swimming Coach/Doctoral Student

rwest2@mix.wvu.edu

304-692-9145

If you have any complaints or issues regarding this study, you may contact:

Dr. Kristen Dieffenbach (Committee Chair)

kristen.dieffenbach@mail.wvu.edu

304-293-0847 or

WVU's Office of Research and Integrity

(304)-293-7073

ORIC@mail.wvu.edu.

Thank you once again for your continued participation and click the link below to begin:

$\underline{\text { Round I Questionnaire }}$ 


\section{Appendix N}

\section{Round I Questionnaire}

\section{Round I Questionnaire-Barrier 1}

\section{Round I Questionnaire}

\section{Round I Questionnaire}

Instructions: In a few words please respond to the scenario provided. You will be provided with general examples of barriers that typically prevent an individual from volunteering to use as thought starters. You are being asked to provide barriers that are specific to you and your position. You may provide as many responses as you like to the scenario. If for you run out of space or do not have enough fields to include all your barriers, please email rwest2@mix.wvu.edu to have an additional questionnaire sent so that additional responses may be added.

Scenario: A swimming nonprofit organization (ie. ASCA, CSCAA, USA Swimming, etc...) is attempting to host an event close to your campus that would promote the sport of swimming. The organization is asking for your help to assist with the event due to your role as a coach for your institution. Please consider the following prompt and answer what BARRIERS would PREVENT you from volunteering for this event. Please assume that no NCAA rules would be violated if you were able to participate:

The following are examples of common barriers that generally occur in volunteering. These are provided as thought starters for you to make specific for yourself and your life. Also, take into consideration your position as a swimming coach in a major athletic department:

Barriers related to personal resources pertain to the human capital of the individual and all items related to that individual. Examples of these may include: discretionary time, income, education, or job duties.

Barriers related to social ties pertain to the extent that an individual is integrated into the community. Examples of these may include: family responsibilities, organizations, groups, or civic duties.

Barriers related to cultural resources pertain to the beliefs and values instilled within you as an individual. Examples of these may include: cultural upbringing, ethnicity, morals, or notion to help others. 
Barriers related to mixed resources pertain to items that may be pervasive regardless of setting or multiple boundaries. Examples of these may include: age, health issues, gender, or roles related to age or gender.

Barriers related to residential context relates to the community's offerings, attributes, and support. Examples of these may include: residential, work, or professional.

Using the scenario above, and considering the your position as a Division I Swimming Coach, what SPECIFIC BARRIER would prevent you from volunteering for this event ?

(One Barrier per field please)

Additional BARRIERS may be provided by clicking ADD BARRIER or you may complete the survey by clicking COMPLETE.

ADD BARRIER

COMPLETE

Thank you once again. You will receive an email for Round II in approximately 5-7 weeks once all of the panelists have responded to Round I and the answers are grouped. 


\section{Appendix O}

\section{Round II Landing Page}

Swim Coach, thank you once again for your participation in this research.

The purpose of this study is to identity barriers of volunteering for collegiate level swimming coaches for nonprofit organizations that may benefit their sport. The potential benefits to nonprofit organizations that support the sport of swimming, is to identify barriers that may prevent a coach from volunteering for an activity and begin to research strategies to mitigate these barriers. Future research may seek methods to overcome those barriers, but the first step is to collectively identify the problem.

You have been asked to participate in this Delphi study due to the fact that you represent a potential executive level volunteer. Your position as a Division I swimming coach of a major athletics department align with the traditional characteristics of an individual who would be deemed an executive level volunteer. You are a part of a larger panel of your peers completing this study.

During Round I you submitted the barriers that may have prevented you from volunteering for an event sponsored by a nonprofit organization that benefits your sport. The responses you have submitted have been grouped with those of your peers in order to create a list that will be utilized in Round II.

\section{Round II}

The amount of time to complete each questionnaire will vary with each panelist; but should range from 10-15 minutes for Round II. You will rate the items provided on a Likert scale as presented in order to determine those barriers that are the most IMPACTFUL and PREVALENT from preventing you participating in a nonprofit organization event. There are no right or wrong answers for the questions provided. The study seeks your expert opinion

\section{Study Schedule Summary}

In order to keep the study on track, you are asked to respond to the round II survey within one week. After 10 days you will receive a reminder email, text message, and phone call to prompt responses and to answer any questions or issues that may be present.

After two weeks, (a) you will receive an email and text message encouraging your participation in the study and requesting the survey completion, (b) allotted an extension to participate in order to attain the highest participation rate possible, (c) a phone call to reinforce participation in the study.

Round III will be sent in approximately 4 weeks and contain rating results from Round II.

Thank you once again for your continued participation. 
If you have questions regarding the administrative process or procedures, you may contact the doctoral student:

Richard (Rick) A. West

WVU Assistant Swimming Coach/Doctoral Student

rwest2@mix.wvu.edu

304-692-9145

If you have any complaints or issues regarding this study, you may contact:

Dr. Kristen Dieffenbach (Committee Chair)

kristen.dieffenbach@mail.wvu.edu

304-293-0847 or

WVU's Office of Research and Integrity

(304)-293-7073

ORIC@mail.wvu.edu.

Thank you once again for your continued participation and click the link below to begin:

$\underline{\text { Round II Questionnaire }}$
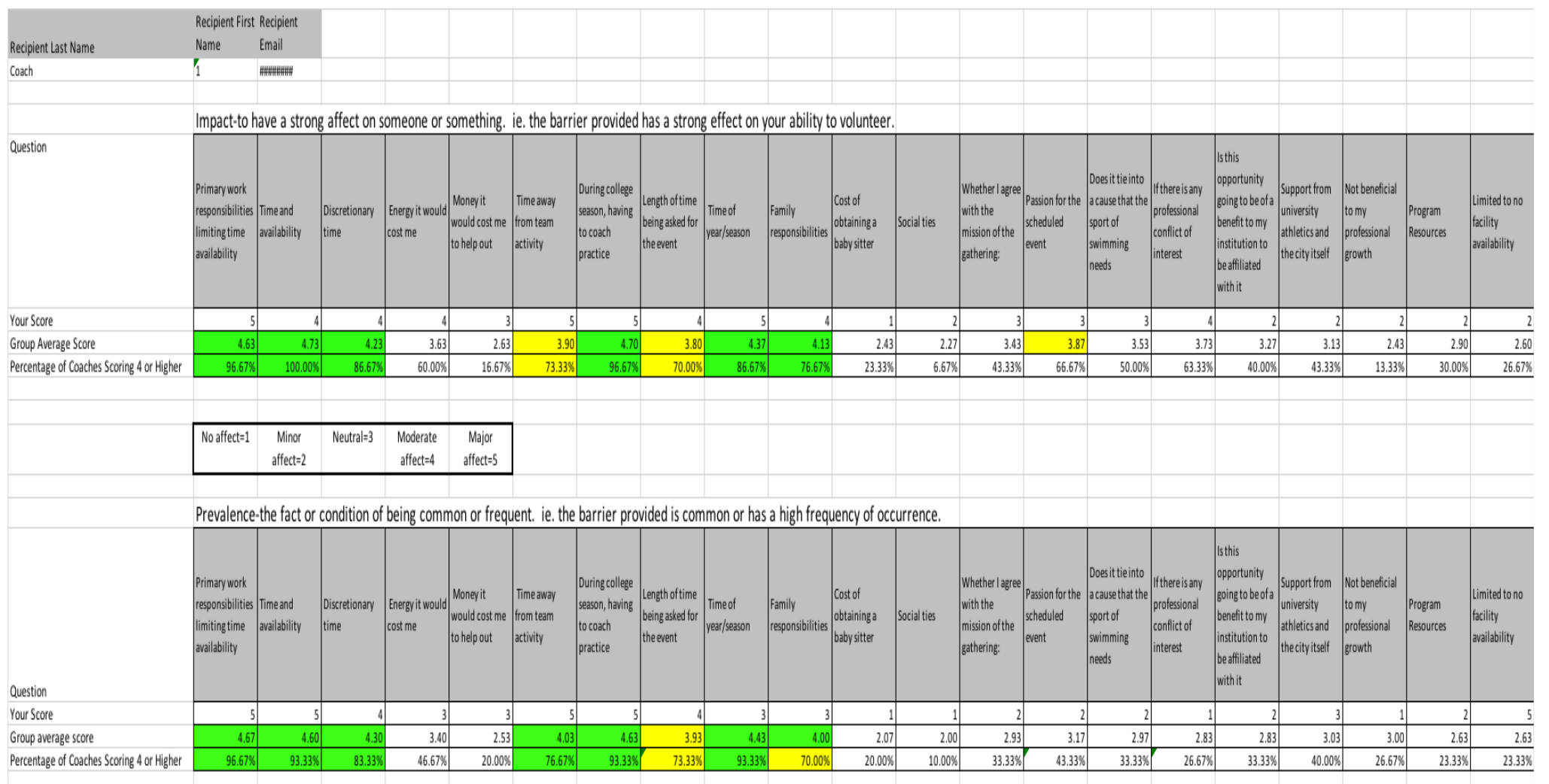


\section{Appendix P}

\section{Round II Questionnaire}

Instructions: You will be asked to rate the responses collected from the panel during Round I. Responses submitted during Round I were grouped to prepare a more concise and manageable list. Each item will be ranked twice while you consider the item's IMPACT and PREVALENCE. Definitions of both IMPACT and PREVALENCE are provided for clarity and consistency.

\section{Definitions:}

Impact-to have a strong affect on someone or something. ie. the barrier provided has a strong effect on your ability to volunteer.

Prevalence-the fact or condition of being common or frequent. ie. the barrier provided is common or has a high frequency of occurrence.

Impact-to have a strong affect on someone or something. ie. the barrier provided has a strong effect on your ability to volunteer.

\begin{tabular}{|c|c|c|c|c|c|}
\hline & & & Impact & & \\
\hline & No affect & Minor affect & Neutral & $\begin{array}{c}\text { Moderate } \\
\text { affect }\end{array}$ & Major affect \\
\hline $\begin{array}{l}\text { Primary work } \\
\text { responsibilities limiting } \\
\text { time availability: This } \\
\text { item's Impact on my } \\
\text { volunteer habit has: }\end{array}$ & 0 & 0 & 0 & 0 & 0 \\
\hline $\begin{array}{l}\text { Time and availability: } \\
\text { This item's Impact on } \\
\text { my volunteer habit } \\
\text { has: }\end{array}$ & 0 & 0 & 0 & 0 & $\mathrm{O}$ \\
\hline $\begin{array}{l}\text { Discretionary time: } \\
\text { This item's Impact on } \\
\text { my volunteer habit } \\
\text { has: }\end{array}$ & 0 & 0 & 0 & 0 & 0 \\
\hline $\begin{array}{l}\text { Energy it would cost } \\
\text { me: This item's Impact } \\
\text { on my volunteer habit } \\
\text { has: }\end{array}$ & 0 & 0 & 0 & 0 & 0 \\
\hline
\end{tabular}




No affect Minor affect Neutral $\begin{gathered}\text { Moderate } \\ \text { affect } \quad \text { Major affect }\end{gathered}$

Money it would cost me to help out: This item's Impact on my volunteer habit has:

Time away from team activity: This item's Impact on my volunteer habit has:

During college season, having to coach practice: This item's Impact on my volunteer habit has:

Length of time being asked for the event: This item's Impact on my volunteer habit has:

Time of year/season: This item's Impact on my volunteer habit

has:

Family responsibilities: This item's Impact on my volunteer habit has:

Cost of obtaining a baby sitter: This item's Impact on my volunteer habit has:

Social ties: This item's Impact on my volunteer habit has:

Whether I agree with the mission of the gathering: This item's Impact on my volunteer habit has:

Passion for the scheduled event: This item's Impact on my volunteer habit has: 


No affect
$\begin{aligned} & \text { Does it tie into a cause } \\ & \text { that the sport of } \\ & \text { swimming needs: This } \\ & \text { item's Impact on my } \\ & \text { volunteer habit has: } \\ & \text { If there is any } \\ & \text { professional conflict of } \\ & \text { interest: This item's }\end{aligned}$
$\begin{aligned} & \text { Impact on my } \\ & \text { volunteer habit has: }\end{aligned}$

Prevalence-the fact or condition of being common or frequent. ie. the barrier provided is common or has a high frequency of occurrence.

Prevalence 


$\begin{array}{llcc}\text { Never } & \text { Rarely } & \begin{array}{c}\text { Prevalence } \\ \text { Occaisonally }\end{array} & \begin{array}{c}\text { A moderate } \\ \text { amount }\end{array} \text { A great deal } \\ \text { Never } & \text { Rarely } & \text { Occaisonally } & \begin{array}{c}\text { A moderate } \\ \text { amount }\end{array} \text { A great deal }\end{array}$

Primary work responsibilities limiting time availability: This item being a barrier to my volunteerism has

a Prevalence of:

Time and

availability: This item being a barrier to my volunteerism has

a Prevalence of:

Discretionary

time: This item being a barrier to my

volunteerism has

a Prevalence of:

Energy it would cost me: This item being a barrier to my volunteerism has a Prevalence of:

Money it would cost me to help out: This item being a barrier to my volunteerism has a Prevalence of:

Time away from team activity: This item being a barrier to my volunteerism has a Prevalence of:

During college season, having to coach practice: This item being a barrier to my volunteerism has a Prevalence of:

Length of time being asked for the event: This item being a barrier to my volunteerism has

a Prevalence of: 
Prevalence

Never Rarely Occaisonally $\begin{gathered}\text { A moderate } \\ \text { amount }\end{gathered}$ A great deal

Time of year/season: This item being a barrier to my volunteerism has

a Prevalence of:

Family

responsibilities: This item being a barrier to my volunteerism has

a Prevalence of:

Cost of obtaining a baby sitter: This item being a barrier to my volunteerism has

a Prevalence of:

Social ties: This item being a barrier to my volunteerism has a Prevalence of:

Whether I agree with the mission of the gathering: This item being a barrier to my volunteerism has a Prevalence of:

Passion for the scheduled event: This item being a barrier to my volunteerism has a Prevalence of:

Does it tie into a cause that the sport of swimming needs: This item being a barrier to my volunteerism has a Prevalence of:

If there is any professional conflict of interest: This item being a barrier to my volunteerism has

a Prevalence of: 


\section{Prevalence}

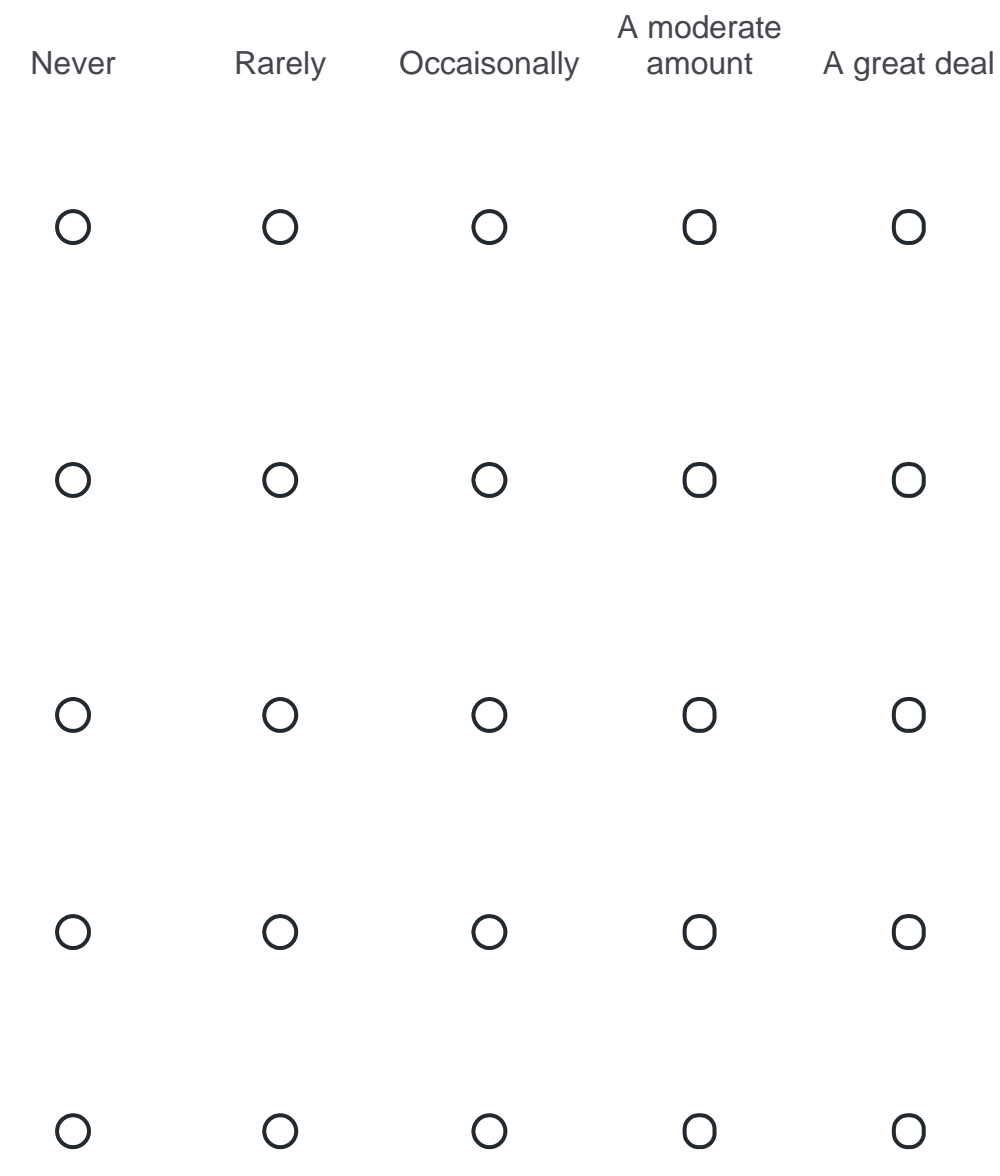

Is this opportunity going to be of a benefit to my institution to be affiliated with it: This item being a barrier to my volunteerism has a Prevalence of:

Support from university athletics and the city itself: This item being a barrier to my volunteerism has a Prevalence of:

Not beneficial to my professional growth: This item being a barrier to my volunteerism has a Prevalence of:

Program Resources: This item being a barrier to my volunteerism has a Prevalence of:

Limited to no facility availability: This item being a barrier to my volunteerism has a Prevalence of: 


\section{Appendix Q}

\section{Round III Landing Page}

Swim Coach, thank you once again for your participation in this research.

The purpose of this study is to identity barriers of volunteering for collegiate level swimming coaches for nonprofit organizations that may benefit their sport. The potential benefits to nonprofit organizations that support the sport of swimming, is to identify barriers that may prevent a coach from volunteering for an activity and begin to research strategies to mitigate these barriers. Future research may seek methods to overcome those barriers, but the first step is to collectively identify the problem.

You have been asked to participate in this Delphi study due to the fact that you represent a potential executive level volunteer. Your position as a Division I swimming coach of a major athletics department align with the traditional characteristics of an individual who would be deemed an executive level volunteer. You are a part of a larger panel of your peers completing this study.

During Round II you rated each item from Round I in terms of Impact and Prevalence. The Round II the responses of the entire panel will be shared with you for each item for both impact and prevalence. You will also be shown your responses from Round II as well. All panelists will have the opportunity to reconsider their answers in light of the group responses.

\section{Round III}

The amount of time to complete each questionnaire will vary with each round and panelist but should range from 5-10 minutes for Round III. You will be viewing each item from Round II and both the group response and your personal response. You will then be asked to reconsider your answer now that you have viewed the group response. You may leave your answer exactly the same, raise your score, or lower your score for that item. The main focus of the study is to find a consensus (agreement) among you and your peers as to both the impact and prevalence of that barrier on your ability to volunteer for a nonprofit event that benefits your sport. Items that reach a mean score of 4.0 and have at least $75 \%$ of the panel with a score of 4.0 or higher will have met the standard of consensus (agreement) for that particular rating either impact or prevalence. Once again, you are not required to change your score, you are merely being asked to reconsider it, now that the group's results are shared with you.

\section{Study Schedule Summary}

In order to keep the study on track, you are asked to respond to the round III survey within one week. After 10 days you will receive a reminder email, text message, and phone call to prompt responses and to answer any questions or issues that may be present.

After two weeks, (a) you will receive an email and text message encouraging your participation in the study and requesting the survey completion, (b) allotted an extension to 
participate in order to attain the highest participation rate possible, (c) a phone call to reinforce participation in the study.

The level of consensus (agreement) that occurs during Round III will determine if items reach a group level of agreement. You will receive an email from in in four to five weeks with the summary of the findings from this study. Thank you once again for your participation and I look forward to speaking with you again soon.

If you have questions regarding the administrative process or procedures, you may contact the doctoral student:

Richard (Rick) A. West

WVU Assistant Swimming Coach/Doctoral Student

rwest2@mix.wvu.edu

304-692-9145

If you have any complaints or issues regarding this study, you may contact:

Dr. Kristen Dieffenbach (Committee Chair)

kristen.dieffenbach@mail.wvu.edu

304-293-0847 or

WVU's Office of Research and Integrity

(304)-293-7073

ORIC@mail.wvu.edu.

$\underline{\text { Round III Questionnaire }}$ 
Appendix R

\section{Round III Questionnaire}

Instructions: You will be asked to reconsider your original response (see attached file-Your Score) from Round II as you compare it to the panel's overall response (see attached file-Group Average Score) from Round II. You may leave your score as is, raise, or lower your score based off of this new information. Once again you will be rating each item twice in terms of impact and prevalence. The objective of this round is to find consensus (agreement) as to those barriers that are prevalent and impact your ability to volunteer for a nonprofit organization's event that benefits your sport.

\section{Definitions:}

Impact-to have a strong affect on someone or something. ie. the barrier provided has a strong effect on your ability to volunteer.

Prevalence-the fact or condition of being common or frequent. ie. the barrier provided is common or has a high frequency of occurrence.

\section{Example:}

Item \# 1 Barrier

Your Score-Impact=4

Group Average Score-Impact $=4.07$

Percentage of Coaches Scoring 4 or Higher $=85.5 \%$

Your Score Prevalence=4

Group Average Score-Prevalence=4.13

Percentage of Coaches Scoring 4 or Higher $=95.5 \%$

Items that reach a mean score of 4.0 and have at least $75 \%$ of the panel with a score of 4.0 or higher will have met the standard of consensus (agreement) for that particular rating either impact or prevalence. Once again, you are not required to change your score, you are merely being asked to reconsider it, now that the group's results are shared with you.

Thank you once again. You will receive an email in approximately three to four weeks with a summary of the entire study. 
Impact-to have a strong affect on someone or something. ie. the barrier provided has a strong effect on your ability to volunteer.

$\begin{array}{ccc} & \text { Impact } & \\ \text { No affect } \quad \text { Minor affect } & \text { Neutral } & \begin{array}{c}\text { Moderate } \\ \text { affect } \quad \text { Major affect }\end{array}\end{array}$

Primary work responsibilities limiting time availability: This item's Impact on my volunteer habit has:

Time and availability: This item's Impact on my volunteer habit has:

Discretionary time: This item's Impact on my volunteer habit has:

Energy it would cost me: This item's Impact on my volunteer habit has:
O
$\mathrm{O}$

O

O

O

Money it would cost me to help out: This item's Impact on my volunteer habit has:

Time away from team activity: This item's Impact on my volunteer habit has:

During college season, having to coach practice: This item's Impact on my volunteer habit has:

Length of time being asked for the event: This item's Impact on my volunteer habit has:

Time of year/season: This item's Impact on my volunteer habit has: 


$\begin{array}{ccc} & \text { Impact } & \\ \text { No affect } \quad \text { Minor affect } & \text { Neutral } & \text { Moderate } \\ \text { affect } \quad \text { Major affect }\end{array}$

Family responsibilities: This item's Impact on my volunteer habit has:

Cost of obtaining a baby sitter: This item's Impact on my volunteer habit has:

Social ties: This item's Impact on my volunteer habit has:

Whether I agree with the mission of the gathering: This item's Impact on my volunteer habit has:

Passion for the scheduled event: This item's Impact on my volunteer habit has:

Does it tie into a cause that the sport of swimming needs: This item's Impact on my volunteer habit has:

If there is any professional conflict of interest: This item's Impact on my volunteer habit has:

Is this opportunity going to be of a benefit to my institution to be affiliated with it: This item's Impact on my volunteer habit has:

Support from university athletics and the city itself: This item's Impact on my volunteer habit has: 


\begin{tabular}{|c|c|c|c|c|c|}
\hline & & & Impact & & \\
\hline & No affect & Minor affect & Neutral & $\begin{array}{c}\text { Moderate } \\
\text { affect }\end{array}$ & Major affect \\
\hline $\begin{array}{l}\text { Not beneficial to my } \\
\text { professional growth: } \\
\text { This item's Impact on } \\
\text { my volunteer habit } \\
\text { has: }\end{array}$ & 0 & 0 & 0 & 0 & 0 \\
\hline $\begin{array}{l}\text { Program Resources: } \\
\text { This item's Impact on } \\
\text { my volunteer habit } \\
\text { has: }\end{array}$ & 0 & 0 & 0 & 0 & 0 \\
\hline $\begin{array}{l}\text { Limited to no facility } \\
\text { availability: This item's } \\
\text { Impact on my } \\
\text { volunteer habit has: }\end{array}$ & 0 & 0 & 0 & 0 & 0 \\
\hline
\end{tabular}

Prevalence-the fact or condition of being common or frequent. ie. the barrier provided is common or has a high frequency of occurrence.

Prevalence
Never Rarely Occaisonally $\begin{gathered}\text { A moderate } \\ \text { amount }\end{gathered}$ A great deal

Primary work responsibilities limiting time availability: This item being a barrier to my volunteerism has a Prevalence of:

Time and availability: This item being a barrier to my volunteerism has a Prevalence of:

Discretionary time: This item being a barrier to my volunteerism has a Prevalence of: 


\section{Prevalence}

Never

Rarely

Occaisonally

A moderate

amount

A great deal

Energy it would cost me: This item being a barrier to my

volunteerism has

a Prevalence of:

Money it would cost me to help out: This item being a barrier to my volunteerism has a Prevalence of:

Time away from team activity: This item being a barrier to my volunteerism has

a Prevalence of:

During college season, having to coach practice: This item being a barrier to my volunteerism has a Prevalence of:

Length of time being asked for the event: This item being a barrier to my volunteerism has a Prevalence of:

Time of year/season: This item being a barrier to my volunteerism has a Prevalence of:

Family responsibilities: This item being a barrier to my volunteerism has a Prevalence of:

Cost of obtaining a baby sitter: This item being a barrier to my volunteerism has a Prevalence of:

O

O

O

O

O

O

O

O

O

O

O

O

O

0

0

0

O

O

O

0

0

O

0

0

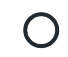

0

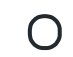




\section{Prevalence}

Never Rarely Occaisonally amount A great deal

Social ties: This item being a barrier to my volunteerism has

a Prevalence of:

Whether I agree with the mission of the gathering: This item being a barrier to my volunteerism has a Prevalence of:

Passion for the scheduled event: This item being a barrier to my volunteerism has

a Prevalence of:

Does it tie into a cause that the sport of swimming needs: This item being a barrier to my volunteerism has a Prevalence of:

If there is any professional conflict of interest: This item being a barrier to my volunteerism has a Prevalence of:

Is this opportunity going to be of a benefit to my institution to be affiliated with it: This item being a barrier to my volunteerism has a Prevalence of:

Support from university athletics and the city itself: This item being a barrier to my volunteerism has a Prevalence of: 


\begin{tabular}{|c|c|c|c|c|c|}
\hline & & & Prevalence & & \\
\hline & Never & Rarely & Occaisonally & $\begin{array}{l}\text { A moderate } \\
\text { amount }\end{array}$ & A great deal \\
\hline $\begin{array}{l}\text { Not beneficial to my } \\
\text { professional } \\
\text { growth: This item } \\
\text { being a barrier to my } \\
\text { volunteerism has } \\
\text { a Prevalence of: }\end{array}$ & 0 & 0 & 0 & 0 & 0 \\
\hline $\begin{array}{l}\text { Program } \\
\text { Resources: This item } \\
\text { being a barrier to my } \\
\text { volunteerism has } \\
\text { a Prevalence of: }\end{array}$ & 0 & 0 & 0 & $\mathrm{O}$ & $\mathrm{O}$ \\
\hline $\begin{array}{l}\text { Limited to no facility } \\
\text { availability: This item } \\
\text { being a barrier to my } \\
\text { volunteerism has } \\
\text { a Prevalence of: }\end{array}$ & 0 & 0 & 0 & 0 & 0 \\
\hline
\end{tabular}




\section{Appendix S}

\section{Summary of Results}

Swim Coach, thank you once again for your participation in this research.

The purpose of this study is to identity barriers of volunteering for collegiate level swimming coaches for nonprofit organizations that may benefit their sport. The potential benefits to nonprofit organizations that support the sport of swimming, is to identify barriers that may prevent a coach from volunteering for an activity and begin to research strategies to mitigate these barriers. Future research may seek methods to overcome those barriers, but the first step is to collectively identify the problem.

You have been asked to participate in this Delphi study due to the fact that you represent a potential executive level volunteer. Your position as a Division I swimming coach of a major athletics department aligns with the traditional characteristics of an individual who would be deemed an executive level volunteer. You are a part of a larger panel of your peers completing this study. The Delphi is a group process for dealing with complex issues through structured communication whereby there is: (a) some feedback on individual contributions, (b) some assessment of group judgment, (c) some opportunity for individuals to revisit views, and (d) a degree of anonymity for individual responses (Linstone \& Turoff, 1975).

During this study you were asked for your own personal feedback during first round. The second round presented you with the grouped responses from everyone in round one. You were then asked to rate all of the items in terms of impact and prevalence. During round three you were presented with your individual ratings and that of the group from round two so that you may reconsider and possibly rerate the items. Items that reached a mean of 4.0 or higher were said to have reached consensus (agreement) and those not reaching consensus were discarded.

You will now be presented all of the items that reached consensus (agreement) and I would like to invite you to participate in a brief verification interview to expand on your answers. Should you agree to the verification interview simply respond to this email with a day and time that would be appropriate for a phone call. The interview will take no more than a halfhour of your time and I sincerely appreciate your assistance in advance. Thank you once again for your assistance and time during this study. Please feel free to contact me with any questions at all.

Richard (Rick) A. West

WVU Assistant Swimming Coach/Doctoral Student rwest2@mix.wvu.edu

304-692-9145 


\section{Summary of Results:}

Items that reached consensus:

(Mean response of 4.0 and were at least a 4.0 on $75 \%$ of the panel's responses)

\section{Items reaching consensus for both Impact and Prevalence:}

Item 1 - Primary work responsibilities limiting time availability (I-4.57/100\%) (P-4.53/93.33\%)

Item 2- Time and availability (I-4.70/100\%) (P-4.70/100\%)

Item 3- Discretionary time (4.0/76.67\%) (P-4.10/76.67\%)

Item 7- During college season, having to coach practice (I-4.70/96.67\%) (P-4.67/96.67\%)

Item 8- Length of time being asked for the event (I-4.0/76.67\%) (P-4.2/80\%)

Item 9- Time of year/season (I-4.50/90\%) (P-4.60/96.67\%)

Item 10- Family responsibilities (I-4.10/80\%) (P-4.23/83.33\%)

\section{Items reaching consensus for Prevalence only:}

Item 6-Time Away from team activity (4.27/80\%)

Of the 21 items created by the panel during Round I, 7 reached consensus as both impactful and prevalent during Round III with only 1 item meeting consensus for prevalence only.

Of the 5 items (Items: 1,2,3, 7, \& 9) reaching consensus during Round II all 5 reached consensus again during Round III.

Item 6 reached consensus during both Round II and III for Prevalence only.

Item 8 did not reach consensus for Impact or Prevalence during Round II but did so during Round III.

Item 10 did reach consensus for Impact but no Prevalence during Round III. However, the item did reach consensus for both indicators during Round III.

\section{Items reaching consensus for both Impact and Prevalence:}

Item 1-Primary work responsibilities limiting time availability -Personal Resource

Item 2- Time and availability -Personal Resource

Item 3-Discretionary time-Personal Resource

Item 7-During college season, having to coach practice -Personal Resource

Item 8- Length of time being asked for the event-Personal Resource

Item 9- Time of year/season-Personal Resource

Item 10- Family responsibilities -Social Ties

Items reaching consensus for Prevalence only:

Item 6-Time Away from team activity-Personal Resource 


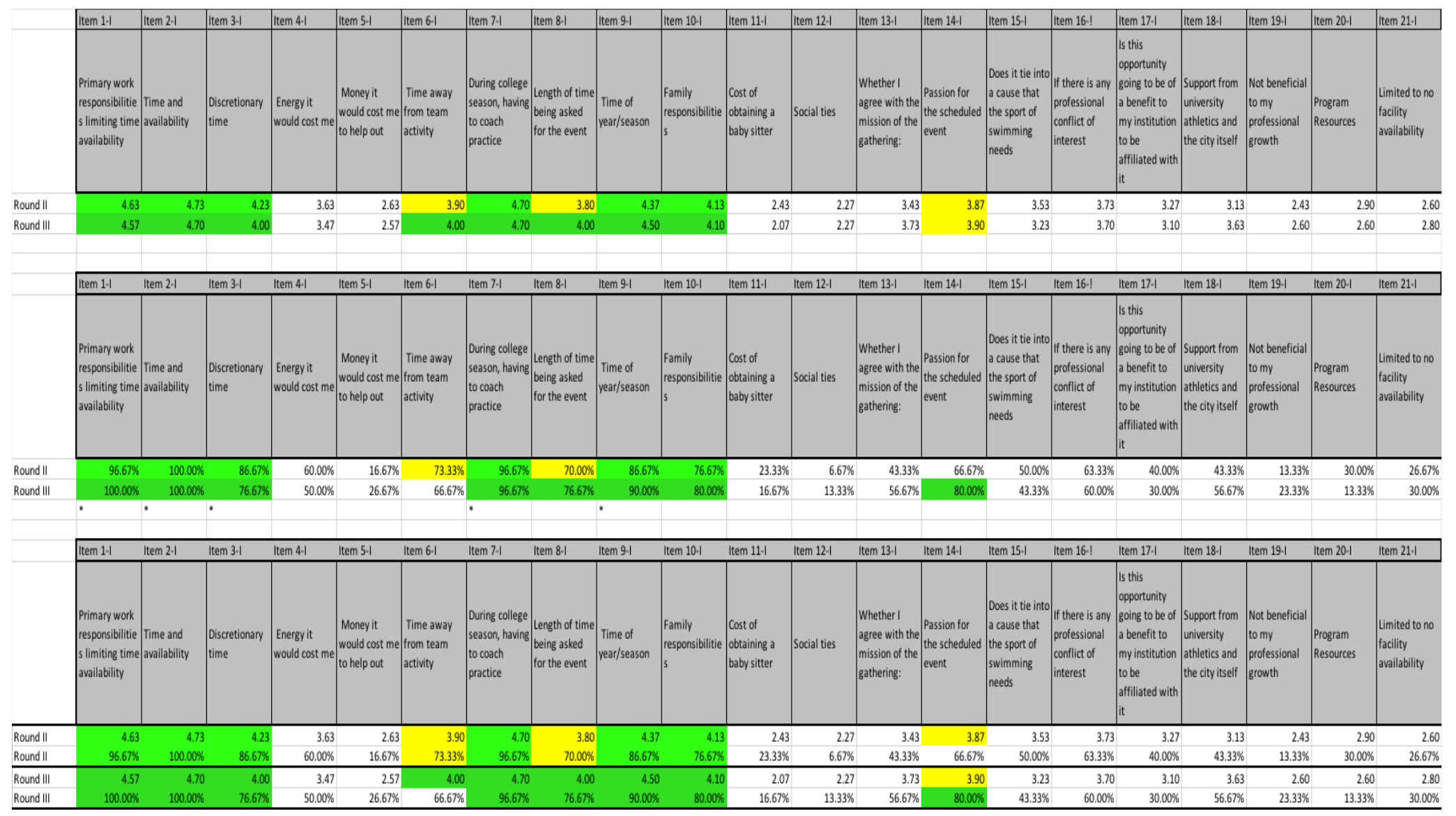




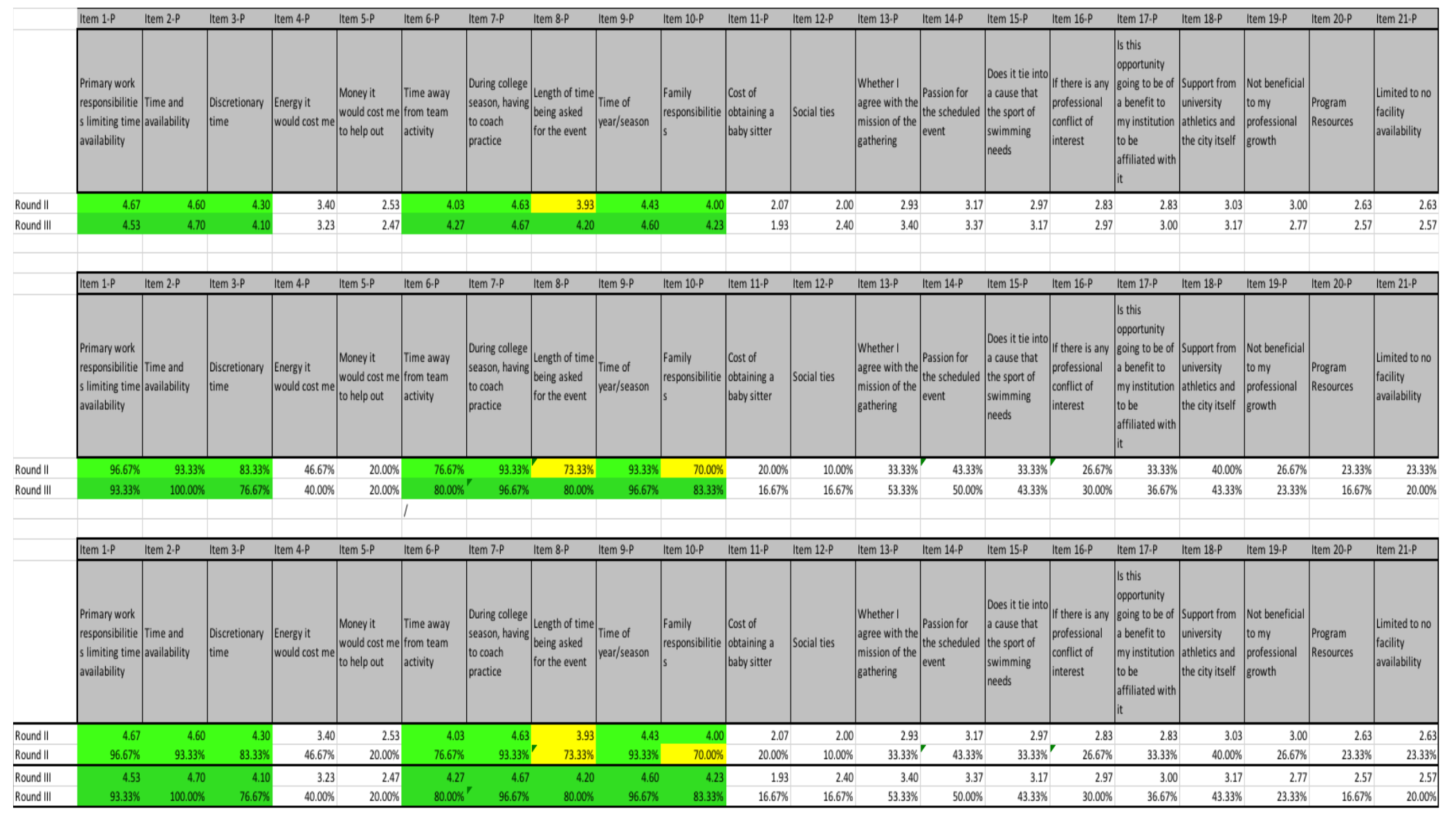




\section{Appendix T}

\section{Semi-structured Interview Script}

Instructions: Thank you for participating in a short interview to clarify your responses and give a little more insight into these barriers. I will ask you a few questions about the final list of barriers the group agreed upon, your personal thoughts on the barriers themselves, and any strategies or methods that you may be aware to overcome these barriers.

Question 1: What are your overall thoughts on the group's final list of the most prevalent and impactful barriers preventing coaches from volunteering with a nonprofit that benefits their sport?

Question 2: What are your thoughts on the final list of barriers that met both the criteria of impact and prevalence?

Question 3: What are your thoughts on the final list of barriers that met the criteria of impact but not prevalence?

Question 4: What are your thoughts on the final list of barriers that met the criteria of prevalence but not impact?

Question 5: What are your thoughts on the final list of barriers that met neither the criteria of impact and prevalence?

Question 6: What are your thoughts on the list of barriers categorization into Personal Resources, Social Ties, Cultural, Mixed, and Residential?

Question 7: What are your thoughts on the possibility of coaches having the ability to overcome these barriers?

Question 8: Do you have any thoughts on strategies that you have used or are familiar with that may help coaches to overcome these barriers?

Question 9: What are your thoughts on utilizing strategies that may be provided to you on overcoming these barriers? 